\title{
LOS PUEBLOS DEL AGUA. EL INC EN LA PROVINCIA DE ALBACETE
}

\section{WATER TOWNS. THE INC IN THE PROVINCE OF ALBACETE}

\author{
Plácida Molina Ballesteros \\ Doctoranda en Historia del Arte \\ Profesora tutora del Centro Asociado de la UNED \\ Albacete, España \\ pmolina82@alumno.uned.es \\ ORCID id: https://orcid.org/0000-0002-1344-8977
}

Cómo citar este artículo: Molina Ballesteros. P. (2021). Los pueblos del agua. El INC en la provincia de Albacete. Al-Basit (66), 141-206. http://doi.org/10.37927/ al-basit.66_4

Recibido/Received: 08-03-2021

Aceptado/Accepted: 24-05-2021

RESUMEN: El objetivo de este artículo es analizar los cambios acontecidos en el paisaje cultural de la provincia a través de la construcción de los cinco pueblos promovidos por el Instituto $\mathrm{Na}$ cional de Colonización (INC) de Albacete. El punto principal de nuestra investigación es valorar y divulgar la experimentación vanguardista en su mezcla con lo vernáculo en este tipo de pueblos, y analizar las diferentes disciplinas artísticas que intervinieron en su levantamiento. La contribución al patrimonio artístico contemporáneo de la provincia cuenta con referentes tales como los arquitectos que protagonizaron el cambio de la arquitectura contemporánea española, por
ABSTRACT: The aim of this article is to analyse the changes that took place in the cultural landscape of the province through the construction of the five villages promoted by the Instituto $\mathrm{Na}$ cional de Colonización (INC) of Albacete. The main point of our research is to value and disseminate the avant-garde experimentation in its mixture with the vernacular in this type of villages, and to analyse the different artistic disciplines that were involved in their construction. The contribution to the contemporary artistic heritage of the province has references such as the architects who played a leading role in the change of contemporary Spanish architecture, for example, José 
ejemplo, José Luis Fernández del Amo Moreno y Pedro Castañeda Cagigas o artistas nacionales como José Luis Sánchez Fernández y Manuel Rivera Hernández del grupo El Paso, regionales con Antonio Dorado García y locales como José Martínez Zamorano. La metodología practicada es la recopilación documental, parte de visitas técnicas a los pueblos, la consulta en los archivos ministeriales y privados, entrevistas, el estudio de la actualización del inventario provincial del INCIRYDA y los registros fotográficos de las obras artísticas y objetos litúrgicos.

PALABRAS CLAVE: Instituto Nacional de Colonización; Albacete; arte; vanguardia; arquitectura; paisaje; vernáculo; Pedro Castañeda Cagigas; José Luis Fernández del Amo Moreno; Manuel Rivera Hernández.
Luis Fernández del Amo Moreno and Pedro Castañeda Cagigas or national artists such as José Luis Sánchez Fernández and Manuel Rivera Hernández of the El Paso group, regional artists such as Antonio Dorado García and local artists such as José Martínez Zamorano. The methodology used is documentary compilation, based on technical visits to the villages, consultation in ministerial and private archives, interviews, the study of the updated provincial inventory of the INC-IRYDA and photographic records of the artistic works and liturgical objects.

KEY WORDS: National Institute of Colonization; Albacete; art; avant-garde; architecture; landscape; vernacular; Pedro Castañeda Cagigas; José Luis Fernández del Amo Moreno; Manuel Rivera Hernández.

\section{INTRODUCCIÓN}

Decía Plinio el Viejo «del agua, nacen ciudades». Con esta cita se resume la misión que el Instituto Nacional de Colonización (INC) desplegó por la geografía española con la fundación y levantamiento de 300 pueblos de colonización, en terrenos baldíos y con escaso acceso al agua. El mensaje de estas primeras actuaciones en el ámbito rural en la posguerra contenía una naturaleza propagandística contra la proletarización de la clase trabajadora, conocida desde el siglo XIX (Gómez, 1978, pp. 87-91). Junto al INC, también colaboraron en este proyecto la Dirección General de Regiones Devastadas y 
Reparaciones (DGRDR) y el Instituto Nacional de la Vivienda (INV), aunque cada una con objetivos diferentes (Almarcha, 1997).

No obstante, sería erróneo circunscribir la iniciativa del INC a un régimen político autoritario, sin estudiar los precedentes que semejante plan estatal tuvo en los siglos XVII-XVIII y en el siglo XIX, cuando logró constituir un corpus legislativo que marcase los pasos de su desarrollo. En esencia, dicho plan se erigió desde la Edad Moderna (Domínguez, 1992, p. 98; Birriel, 1998) hasta la Contemporánea con objetivos diferentes, modelados por las circunstancias de cada momento, atendiendo a los desafíos históricos. No obstante, y lo que es más importante, es que no fue un proyecto único en España, sino también en muchos países que, con diferentes formas de gobierno, afrontaron la transición hacia la Segunda Revolución Industrial en el ámbito de la agricultura.

Con esta introducción, se intenta clarificar la trayectoria de un problema agrario de mayor calado histórico, en el que la estética contemporánea se implicó profundamente en el aspecto social. A continuación, centramos la atención en los años de mayor actividad del INC ${ }^{1}$ (1940-1970) en Castilla-La Mancha², con el fin de analizar y contextualizar los cinco casos que posee la provincia de Albacete, poniendo en valor una parte de su patrimonio contemporáneo (Al-

\footnotetext{
${ }^{1}$ La creación del Instituto Nacional de Colonización se aprobó mediante Decreto de 18 de julio de 1939, en sustitución del Instituto de la Reforma Agraria de la Ley de 1932. Sus estructuras y competencias sufrieron cambios en 1972, cuando se refundó en el Instituto de la Reforma y Desarrollo Agrario (IRYDA), que permaneció hasta 1995.

${ }^{2}$ De acuerdo con las memorias depositadas en el Archivo Central de Ministerio de Agricultura, en Castilla-La Mancha encontramos un total de veintisiete pueblos de colonización agrupados: trece en Toledo (Bernuy, Malpica del Tajo, La Rinconada, Alberche del Caudillo, Soto de Calera, Talavera la Nueva, Las Vegas, San Antonio, El Bercial, Calera, Corralejo, Canturias y El Dehesón de «El Encinar»), nueve en Ciudad Real (Cinco Casas, Llanos del Caudillo, Villanueva de Franco-Consolación, Santa Quiteria, Villalba de Calatrava, Pueblonuevo de Bullaque, Los Mirones, Umbría de Fresneda y El Bazán), cuatro en Albacete (Mingogil, Nava de Campana, Cañada de Agra y Aguas Nuevas) y uno en Cuenca (Paredes de Melo). Además de dos núcleos aislados (Villatoya y Cilanco, Albacete), una rehabilitación (Castillo de Encomienda de Mudela, Ciudad Real) y actuaciones heredadas de otros planes agrarios del siglo XIX como el poblado de Villaflores (Guadalajara).
} 
marcha, 2003, 2008 y Cruz, 2010, 2015). Desde la visión de la Historia del Arte, se trata de evaluar al INC como escenario experimental de la modernidad artística española, protagonizada por arquitectos y artistas por igual (Jiménez-Blanco, 1995); plasmada en su concepción urbana, arquitectónica y artística, adaptada al ámbito rural y a los nuevos preceptos transicionales hacia el Concilio Vaticano II de las iglesias de colonización de Albacete (De Nito, 2003; Centellas, 2010; Cordero, 2014; Bezares, 2018).

\section{ENTRE LA MANCHA Y LEVANTE}

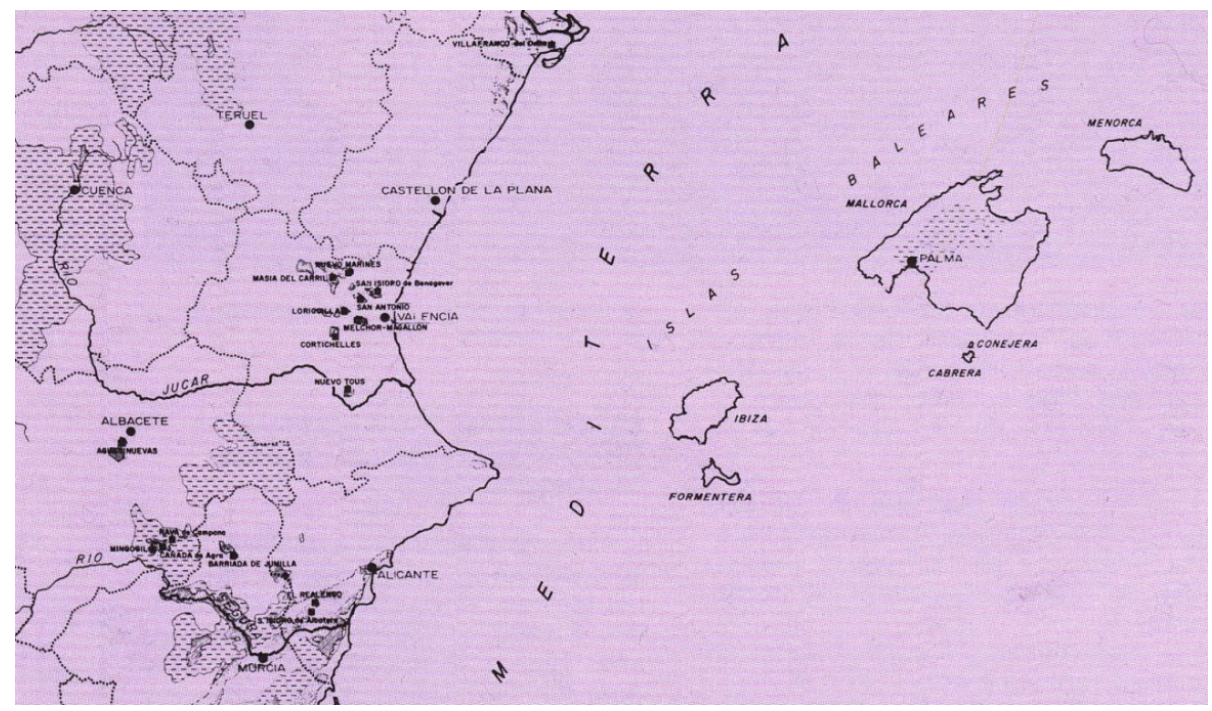

Figura 1. Dominio de las cuencas hidrográficas de los ríos Segura y Júcar. Actividad del INC-IRYDA. Fuente: Tamés Alarcón, 1988.

Al abordar las delimitaciones geográficas de las regiones donde el INC actuó, uno puede sentirse confundido, cuando percibe entre los documentos ministeriales que la provincia de Albacete pertenecía a la Delegación de Levante e Islas, quedando fuera de la región de La Mancha (Fig.1). Lejos de tal intención, la explicación se halla en que el INC procedió a una ordenación territorial (Gómez, 2004, pp. 80-81), guiándose por la influencia de las cuencas hidrográficas y las zonas de alta despoblación como en León y Galicia 
(Río, 2012, pp. 67-68; Zas, 2008), también vinculados a la industria minera.

Por ello, la provincia de Albacete forma parte de la zona de Levante junto a las provincias de Teruel, Castellón, Cuenca, Murcia, Alicante y Valencia (Medina \& Oliva, 2008), bajo dominio de las cuencas de los ríos Segura y Júcar. El INC intervino sobre los terrenos de interés partiendo del Plan de Ordenación Nacional diseñado por Pedro Bidagor Lasarte, junto a la Ley de Bases para la Colonización de Grandes Zonas de 1939 y la Ley sobre Colonización y Distribución de la Propiedad de las Zonas Regables de 1949 (Almarcha, 1997; Molina, 2020, p. 40). Desde ellas se potenciaron dos maneras de aglutinar los terrenos, ya por cesión voluntaria (decreto de 1942), ya por expropiación (Ley de Expropiación Forzosa de Fincas Rústicas, 1946).

En cuanto al proceso de desarrollo constructivo de los pueblos, éste se iniciaba previo estudio y selección del lugar por ingenieros agrónomos y arquitectos. De este modo, la parcelación daba paso a las obras de urbanización y elevación arquitectónica, sucedidas en fases que podían variar según las incorporaciones legislativas, los cambios en los criterios urbanos y las mejoras en las condiciones de vida rural. La segunda variable es objeto de interés en el estudio individual de cada pueblo, como se verá más adelante, dado que el diseño del viario, la forma, su aspecto y su emplazamiento son los factores que ahondan en la contradictoria ortodoxia urbanística del INC a inicios de la década de los cincuenta (Almarcha, 1996); a favor de la innovación, la modernización de la arquitectura contemporánea española, que apostó en partes iguales por lo estético y lo pragmático.

Con respecto a la transformación del paisaje, se emprendían las obras de nivelación, drenaje y canalización de las tierras de cultivo, mientras que, por otro lado, le seguían la distribución urbana y la construcción de los edificios públicos y viviendas de los colonos, obreros y profesionales. No obstante, la construcción alargada en el tiempo era susceptible de modificaciones con el impulso de los 
planes de mejora del bienestar rural, con el que se modernizaron los pueblos de colonización: alumbrado público, carreteras, alcantarillado y conducciones de agua potable.

A pesar de esta pincelada sobre las fases constructivas, las actividades de colonización no fueron simultáneas, a causa de que existían prioridades a la hora de construir los pueblos. En la zona de Levante, como es el caso que nos ocupa, se auxiliaron a las poblaciones afectadas, ya por catástrofes naturales como las riadas de 1949 y 1957, ya por las obras públicas de pantanos y embalses, como sucedió en Valencia entre 1950 y 1963, y los Campos de Hellín (Albacete), que fueron determinantes por motivos de asistencia social en masa (Martínez \& Oliva, 2008, pp. 287-311). Es, por ello, que la colonización no era inmediata y uniforme, prolongándose durante años, como vemos también el caso de Albacete, que fue desde 1959 hasta 1967 en las tres comarcas:
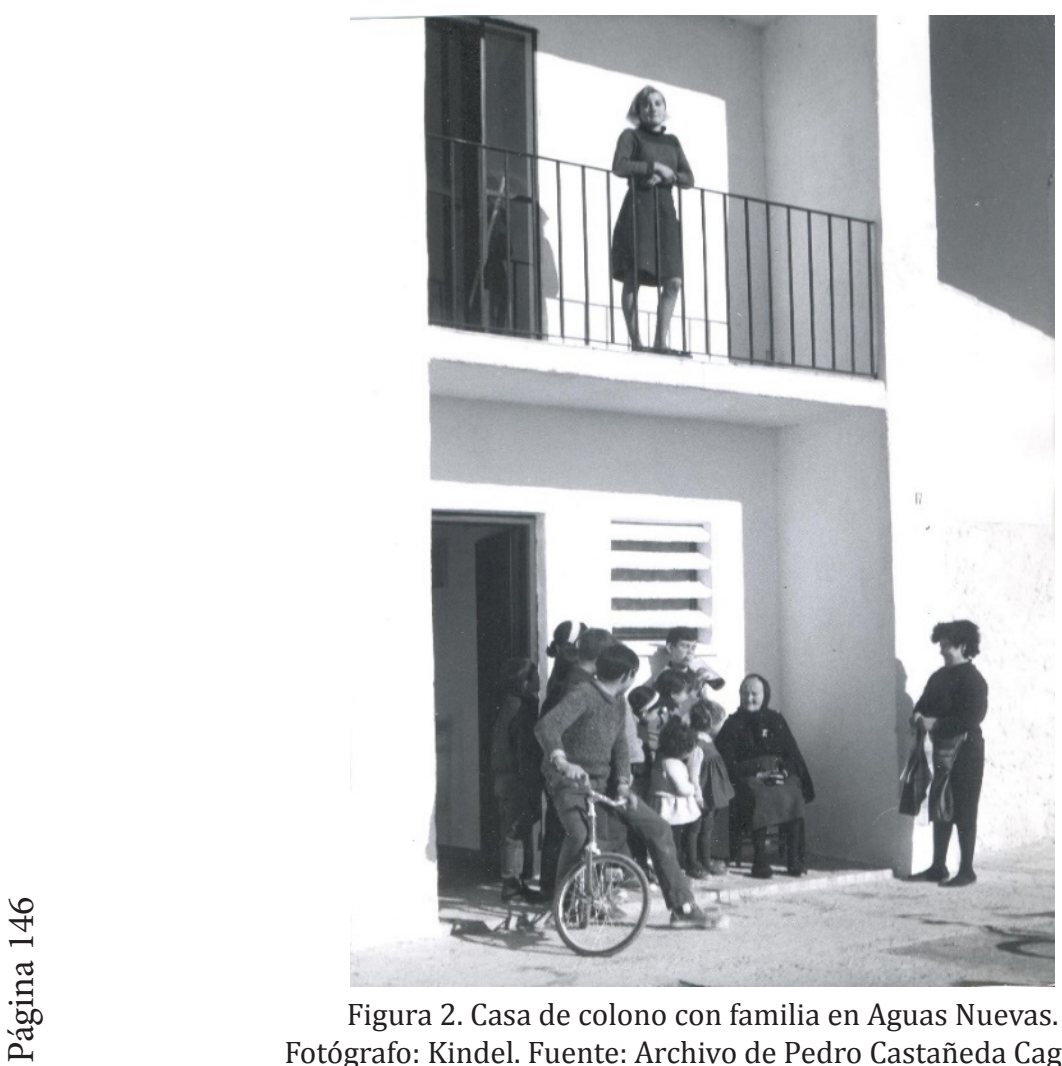

Figura 2. Casa de colono con familia en Aguas Nuevas. Fotógrafo: Kindel. Fuente: Archivo de Pedro Castañeda Cagigas. 
La Zona Regable de Interés Nacional de los Campos de Hellín concentra tres pueblos satélites: Mingogil, Nava de Campana y Cañada de Agra, abastecidos por el agua del río Mundo embalsada en los pantanos de El Talave, Camarillas y El Cenajo, dependientes de la cuenca norte del río Segura, cuyas obras se prolongaron entre 1959 y 1962.

La Zona Regable de Interés Nacional de Los Llanos de Albacete, presidida por el pueblo de Aguas Nuevas, posee un área de influencia que comprende varias pedanías y parajes de una gran riqueza acuífera, explotada para el abastecimiento de agua potable y riego canalizado. La obra completa de colonización se emprendió entre 1961 y 1967, realizándose con el IRYDA varias ampliaciones de viviendas de colonos (Fig.2), además de la concentración parcelaria que duró hasta la década de los ochenta (Rodríguez, 2015, pp. 138-142, 233-243).

La Zona serrana de la comarca de La Manchuela, recoge las primeras actuaciones del INC y el Servicio de Concentración Parcelaria en la finca «Labor de Villatoya». Sin embargo, esta comarca ya había sido objeto de redistribución equitativa de la tierra por la CNT y la UGT, a fin de mitigar las presiones de movimientos sociales que se cobraron vidas en Yeste y Bonete en 1933 (Sánchez, 1996, p. 336). La cercanía al Cabriel, afluente del Júcar, le suministra el agua necesaria a sus vegas y pequeñas huertas. Las obras de concentración parcelaria las continuó el IRYDA en 1981 en el término de Villatoya, incluyéndose las «Casas de Cilanco».

\subsection{La colonización agraria en la provincia de Albacete}

La primera intervención del INC en la provincia fue con la declaración de Zona de Interés Nacional del Canal de Hellín (Fig.3) por Decreto 6 de julio de 1956, que inició el proceso de obtención de terrenos de irrigación (Carmona, 2012). Dos métodos se practicaron en la adquisición de terrenos. Por un lado, dos fincas mediante oferta voluntaria y, por otro, una tercera mediante expropiación por 
causa social, según la Ley de 27 de abril de 1946. El Plan General de Colonización para esta área se aprobó por Decreto de 18 de abril de 1963, donde las parcelas ocupaban un total de 4.626 hectáreas ${ }^{3}$. El acceso al agua se propició por las derivaciones en canalizaciones y acequias de 900 l./seg. del río Mundo y de 250 l./seg. de aguas subterráneas por sondeos del paraje de «El Boquerón». El tipo de cultivo sería principalmente de árboles frutales.

En segundo lugar, la Zona regable de Los Llanos de Albacete (Fig.3) con su declaración de Interés Nacional, que se completó por el Decreto no. 773 de 13 de mayo de 1961. El área comprende una superficie total de 5.200 hectáreas que se dividió en tres sectores. En los Sectores I y II se aprobaron los planes de colonización por los Decretos 2.475 de 20 de septiembre de 1962, modificado en el no․ 3.592 de 27 de diciembre del mismo año, y por Decreto nำ793 de 4 de abril de 1963, en el cual se extendió del Sector II al I sin incluir el Sector III en dicha declaración de Interés Nacional. Por lo que la superficie total se redujo a 4.038 hectáreas ${ }^{4}$. La preparación de los terrenos de cultivo con una gran inversión en sistema de regadío determinó que la producción fuera de alimentos forrajeros, leguminosas, patatas y hortalizas.

Y, en tercer lugar, la concentración parcelaria sustentada por la Ley de Reforma y Desarrollo Agrario del decreto 118/1973, tuvo lugar en la finca «Labor de Villatoya» perteneciente al término municipal de Villatoya. La adquisición de los terrenos fue mediante

\footnotetext{
${ }^{3} 1.115$ hectáreas de terrenos no regables y 3.511 hectáreas (1.761 de reserva y 1.750 excedentes y ocupadas por el INC). En Mediateca-MAPAMA, álbum de Albacete para el XXV Aniversario de la Labor del INC.

${ }^{4}$ El Plan de Obras del Sector I aprobado por Orden Ministerial de 5 de marzo de 1964 dividió el terreno un total de 2.662 hectáreas, en 550 exceptuados, 664 reservada y 1.448 en exceso. La suma de 974 hectáreas en excedentes de la adquisición de terrenos nuevos por oferta voluntaria de los propietarios habría que tenerla en cuenta, además de las 42 hectáreas destinadas a suelo urbanizable donde se situaría el pueblo de Aguas Nuevas. En el caso del Sector II de un total de 1.376 hectáreas se seleccionaron 774 de terrenos exceptuados y 602 de reserva y excedente. En Mediateca-MAPAMA, álbum de Albacete para el XXV Aniversario de la Labor del INC.
} 
oferta voluntaria de la propietaria, doña Pilar Castillo de la Torre. La distribución de un total de 561 hectáreas sería de 78 hectáreas en regadío, 185 para labor de secano, 266 para pastos y monte, y 32 como terreno improductivo. Los futuros titulares fueron un total de 91 empresarios agrícolas, según menciona la orden de 3 de julio de 1981, aunque once eran ya propietarios y ochenta estaban en periodo de tutelaje y acceso a la propiedad.

Con el paso del tiempo, a dichos pueblos de colonización se les reconoció como Entidades Municipales con el Decreto 2697 de 20 de octubre de 1966, sobre el régimen para la constitución y funcionamiento de los pueblos construidos por el INC como Entidades Municipales o Entidades Locales Menores. Su falta de solvencia económica y la escasa densidad demográfica, obligó a clasificarlas como simples barrios de los municipios mayores, aunque conservarían su autonomía administrativa al ser nombrado entre sus vecinos un alcalde pedáneo. Asimismo, el reconocimiento concedido por Patrimonio Cultural de la Junta de Castilla-La Mancha a Cañada de Agra y Villalba de Calatrava en 2015 como Bienes de Interés Cultural; como también su catalogación con la placa de registro de la Fundación Docomomo Ibérico, suponen los primeros pasos hacia una protección y conservación efectiva, que debería extenderse al resto de pueblos. 

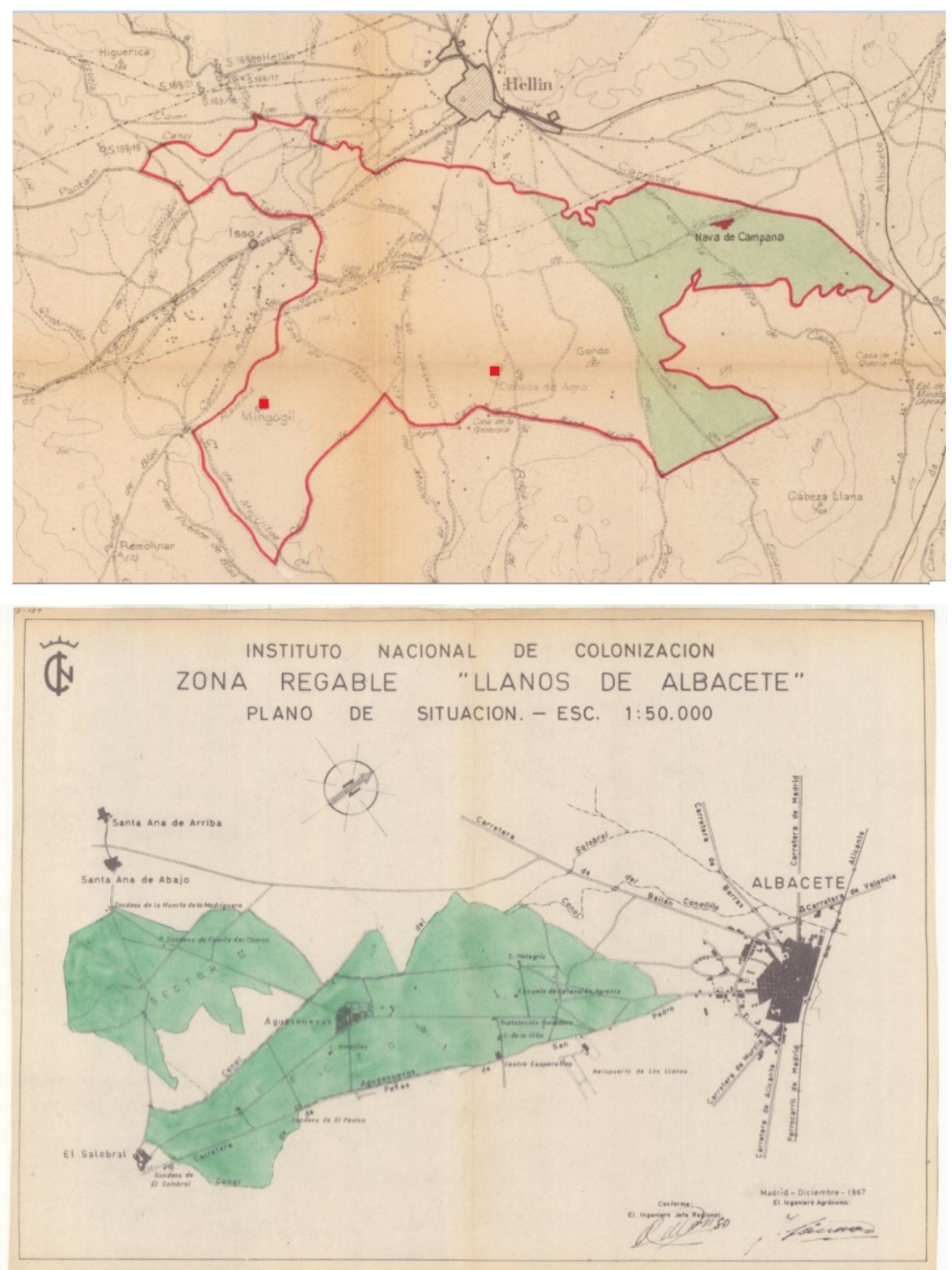

Figura 3. Planos de situación de los pueblos de colonización en la provincia de Albacete. Campos de Hellín y Llanos de Albacete. Fuente: Archivo General de la Administración. 


\section{LOS CAMPOS DE HELLÍN}

\subsection{Mingogil}

En 1959 se iniciaron las obras de construcción del pueblo por el arquitecto Jesús Ayuso Tejerizo, quien simultáneamente estaba diseñando el trazado de Nava de Campana. Posteriormente, el INC aplicó un programa de ampliación que realizó el arquitecto doctor Pedro Castañeda Cagigas, concluyéndose las obras del pueblo el 11 de diciembre de 19645. De acuerdo a los informes del IRYDA consultados en el Archivo General de la Administración, se esperó que Mingogil fuera uno de los tres poblados albaceteños más importantes por su riqueza y extensión de terrenos fértiles con mayores ganancias productivas de árboles frutales, hortalizas y secano. Su entorno urbano de 30 hectáreas (Fig.4) lo componen edificios administrativos (ayuntamiento y vivienda del administrador), iglesia y dependencias parroquiales, dos escuelas, dos viviendas de maestros, dispensario médico y dos artesanías con viviendas adjuntas. En cuanto a las viviendas de los colonos se elevaron un total de ochenta, ocho para los obreros agrícolas, tres de profesionales y dos de artesanos (Canales \& Jerez, 1993).

Las viviendas de colonos se clasifican en tipo A, A', B y B' (Fig.5), y poseen las mismas características de fachada creando una uniformidad urbana sin apenas apreciar diferencia, que únicamente se encuentra en la configuración habitacional y en el diseño de las entradas con porche adosado o separado. Los materiales de construcción locales crean una perspectiva bicromática terrosa del ladrillo que reviste la planta baja y el enjalbegado del segundo nivel, que además se adoptó en el interior de la iglesia.

\footnotetext{
${ }^{5}$ Expediente de constitución de la Entidad Local Menor de Mingogil, creada por el Instituto Nacional de Colonización en el término municipal de Hellín, 1975. Archivo General de la Administración, Madrid (AGA), Entidades locales menores INC, Sección 08, Fondo 11018, no de orden 4340, nº de expediente 02, Albacete/Hellín Mingogil.
} 

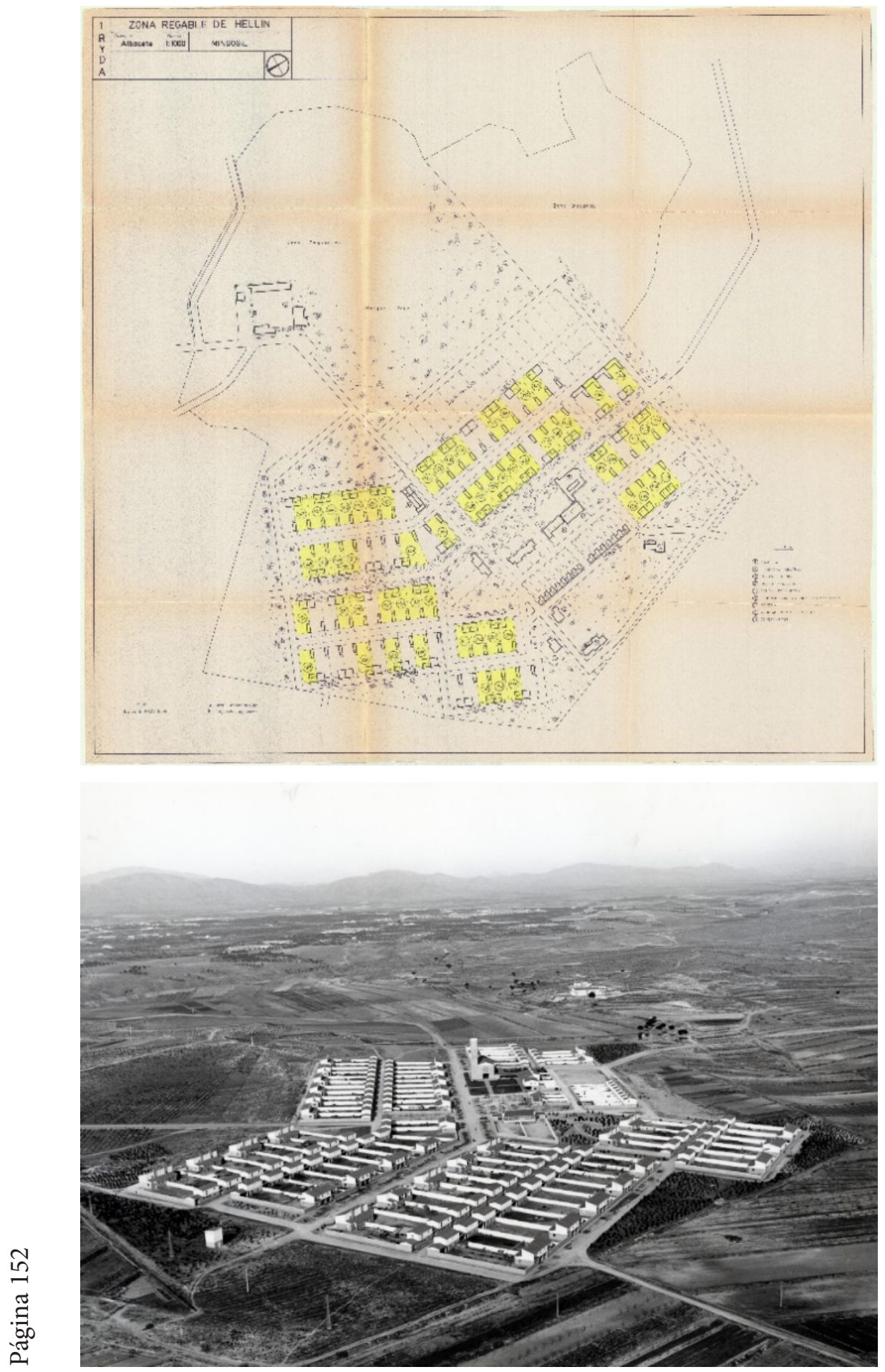


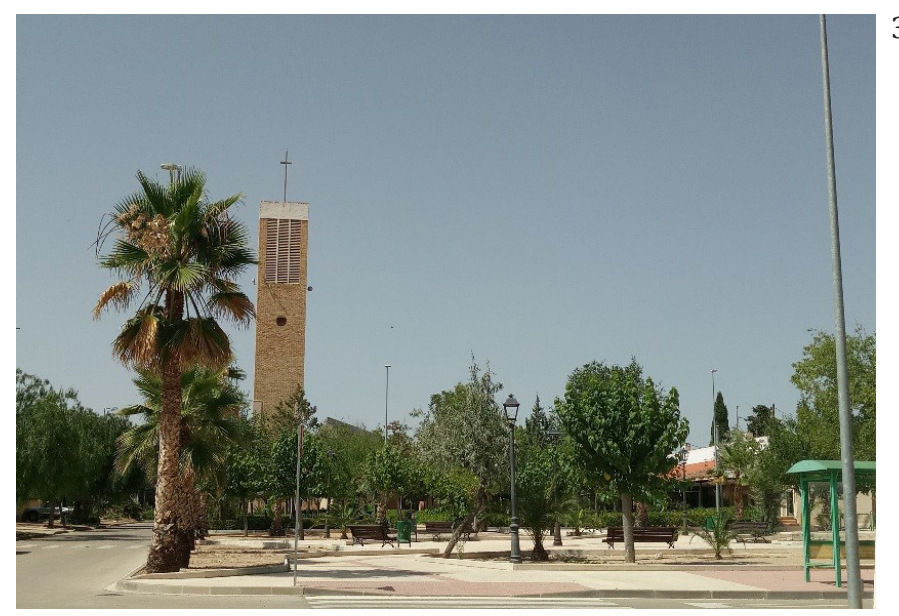

Figura 4. Mingogil. 1. Plano urbano 2. Vista aérea 3. Plaza Fuentes: 1. Delegación de Agricultura de Albacete, 2. Mediateca-MAPAMA y 3. Foto de la autora.
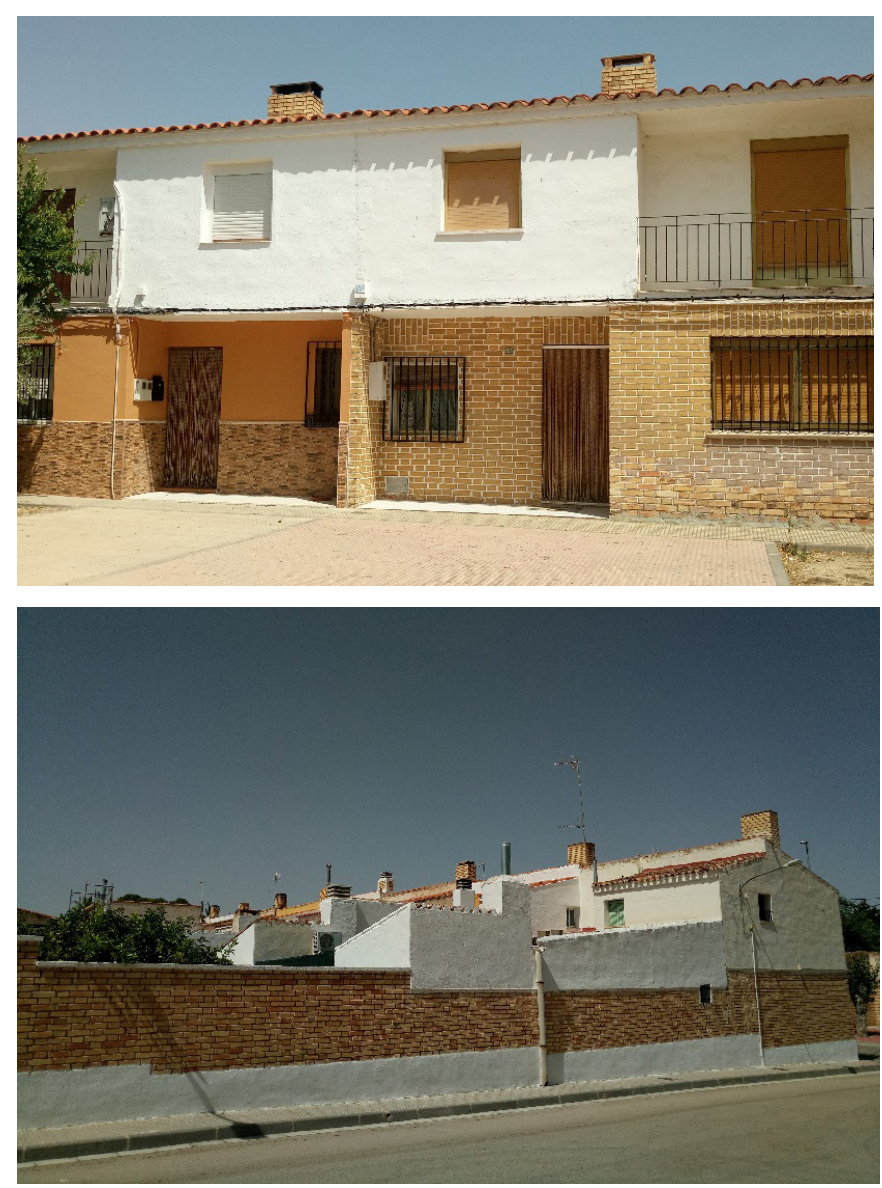


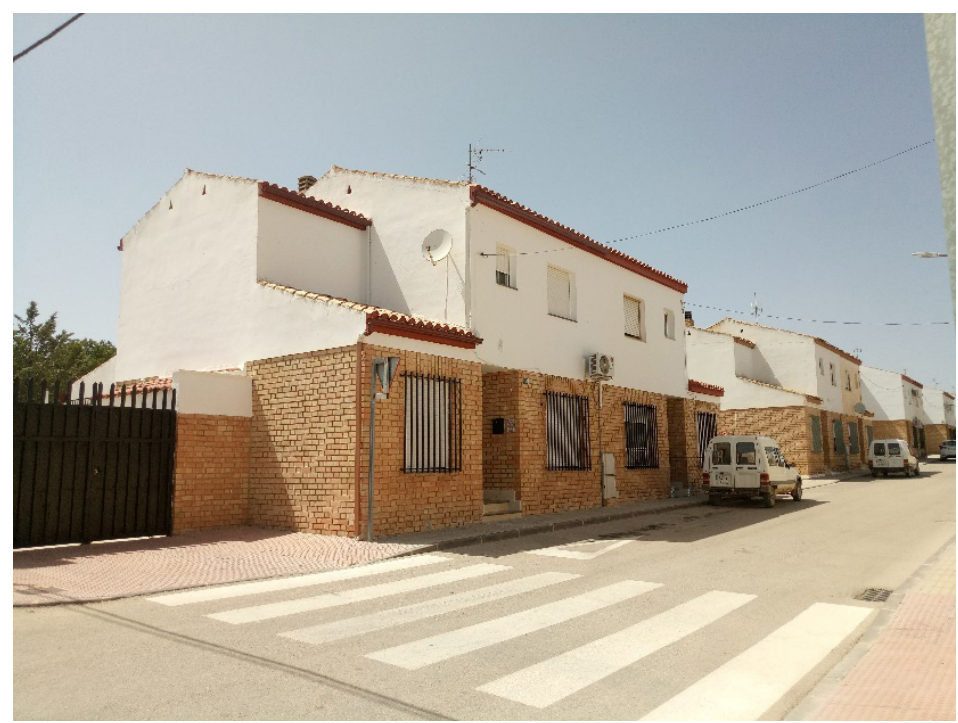

Figura 5. Mingogil. Viviendas de colonos. Fuente: Fotos de la autora.

El emplazamiento de Mingogil es de orientación suroeste y dista de Hellín 8 km (Fig.4). Se ubica sobre un llano de suaves pendientes, en la que una ligera vaguada cruza la mitad del pueblo y por tanto, es considerado una división natural, cuya referencia es la avenida principal. En términos urbanísticos, la malla adoptada para salvar este curso natural de aguas pluviales fue la mezcla de dos mallas ortogonales dispuestas en «L», en las que interactúan espacios verdes circundantes con solares en el centro y en el camino de ronda del pueblo para futuras ampliaciones. La situación del centro edilicio del pueblo se invierte en contraste con Nava de Campana, siendo en esta ocasión la iglesia la que ocupa en centro urbano (Fig.4). Las escuelas, las viviendas de los maestros, los hogares femenino y masculino y los edificios de la cooperativa ocupan terrenos abiertos cercanos a las entradas del pueblo en sus cercanías.

Por encima del equilibrio en altura de las viviendas y demás edificios administrativos, destaca la iglesia y su torre-campanario, de la que se conoce que fue diseño del arquitecto Jesús Ayuso Tejerizo y que fue de las primeras edificaciones en elevarse en el pueblo a través de las fotografías de «Kindel» (Joaquín del Palacio) fecha- 
das en 1957 (Fig.6). De ella solo se conserva una idea exterior de la fachada decorada por un vitral en hormigón de seis paneles sobre estructura de hormigón formando una cruz y una planta basilical de fábrica de ladrillo de aparejo a tizón o a la española. Lo único que se conserva del plan inicial es la imponente torre-campanario de planta cuadrada y aparejo a soga y tizón que se construyó exenta del templo.

En 2005 se decidió demoler el templo por problemas de humedades que dañaron la estructura del edificio (Fig.6). Ante la drástica medida se salvó del interior todo el ajuar litúrgico de Talleres Granda (Fig.7) y las obras de arte sacras (tríptico, escultura de San Isidro, pila bautismal y sagrario). La nueva construcción fue pensada para recuperar la presencia de los vitrales laterales, siendo desconocida la ubicación de los de la fachada. Además, se quiso conservar el vía crucis con estaciones de La Pasión de Jesús de hierro pintado de negro que no aparece inventariado en el INC-IRYDA, y cuya autoría era desconocida hasta ahora. Gracias al registro de elementos artísticos realizados en Extremadura y al estudio comparativo realizado, es atribuible a Arturo Peiró ${ }^{6}$, quien ornamentó el interior de las iglesias de colonización con el mismo diseño de vía crucis en La Bazana, Gargáligas, Vegas Altas del Guadiana y Lácara (Bazán, 2017, p. 224) (Fig.6).

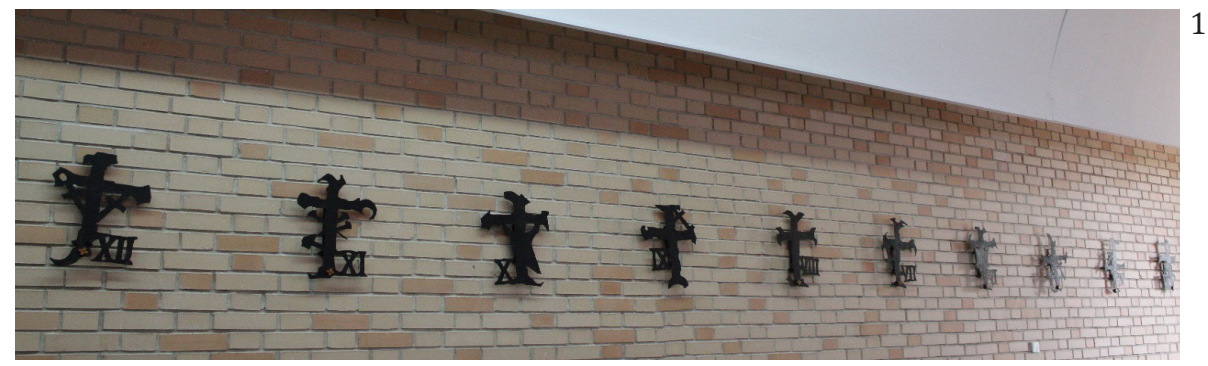

${ }^{6}$ Elementos artísticos de las iglesias de los pueblos del IRYDA. Archivo Central del Ministerio de Agricultura, Madrid (AC-MAPAMA), Inventario general del INC, Carpeta de la provincia de Albacete, n.․ de expediente 3, Albacete/Mingogil. 


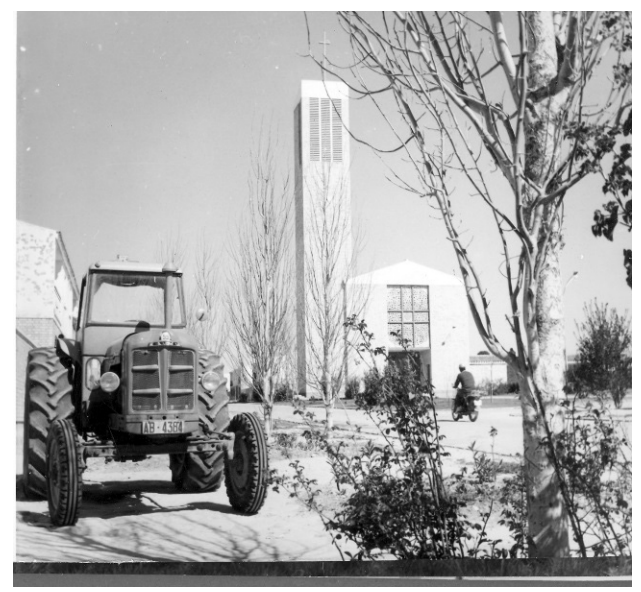

2

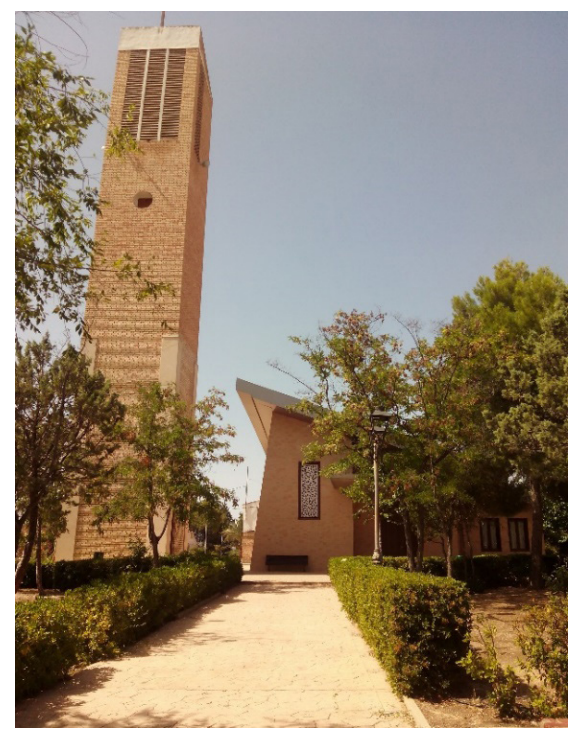

Figura 6. Mingogil. 1. Vía crucis, Arturo Peiró 2. Iglesia antigua 3. Iglesia actual. Fuente: Fotos de la autora (1 y 3) y Mediateca. MAPAMA (2).

Hoy día, se conserva un San Isidro de José Martínez Zamorano (Fig.7), única obra para el INC y de buena factura. Ello se deba al interés de mantener la impronta regional que demostró Fernández del Amo pidiendo la colaboración a artistas locales, como sucedió también en las iglesias de colonización alicantinas con Manuel Baeza Gómez y Adrián Carrillo.

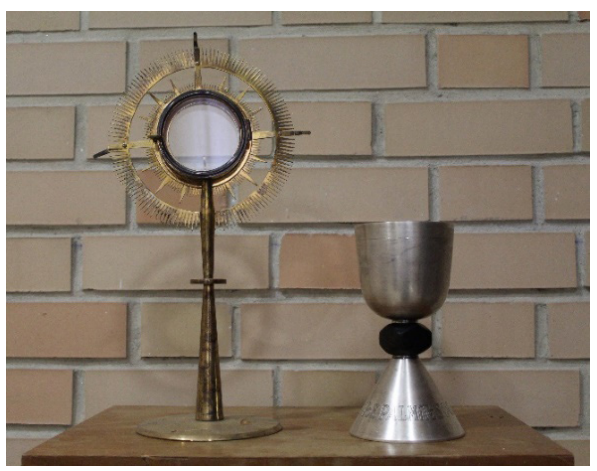

م્

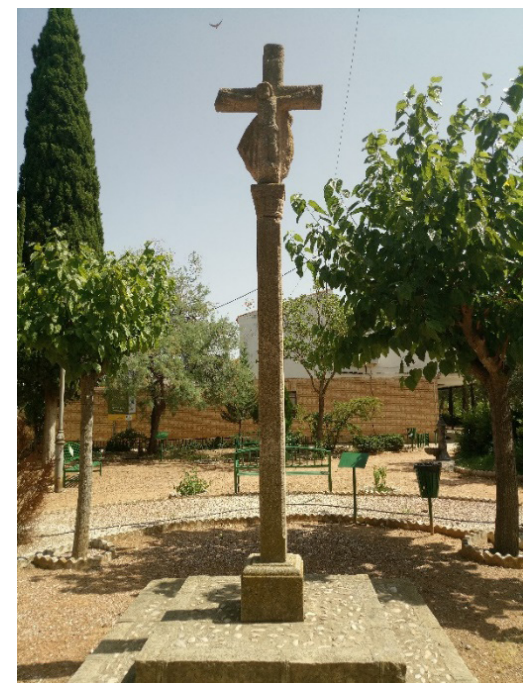




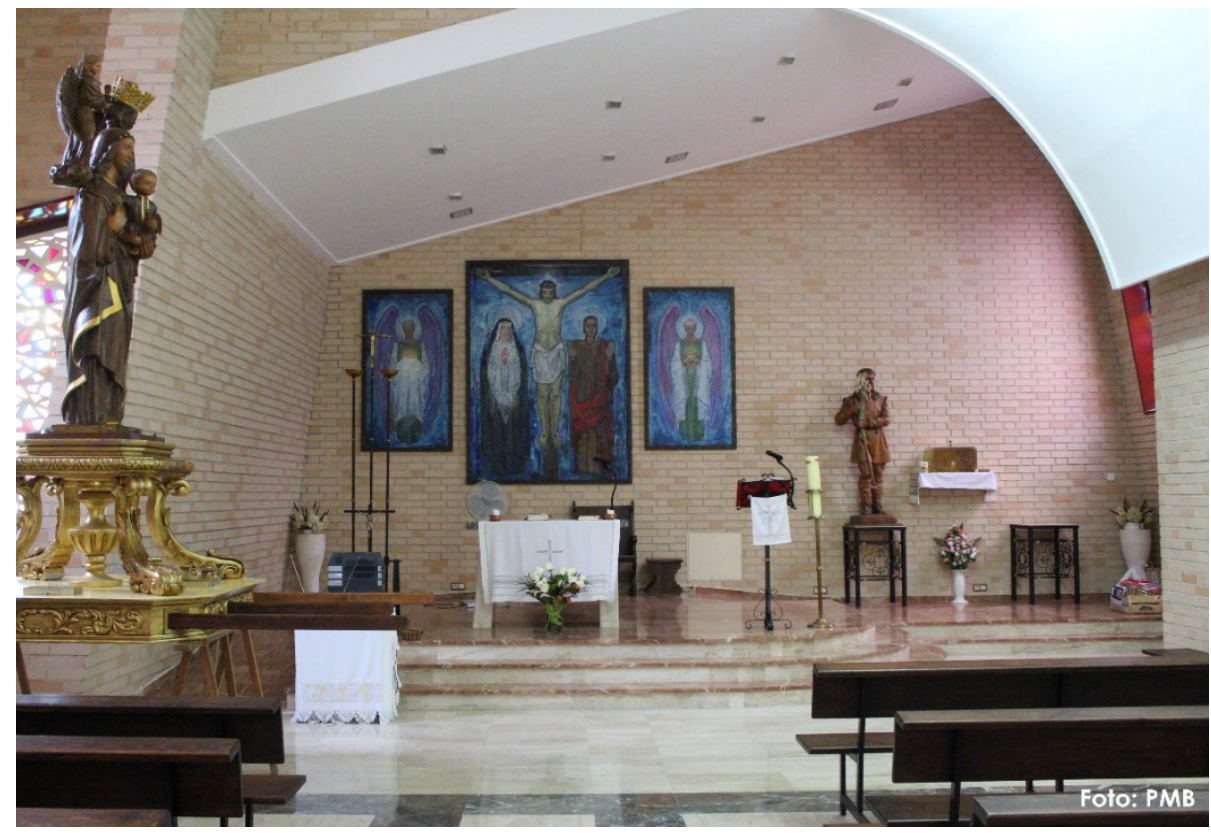

Figura 7. Mingogil. 1. Viril y cáliz, Talleres Granda 2. Crucero, Antón Faílde Gago 3. Interior de la iglesia y elementos artísticos. Coronación de la Virgen, Talleres Granda;

San Isidro, José Martínez Zamorano; tríptico del Calvario, Antonio García Dorado; vitrales anónimos y Crucifijo, José Luis Sánchez Fernández. Fuentes: Fotos de la autora.

Por otro lado, se encuentra una talla de madera no polícroma de La coronación de la Virgen con el niño, que erróneamente se atribuyó a José Luis Sánchez, y que en realidad es de Talleres Granda, al localizar otra de semejantes características en el pueblo de El Torviscal (Fig.7). Finalmente, como única obra pictórica se conserva el tríptico del artista ciudadrealeño Antonio García Dorado con una representación del Calvario, con la Virgen María y San Juan, acompañados por sendas tablas laterales con ángeles oferentes (Fig.7). Dicha temática religiosa no era muy recurrente en el ámbito pictórico del INC. Solía ser más común en escultura o con la sencilla composición de las tres cruces del monte Gólgota coronando las fachadas de las iglesias. Es paradigmática esta muestra de Dorado, ya que es la segunda obra pictórica inventariada por el INC-IRYDA de dicho pintor especialista en el género del retrato y el paisaje, sien- 
do más conocidos sus vitrales ${ }^{7}$. El ambiente lúgubre y la expresión hierática de los personajes de su tríptico contrastan con los rasgos faciales suaves y la caída natural de los pliegues de las vestimentas. El conjunto pictórico figurativo-geométrico es de una intachable simetría que contrasta con la de otros ejemplos de trípticos como el encontrado en Arrabal de San Sebastián (Salamanca) de Veredas y Orejudo. En el exterior de la iglesia, se conserva un crucero de granito de Antón Faílde Gago (Fig.7).

\subsection{Nava de Campana}

Coetáneo a Mingogil, se inició en 1959 por el arquitecto Jesús Ayuso Tejerizo, aunque las obras de su conclusión se cumplieron el 10 de diciembre de 1965 con el arquitecto José Luis Fernández del Amo, tras una ampliación de su trama urbana (Fig.8). El entorno urbano ocupa un total de 22,5 hectáreas. Nava de Campana se emplaza sobre un fértil llano en dirección sureste y distanciada de Hellín por $6 \mathrm{~km}^{8}$. Su malla urbana es muy regular y cerrada en comparación con la de Mingogil, dado que las calles longitudinales van de un extremo a otro del pueblo sin converger en una plaza, y es inexistente la conjugación con espacios arbolados. Su finalidad es la distribución de 38 viviendas de colonos, ocho obreros agrícolas y tres de profesionales.

Las dos plazas que se rehúnden en la trama son las del Cine y de las Escuelas (Fig.9), donde se aglomeran las artesanías y los

\footnotetext{
${ }^{7}$ En el catálogo de la exposición en la Sala del Prado del Ateneo de Madrid, se señala una breve biografía en la que someramente se menciona su contribución pictórica y vitralista en el INC entre 1964 y 1966. El otro ejemplo pictórico es un óleo sobre tabla de La Pasión (1962) ubicado en la iglesia aragonesa de Pinsoro. En Antonio García Dorado, Cuadernos de Arte Sala del Prado del Ateneo de Madrid, no. 119, 1968, en: Biblioteca Museo Nacional Centro de Arte Reina Sofía (B-MNCARS), Depósito Normal, Folletos, caja 140-23, 88213, CDB. 88213 y Biblioteca Museo Nacional Centro de Arte Reina Sofía (B-MNCARS), Fondo Biblioteca Fernández del Amo, Depósito Normal, Folletos, caja 41-27, 218173, CDB. 218173.

${ }^{8}$ Extracto Constitución de la Entidad Local Menor de Nava de Campana, creada por el INC en el término de Hellín, 1975. Archivo General de la Administración, Madrid (AGA), Entidades locales menores INC, Sección 08, Fondo 11018, no de orden 4341/1, no de expediente 01, Albacete/Hellín Nava de Campana.
} 
centros de ocio a excepción del centro cooperativo, los hogares rurales y el campo de juego. Algo inusual en la práctica urbana del INC, pero que ya se vio en pueblos alicantinos como San Isidro de Albatera o almerienses como Puebla de Vícar, es la independización de la iglesia ubicada en el camino de ronda y sin conexión directa con el resto de edificios administrativos y ocio. La armonía en las tipologías arquitectónicas y sus materiales es igual a la de Mingogil. La unidad estética y estructural se divide en manzanas de ocho y catorce viviendas modulares de colonos y obreros agrícolas de tipo A y A', estas últimas construidas en la segunda fase y con claras influencias espaciales de José Luis Fernández del Amo, quien además contribuyó con la adaptación del viario para carros y peatones (Fig.9).

En el camino de ronda del pueblo pasa desapercibida la iglesia y su espadaña de diseño minimalista que oculta tras de sí las tres campanas (Fig.10). En su totalidad es una obra en ladrillo de tonalidades terrosas con una fachada asimétrica presidida por un vitral abstracto en hormigón de sencillo diseño. La estética de su techumbre rompe con los esquemas preestablecidos disponiendo los tramos cruzados a modo de espiga, jugando con los volúmenes, la luz de los vitrales laterales y el color blanco de los paramentos.

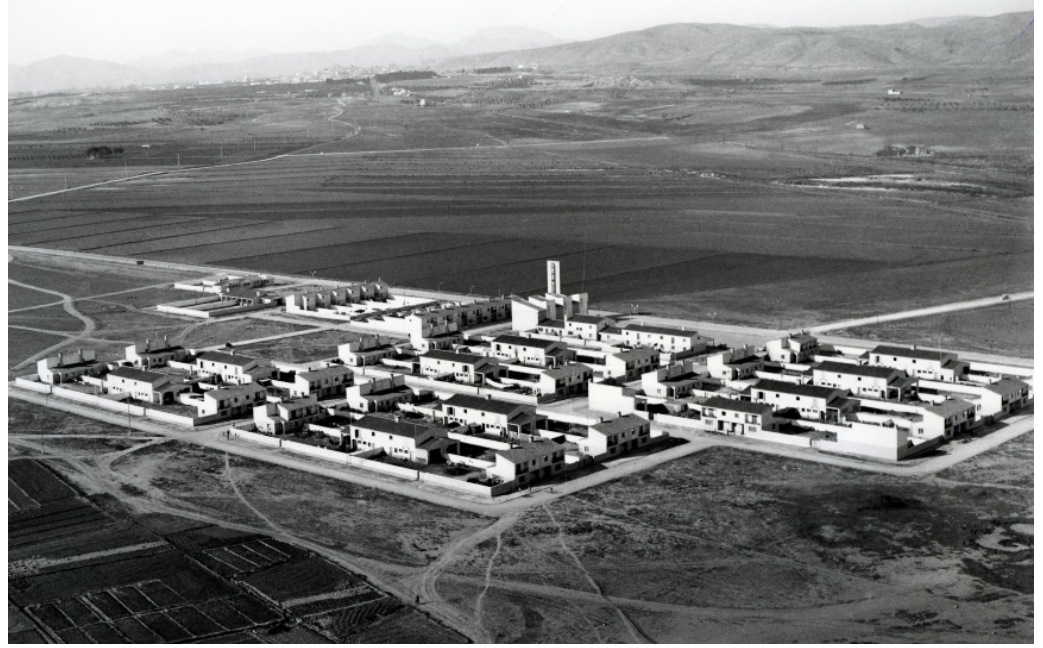



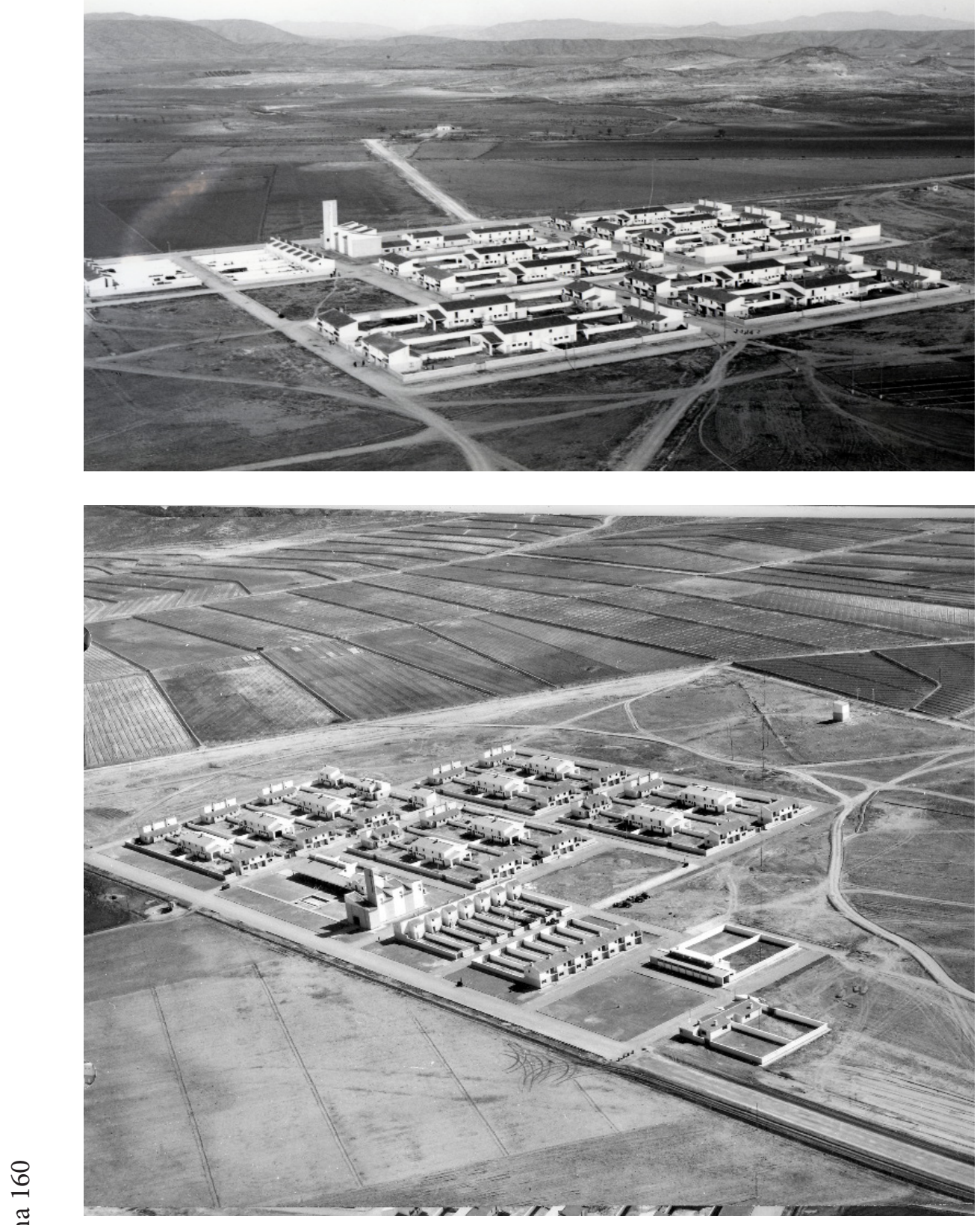

Figura 8. Nava de Campana. Vistas aéreas desde distintas perspectivas.

Fuente: Mediateca. MAPAMA. 

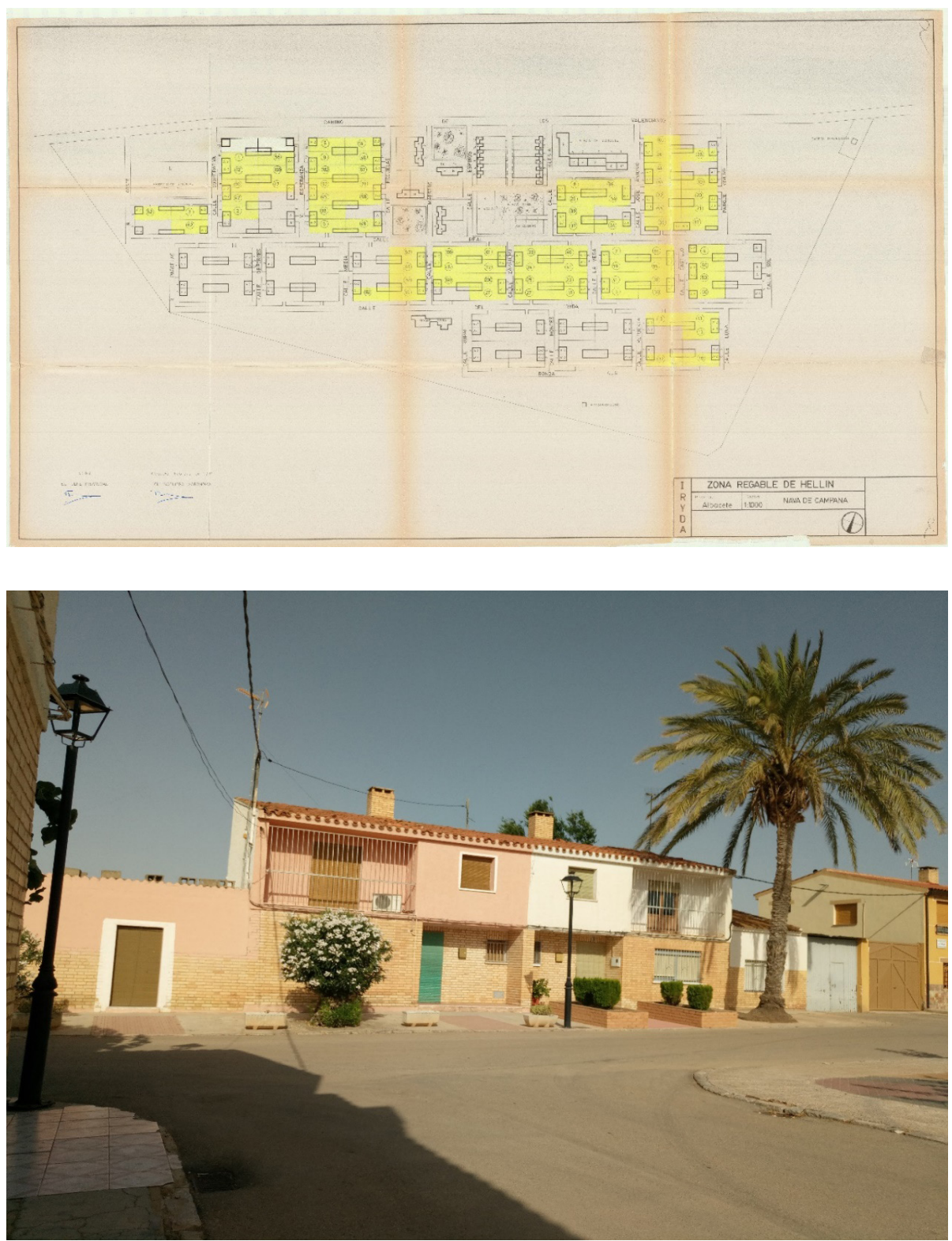

Figura 9. Nava de Campana. 1. Plano urbano 2. Vivienda de colono. Fuentes: 1. Delegación de Agricultura de Albacete 2. Foto de la autora. 
De los laterales de la única nave y el coro aparecen los coloridos vitrales abstractos de 1965, que iluminan la diáfana estancia, obra de Antonio Rodríguez Valdivieso (Fig.11) ${ }^{9}$. En la cabecera, un San Francisco de Asís en forja y anclado (Fig.11), con brazos abiertos en forma de cruz, implora con su mirada hacia el frente, mientras revolotean a su alrededor palomas que parecen entrar a la iglesia por uno de los vitrales. El efecto escénico, diseño del escultor almanseño José Luis Sánchez, cubre todo el paramento enladrillado con la intención de insuflar expresividad y movimiento a un espacio que recuerda a una construcción industrial.

Dicha escultura abarca las experimentaciones sobre la materia que José Luis Sánchez realizó a lo largo de la década de 1950, cuya creatividad despertó la influencia de los móviles de Ángel Ferrant -durante las clases que recibió en la Escuela de Artes y Oficios de Madrid entre 1952 y 1954-, y la fusión de artes plásticas que vio en la X Trienale di Milano (1954). Todo ello se conjugó en el empleo de diversos materiales, en los que José Luis Sánchez descubrió que la escultura implica algo más que una simple técnica imitativa de la realidad, en la que el papel del escultor es prestar atención a las posibilidades que el azar le da al uso de la materia y las formas sugeridas; del mismo modo que un arquitecto debe amoldarse al espacio a diseñar, adaptando sus conocimientos a unos materiales, terreno y significancia.

${ }^{9}$ Elementos artísticos de las iglesias de los pueblos del IRYDA. Archivo Central del Ministerio de Agricultura, Madrid (AC-MAPAMA), Inventario general del INC, Carpeta de la provincia de Albacete, n. ${ }^{\circ}$ de expediente 4 , Albacete/Nava de Campana. 

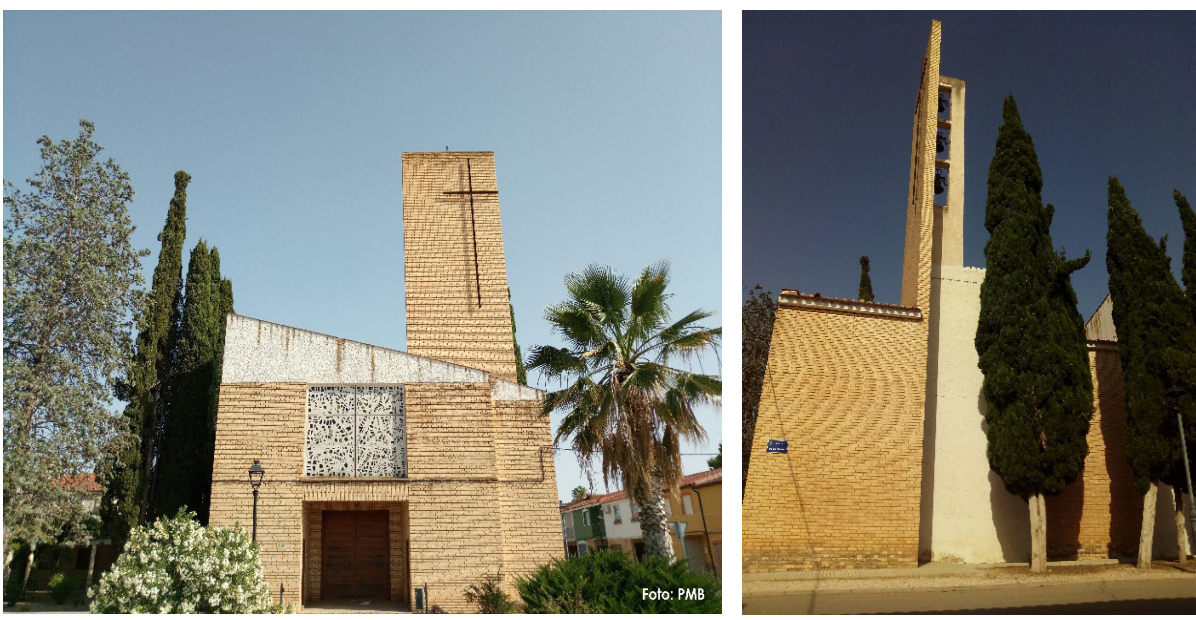

Figura 10. Nava de Campana. Fachada y campanario de la iglesia. Fuente: Fotos del autora.

Fue así que José Luis Sánchez tomó la decisión de dedicarse a la Escultura experimentando entonces distintas técnicas como el modelado en hueco en escayola, esculturas de alambres, barro, cerámica, tallas en madera, vaciados en bronce, etc. con los que forjó un estilo propio. Su posición en la esfera cultural y su don de gentes en la lucha de transición entre lo académico y lo moderno, resultó interesante al director del Museo de Arte Contemporáneo, José Luis Fernández del Amo, como figura polifacética y atractiva para el mundo expositivo y de colonización ${ }^{10}$. Cuando se inició su camino en el INC, Jacqueline Canivet nos comenta que acompañaba a su esposo a la sede del Paseo de la Castellana, donde entablaron relación profesional y de amistad con los arquitectos.

\footnotetext{
${ }^{10}$ José Luis Fernández del Amo Moreno desempeñó dos cargos públicos relevantes en su trayectoria profesional. Además de ser arquitecto funcionario del Servicio de Arquitectura del INC desde 1947 hasta 1965, fue el primer director del Museo de Arte Contemporáneo, actual Museo Nacional Centro de Arte Reina Sofía, entre 1952 y 1958. Su ardua labor en defensa de la vanguardia española apoyada en la idea de «integración de las artes» en el ámbito nacional, fue igual de importante que en la internacional. Contó siempre con la colaboración y participación de artistas, que tuvieron un duro comienzo de promoción artística, y que, junto a él alcanzaron una reputación internacional.
} 

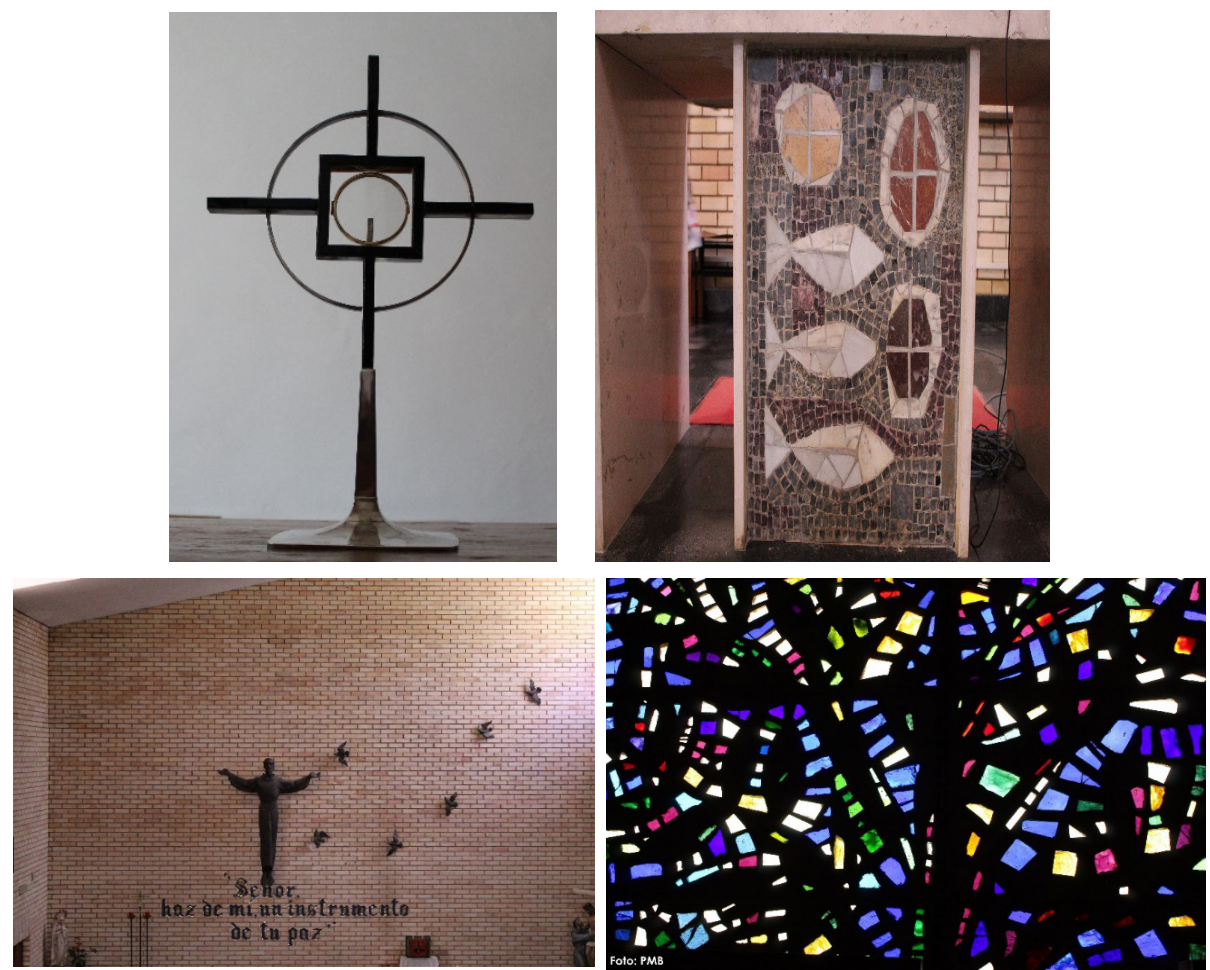

Figura 11. Nava de Campana. Custodia, José Luis Sánchez; mosaico de altar, anónimo; San Francisco de Asís, José Luis Sánchez Fernández; vitral de Antonio Rodríguez Valdivieso. Fuente: Fotos de la autora.

Es anecdótico el intercambio de sagrarios musivarios entre Nava y Cañada, a voluntad del párroco anterior, justificándose en la combinación estética entre el sagrario de Cañada y el mosaico del altar de Nava, no reflejada en el estudio de Bezares. El sagrario de Nava, ubicado en Cañada, es de proporciones cúbicas y en el frente con esmaltes de colores resaltan los símbolos de la multiplicación de los panes y los peces. Su autoría se desconoce, pudiéndose atribuir a un artista independiente o a los Talleres Granda, porque guarda relación con el de Mingogil por el detalle del mismo diseño de la llave que lo abre. En la sacristía se conserva el mobiliario de Granda y una custodia de sencillo diseño atribuido a José Luis Sánchez (Fig.11), tras un estudio comparativo con los conservados en su colección privada. 


\subsection{Cañada de Agra}

El diseño del pueblo de Cañada de Agra se encargó al arquitecto José Luis Fernández del Amo. Las obras se iniciaron en mayo de 1962 y se concluyeron el 14 de febrero de 1966. Su ubicación central jerarquiza la ordenación territorial de la zona regable del Canal de Hellín con un distanciamiento de los otros dos pueblos y de las poblaciones mayores vecinas basado en el sistema de «módulo carro»: Cañada de Agra a Hellín (6,7 km), Isso (8,8 km), Mingogil $(4,2 \mathrm{~km})$ y Nava de Campana $(5,5 \mathrm{~km})^{11}$.

Su emplazamiento ${ }^{12}$ (Fig.12) de orientación sur reúne la peculiaridad de su orogenia que da sentido innovador al trazado urbano orgánico, aprovechando las sinuosidades de una media ladera abierta hacia el valle de cultivos frutales y de secano (Manchón, 2006; Cordero \& Gutiérrez, 2020, pp. 129-135). Fernández del Amo optó por el desarrollo del pueblo de este modo conservando el paisaje circundante y la posición estratégica que éste tenía frente a Nava de Campana y Mingogil asentados en el valle. No obstante, su planificación supuso un ahorro del trabajo de nivelación del terreno en cuanto que la forma de la colina daba al arquitecto y al agrimensor facilidades en el estudio parcelario, en las vías de circulación en fondo de saco y en el estudio espacial del urbanismo (Almarcha, 2004) (Fig. 12), de marcado sentido integrista al preservar arboleda autóctona e interconectar edificios edilicios y viviendas. El conjunto semiovalado semejante al proyectado en los planos de Torres Salinas (Toledo, 1951) está circunvalado por una vía terrestre, que conecta con la carretera que le une a los otros dos pueblos y el centro cívico (Fernández del Amo \& Centellas, 2015) (Fig.12).

\footnotetext{
${ }^{11}$ Extracto Constitución de la Entidad Local Menor de Cañada de Agra, creada por el INC, dependiente del Ayto. de Hellín, 1975. Archivo General de la Administración, Madrid (AGA), Entidades locales menores INC, Sección 08, Fondo 11018, no de orden 4340/5, no de expediente 01, Albacete/Hellín Cañada de Agra.

${ }^{12}$ Proyecto del pueblo de Cañada de Agra. Zona de Hellín (Albacete), 1962. Archivo Central del Ministerio de Agricultura, San Fernando de Henares Madrid (ACMAPAMA), Proyecto no. 11693.
} 

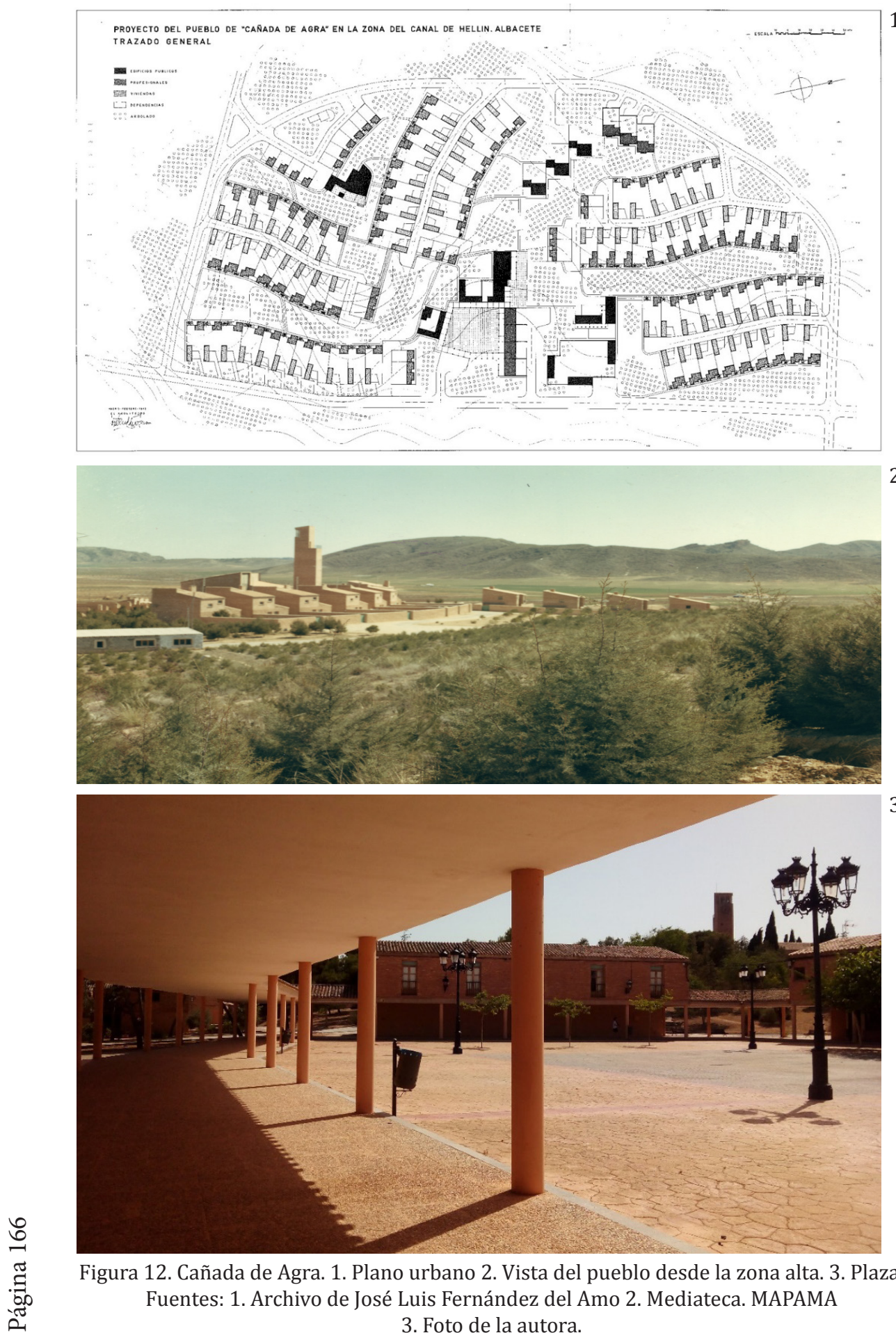

Figura 12. Cañada de Agra. 1. Plano urbano 2. Vista del pueblo desde la zona alta. 3. Plaza. Fuentes: 1. Archivo de José Luis Fernández del Amo 2. Mediateca. MAPAMA 3. Foto de la autora. 
El total de edificaciones que lo constituyen es de 125 entre área urbana, parques y bosquetes alcanzando una superficie de 24,15 hectáreas, siguiendo las normas dictadas por la Dirección General y atendiendo al factor demográfico. Como entidad local municipal alberga los servicios mínimos administrativos (ayuntamiento y vivienda del funcionario), religiosos (iglesia con casa rectoral y dependencias parroquiales), educativos (tres escuelas y viviendas de maestros), sanitarios (dispensario y vivienda del médico) y sociolaborales (Hermandad Sindical y dos hogares rurales), además de las cuatro tiendas y un bar con sus respectivas viviendas (Centellas, 2010; Cordero, 2012).

El centro cívico es de acceso directo por la carretera y concentra en una plaza porticada el ayuntamiento y la vivienda del administrativo, el bar y la vivienda del tabernero, cuatro artesanías o comercios, el edificio social y la clínica y vivienda del médico (Fig.12). Los edificios de labor como la Hermandad Sindical y los hogares rurales se encuentran en un lateral del núcleo, mientras que las escuelas y viviendas de los maestros sí que están incluidas en el núcleo y próximas a la plaza, aunque a un nivel más elevado.

Rodeando las edificaciones descritas están las 80 viviendas de colonos de patrimonio familiar y las 24 para colonos de parcela complementaria. Cada parcela destinada a los colonos se dividió en dos partes: una, para las dependencias agrícolas y otra, para vivienda en vista a la expansión de ésta. Por un lado, dentro de las de patrimonio familiar se distinguen cuatro tipos de vivienda: la A y B de dos alturas y la C y D de una sola. Todas ellas responden a un diseño similar difiriendo sólo en su orientación solar. Por otro lado, las de parcela complementaria comprenden tres tipos: la a, b y c de dos plantas y la variante a' sobre la orientación (Fig.13).

Como indica el colectivo actual de arquitectos, José Luis Fernández del Amo fue de los pioneros en la defensa al uso de materiales locales. De ellos pulió su aspecto sencillo y quizás robusto, obteniendo las cualidades plásticas de sus texturas y colores (Fig.13), que integraban el conjunto arquitectónico en los parajes ocres de 
La Mancha, cobrando un aire etéreo y abstracto como solía decir él mismo: «sólo el arte abstracto me enseñó a ver la belleza estricta y desnuda en tierras de La Mancha» (Fernández del Amo, 1991, p. 18; Fernández del Amo \& Centellas, 2015, pp. 276-277). No obstante, su ingenio fue una solución a las dificultades por las que la arquitectura española pasaba en la posguerra, ante las carencias de suministro de acero y hierro (Azpilicueta, 2004, pp. 161-163), así como por los obstáculos que encontraron los arquitectos en el desafío de buscar una vivienda digna; especialmente debatida a nivel internacional por Pedro Muguruza Otaño en el Congreso de Arquitectura de Oporto en 1942 (Bustos, 2016).

Tanto es así, que la pericia creativa de Fernández del Amo se transfirió a los edificios de sus pueblos de colonización como Cañada de Agra (Fernández del Amo, 1974, 1995), en los que procede al cuidado de la unidad arquitectónica desde una base de hormigón, un zócalo de mampostería consolidando las esquinas y las guarniciones con sillar, el enladrillado a soga y tizón en la segunda planta hasta un forjado y una cubierta de hormigón mezclado con piezas cerámicas para aligerar la fábrica. Un detalle que se hace a veces heterogéneo en algunos pueblos de colonización es la cerrajería y carpintería.

En el nivel más alto del pueblo la iglesia (Fig.14), la casa rectoral y los locales de Acción Católica se alzan y divisan el valle desde una vista privilegiada como faro de la Fe y ejemplo de la integración de las artes (Fernández del Amo, 1995, pp. 35-47). El volumen de fábrica de ladrillo rojo es un diseño irregular de la planta basilical, que se une en el exterior a la torre-campanario con balconada por un porche, único indicador de la existencia de una «falsa» fachada, junto al frente de azulejería de peces, cruces y panes de Antonio Hernández Carpe. No obstante, el diseño de 1962 sustituyó al primer boceto de 1959 con un aire innovador más austero y próximo al de la iglesia de El Realengo (Alicante, 1953) (De Nito, 2003) (Fig.14).

$\mathrm{Su}$ acceso se hace por una escalera monumental, a cuyo lado izquierdo se encuentra un San Isidro de formas redondeadas y gusto 

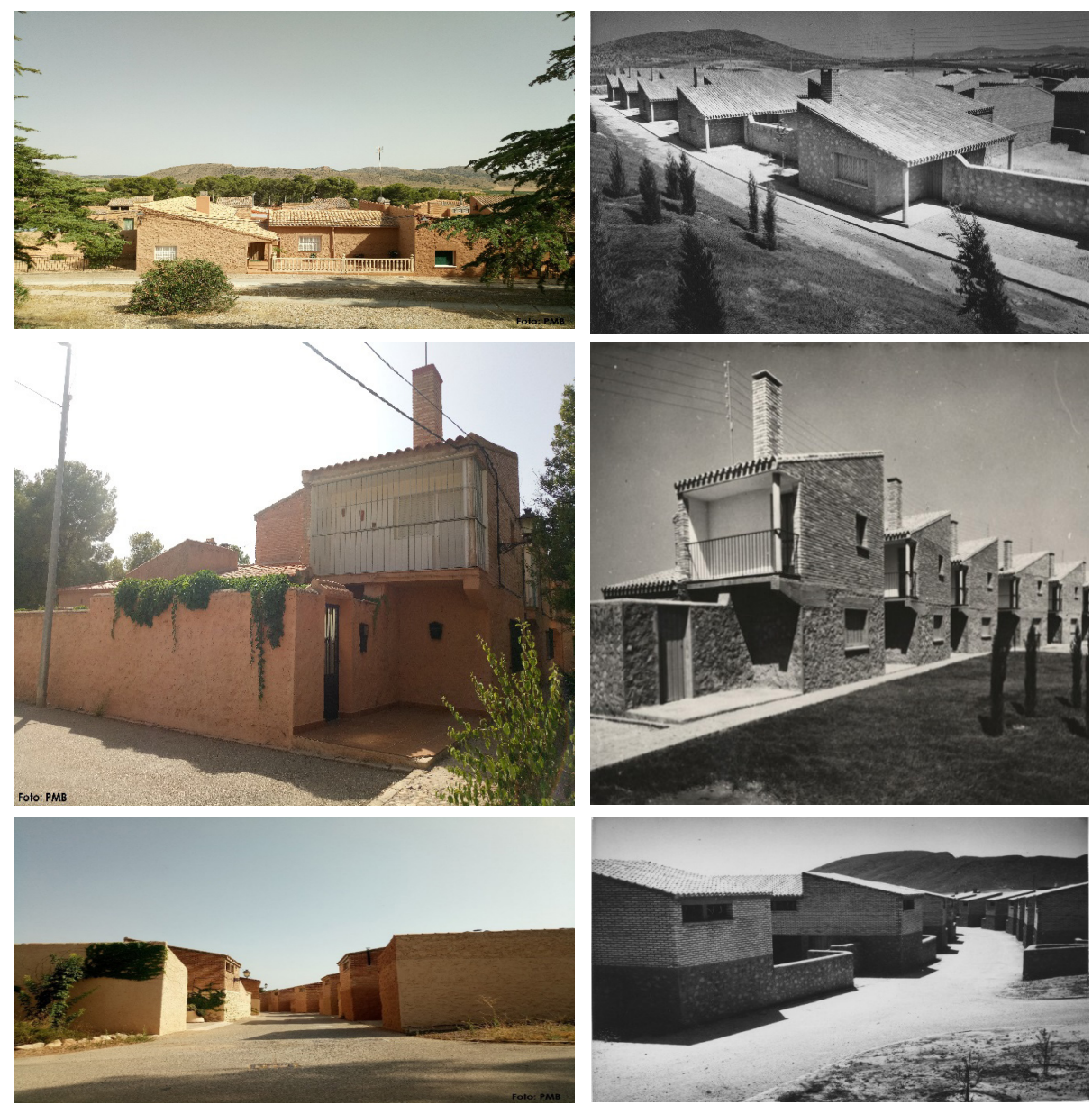

Figura 13. Cañada de Agra. Viviendas de colonos y calles del pueblo. Fotógrafo: Kindel. Fuente: Archivo de José Luis Fernández del Amo (blanco y negro) y de la autora (color).

románico de Antonio Faílde Gago, como el de Aguas Nuevas. Su interior obedece a nuevas introducciones estructurales, posiblemente influidas por el «muro dinámico» de Miguel Fisac (De Nito, 2003) (Fig. 14), sobre el que se abre un listel de vitrales abstractos (1966) de Antonio Hernández Carpe, y que cierra la curva del ábside en un vitral de grandes dimensiones. Una nave lateral de doble piso alberga el coro al que se accede por una escalera de diseño minimalista, presidida por un Crucifijo de bronce sobre cruz de madera de José Luis Sánchez. 
Bajo el coro el baptisterio presenta un fondo mural alicatado de vieiras y cruces de Carpe y una tabla en mediorrelieve en madera del Bautismo de Cristo de Teresa Eguíbar Galarza (Fig.16) para los Talleres Granda, de la misma composición que empleó el escultor barroco Gregorio Fernández. De frente al altar y de claras trazas posconciliares, se distribuye el altar de cerámica vitrificada con diversas técnicas (incisión, impresión, estampillado y pintado) en todos sus frentes con signos cristianos atribuido a Arcadio Blasco Pastor $^{13}$ (1966) (Centellas, 2010; Centellas \& Bazan, 2017; Bezares, 2018), autor también de otro altar (1963-1964) de misma factura en la iglesia de colonización de Maruanas (Córdoba, arquitecto Juan Arturo Guerrero Aroca, 1962) que crea un conjunto único con el retablo cerámico (Fig.16).

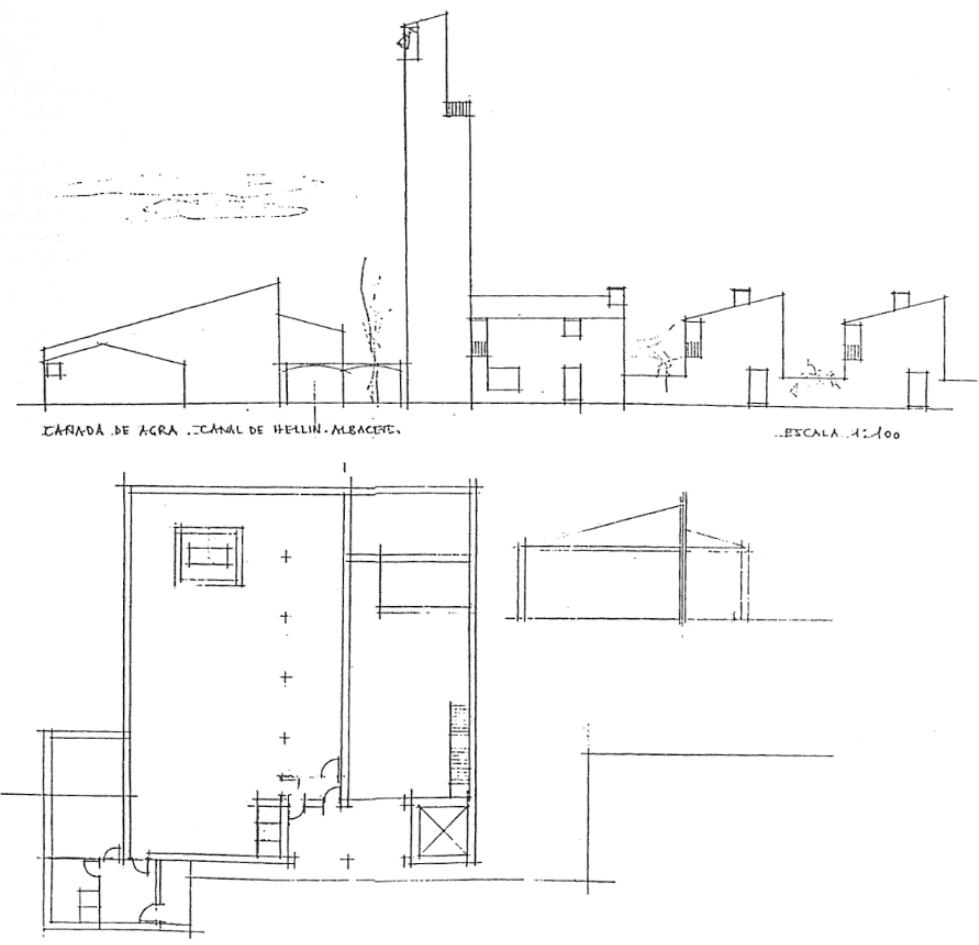

${ }^{13}$ Elementos artísticos de las iglesias de los pueblos del IRYDA. Archivo Central del Ministerio de Agricultura, Madrid (AC-MAPAMA), Inventario general del INC, Carpeta de la provincia de Albacete, n.o de expediente 2, Albacete/Cañada de Agra. 


\section{CAÑAdA DE AGRA. (ALBACETE) IGLESIA Y CASA RECTORAL. ESCALA}
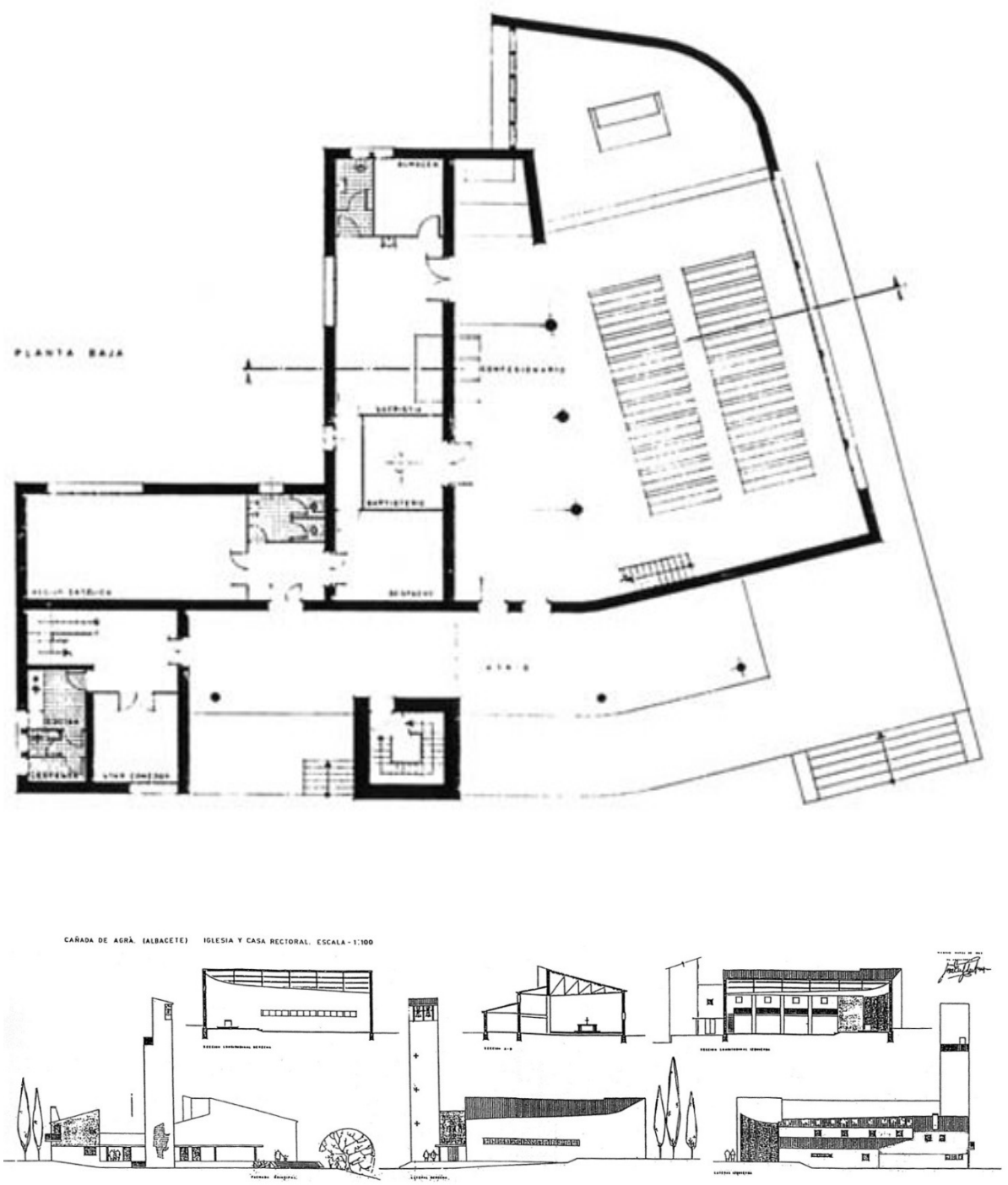

Figura 14. Cañada de Agra. 1. Alzado y planta de la iglesia, 1959.

2 y 3. Planta, secciones y alzados de la iglesia, 1962.

Fuentes: Archivo de José Luis Fernández del Amo y De Nito, 2003. 
Este escaso repertorio rico en técnicas de Arcadio Blasco Pastor, debe asociarse a la serie de cuadros cerámicos que realizó entre 1956 y 1964, puesto que son fruto de una adaptación que brilla a causa de los esmaltes nostálgicos de Manises con la materia como superficie gestual del modelado, el tipo de arcilla y los métodos de cocción.

En definitiva, un logro expresivo tridimensional que en la década de 1960 persiguió el significado y la función de compromiso social del arte en murales y relieves cerámicos. Por otro lado, sobre el ceramista alicantino hemos de apuntar la estrecha relación que poseía con La Mancha, porque se formó en los alfares conquenses, que le dieron los conocimientos e inspiración necesaria para experimentar la vanguardia en un material tan maleable y olvidado, como decía su compañero y amigo José Luis Sánchez Fernández (Ruiz, 2016). Junto a él y su esposa, la ceramista y mosaicista francesa Jacqueline Canivet, realizaron la exposición «Tres ceramistas» del Ateneo de Madrid en la sala del Prado en 1957.

Detrás, anclado a la cabecera del ábside, una talla en madera de San José con el niño Jesús (Fig.16) en sus brazos gravita mimetizado con el fondo enladrillado. Su autoría no está determinada, pero la calidad del cincelado en los ropajes y el rostro cabe la posibilidad de que sea obra de Lorenzo Frechilla del Rey, quien trabajó para Talleres Granda.

El sagrario que está en Nava, tal como comentamos, debería presidir el altar, aunque según los preceptos conciliares, debe ocupar la capilla del sacramento de la nave lateral junto a dos reclinatorios, pertenecientes a Talleres Granda. Su forma cúbica está reforzada por un listelo de forja con relieve. La compuerta centrada está decorada por un mosaico de teselas regulares que dibujan a modo

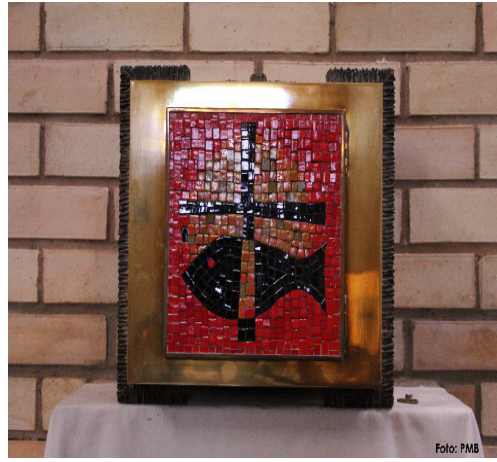

Figura 15. Cañada de Agra. Sagrario con frente musivario, Jacqueline Canivet. Fuente: foto de la autora. de figuras negras sobre fondo rojo el pez y la cruz (Fig.15). 


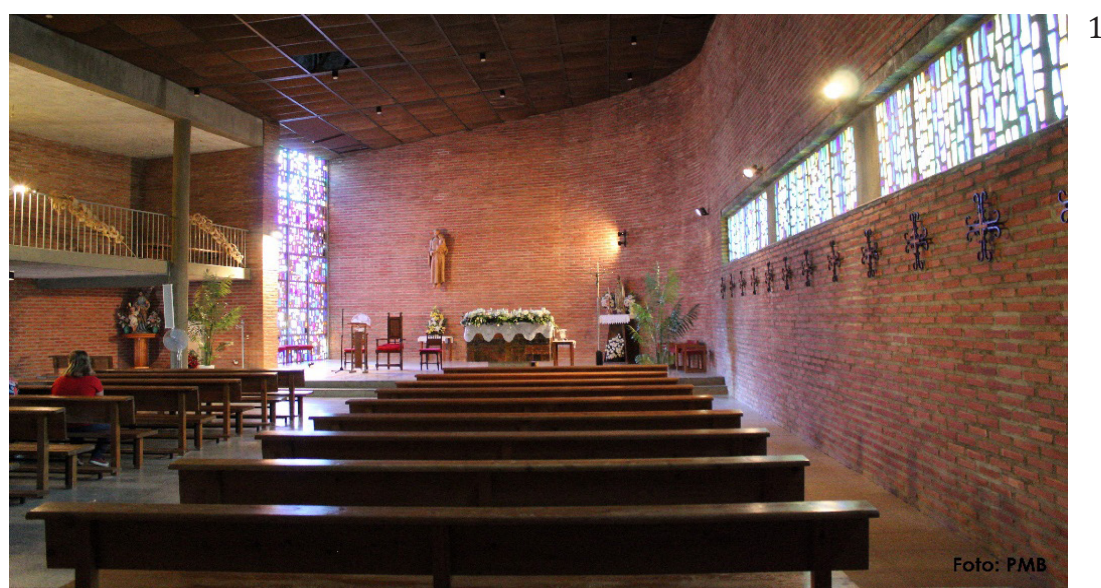

2

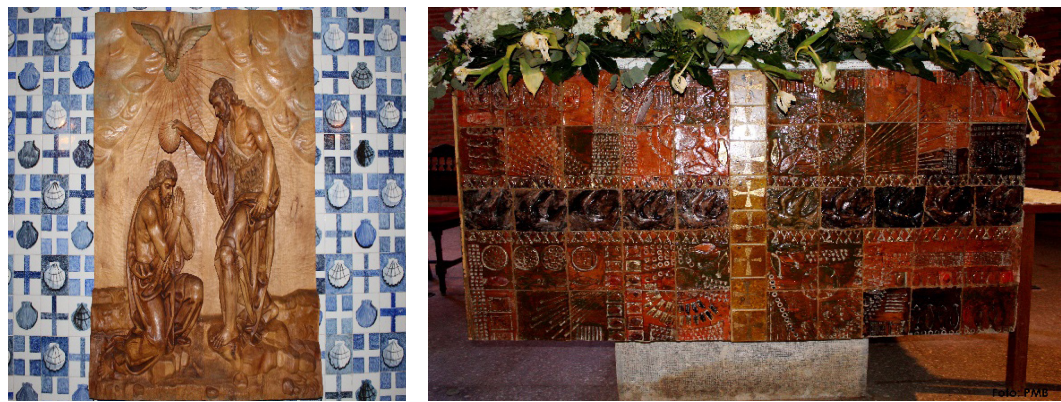

4
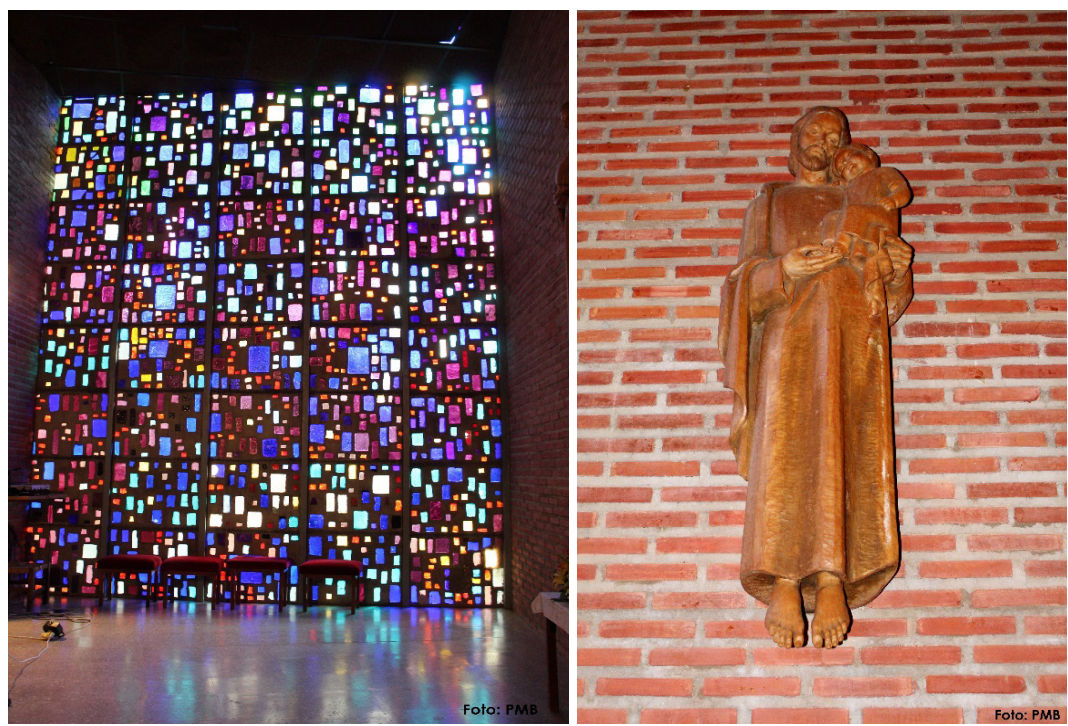

Figura 16. Cañada de Agra. 1. Interior de la iglesia 2. Mural cerámico de Antonio

Hernández Carpe y mediorrelieve de madera de Teresa Eguíbar Galarza 3. Altar cerámico de Arcadio Blasco Pastor 4. Vitrales de Antonio Hernández Carpe 5. Talla de bulto redondo de San José con el niño de Lorenzo Frechilla del Rey, Talleres Granda. Fuente: Fotos de la autora. 


\section{LOS LLANOS DE ALBACETE}

\subsection{Aguas Nuevas}

La zona regable fue declarada de Interés Nacional por decreto 773/1961, de 13 de mayo (BOE n. ${ }^{\circ}$ 115, de 15-05-1961), siendo jefe provincial Francisco Enguídanos Miguel. La construcción del pueblo se inició tras la aprobación del Plan General de Colonización en el Sector I el 20 de abril de $1963^{14}$ y se concluyó en diciembre de $1967^{15}$. El encargo desde el INC se realizó al arquitecto doctor Pedro Castañeda Cagigas en 1963, cuyas labores se extendieron hasta 1967 al dividir en cuatro fases la construcción del nuevo pueblo. El diseño urbano de Aguas Nuevas fue pensado desde el pragmatismo, que caracteriza el repertorio urbanístico de Castañeda Cagigas en el INC, al apoyarse en los ingenieros agrónomos, por lo que fue reconocido con el Mérito Agrícola en 1956.

La planicie del paraje endorreico era un inconveniente el transporte del agua hasta las parcelas de cultivo y el pueblo, siendo necesario un estudio paisajístico. El registro de escasos desniveles naturales de poca pendiente, dieron lugar a la creación de niveles artificiales, lo cual influyó en la orientación Este-Oeste y situación del núcleo urbano sobre una malla ortogonal mixta, que a simple vista no difiere de los criterios urbanos del Servicio de Arquitectura del INC, aunque resulta similar a Cañada de Agra (Fig.17). El giro

14 Por decreto 475/1962, 20 de septiembre (BOE no239, de 05-10-1962), modificado por el decreto 3592/196, de 27 de diciembre (BOE no17, de 19-011963), por el que se aprobó el Plan General de Colonización Sector I (BOE no5, de 20-04-1963). Y en Expediente de constitución de la Entidad Local Menor de Aguas Nuevas, creada por el Instituto Nacional de Colonización en la zona regable de Los Llanos de Albacete, dependiente del Ayuntamiento de Albacete, 1967, Archivo General de la Administración, Madrid (AGA). Entidades locales menores INC, Sección 08, Fondo 11018, no de orden 4332, no de expediente 02, Albacete/ Aguas Nuevas.

${ }^{15}$ Expediente de constitución de la Entidad Local Menor de Aguas Nuevas, creada por el Instituto Nacional de Colonización en la zona regable de Los Llanos de Albacete, dependiente del Ayuntamiento de Albacete, Archivo General de la Administración, Madrid (AGA), Entidades locales menores INC, Sección 08, Fondo 11018, n.ํ de orden 4332, no de expediente 02, Albacete/Aguas Nuevas. 
de dicha malla hacia el Sur-Este fue la solución para la distribución solar de las viviendas modulares de los colonos, como también para que las principales carreteras que la atraviesan, quedasen paralelas a las canalizaciones, acequias y acueductos.

Es por ello, que Aguas Nuevas tiene un aporte agronómico y urbanístico interesante que no queda alejado del tratamiento modernizante de su arquitectura, que siguió cuatro fases de construcción ${ }^{16}$. Los fines destinados a la nueva población eran la explotación agrícola y ganadera sobre terrenos expropiados a antiguos cortijos de las fincas de «Casa González», «Melegriz», «Casa de la Viña» y «Salomón», irrigados con el agua sustraída por pozos de los paisajes de «El Salobral», «El Pasico», «Fuente del Charco» y «La Madriguera».

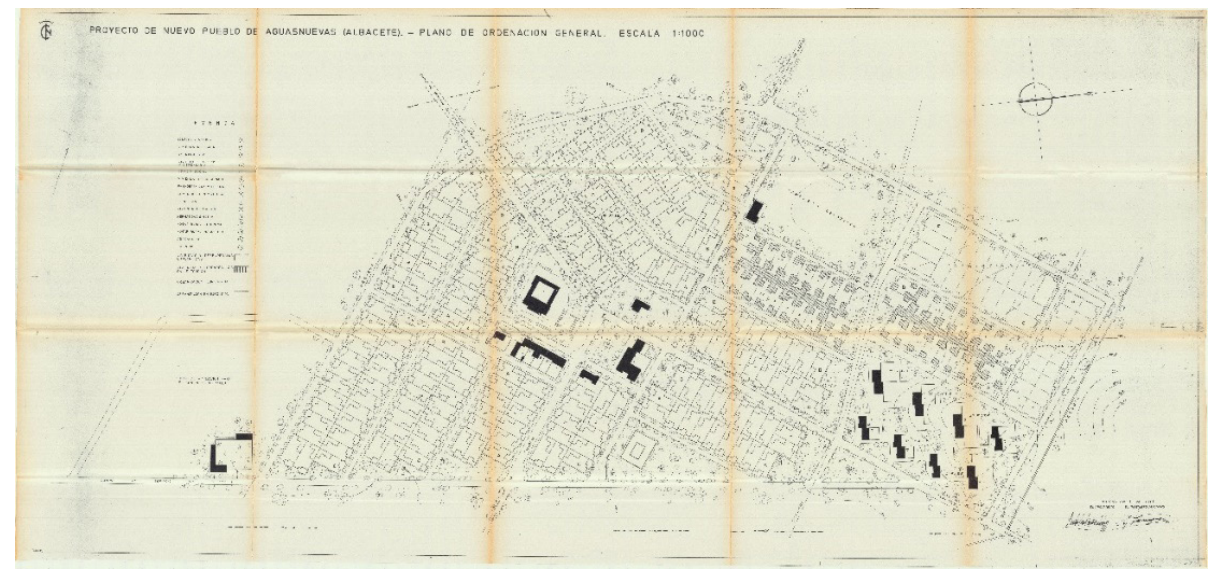

Figura 17. Aguas Nuevas. Plano urbano. Fuente: Delegación de Agricultura. Archivo Regional de Castilla-La Mancha.

Como entidad municipal poseía construcciones civiles (el ayuntamiento, la vivienda del funcionario del ayuntamiento), religiosas (la iglesia, los salones de Acción Católica y vivienda del párroco), sociales (el Hogar Masculino y Femenino para el desarrollo de

\footnotetext{
${ }^{16}$ Proyectos de las cuatro fases del nuevo pueblo de Aguas Nuevas en la zona de los Llanos de Albacete, Archivo Central del Ministerio de Agricultura, Madrid (ACMAPAMA). Proyecto de la primera fase (1963), n.ํㅜ 12332; de la segunda fase (1964), n.ํ12797; de la tercera fase de edificios generales (1964), n.o 13811 y de la cuarta fase (1967), n.o 15619.
} 
actividades formativas para todas las edades), de ocio y recreativos (un bar, un cine y un campo de deportes), educativas con un total de seis escuelas y seis viviendas para maestros ${ }^{17}$, sanitarias (el dispensario y la vivienda del médico) y finalmente, un cementerio. Además de ello, se realizaron las concesiones de tres artesanías y cinco tiendas con viviendas, un Centro Cooperativo y una casa cuartel de la Guardia Civil $^{18}$ (Fig.18). No obstante, la relevancia de este pueblo de colonización se debe a la presencia del Parque de Maquinaria Agrícola del INC para la provincia.
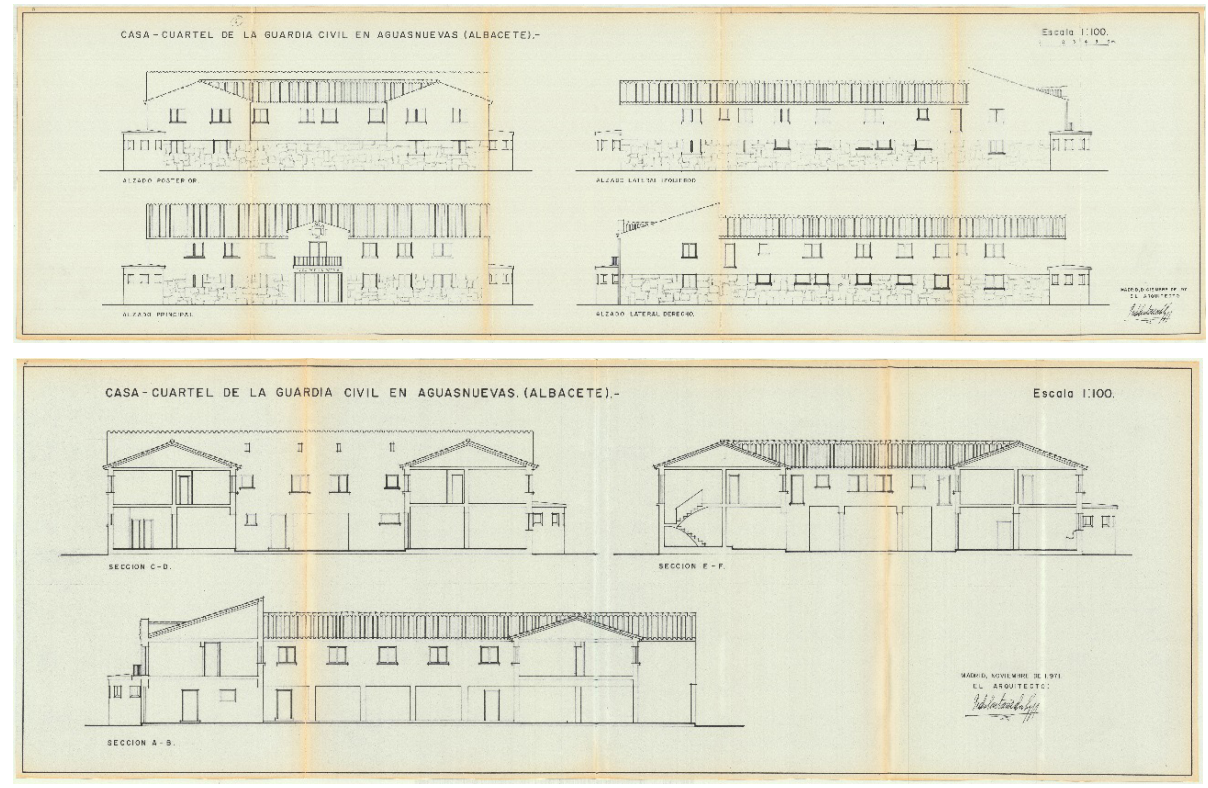

${ }^{17}$ Proyecto de las escuelas y edificios principales del centro de enseñanza general básica (EGB) de Aguas Nuevas, Archivo Regional de Castilla-La Mancha, Toledo (ARCLM), Fondo de Agricultura, Medio Ambiente y Desarrollo rural, incluidas las direcciones provinciales. Signatura ES.45.021.ACLM/96, Caja 1. Firmado el 27 de mayo de 1975, por el arquitecto Pedro Castañeda Cagigas y el aparejador Ernesto García Domingo, aunque también consta como colaborador el arquitecto Miguel Herrero Urgel. La construcción no se inició hasta el 25 de septiembre de 1979.

${ }_{18}^{18}$ Proyecto del cuartel de la Guardia Civil redactado por el arquitecto Pedro Castañeda Cagigas en enero de 1972 y aprobado en abril del mismo año, con la asistencia del aparejador Ernesto García Domingo, Archivo Regional de CastillaLa Mancha, Toledo (ARCLM), Fondo de Agricultura, Medio Ambiente y Desarrollo rural, incluidas las direcciones provinciales. Signatura ES.45.021.ACLM/97, Caja 2, n. 9640 . 


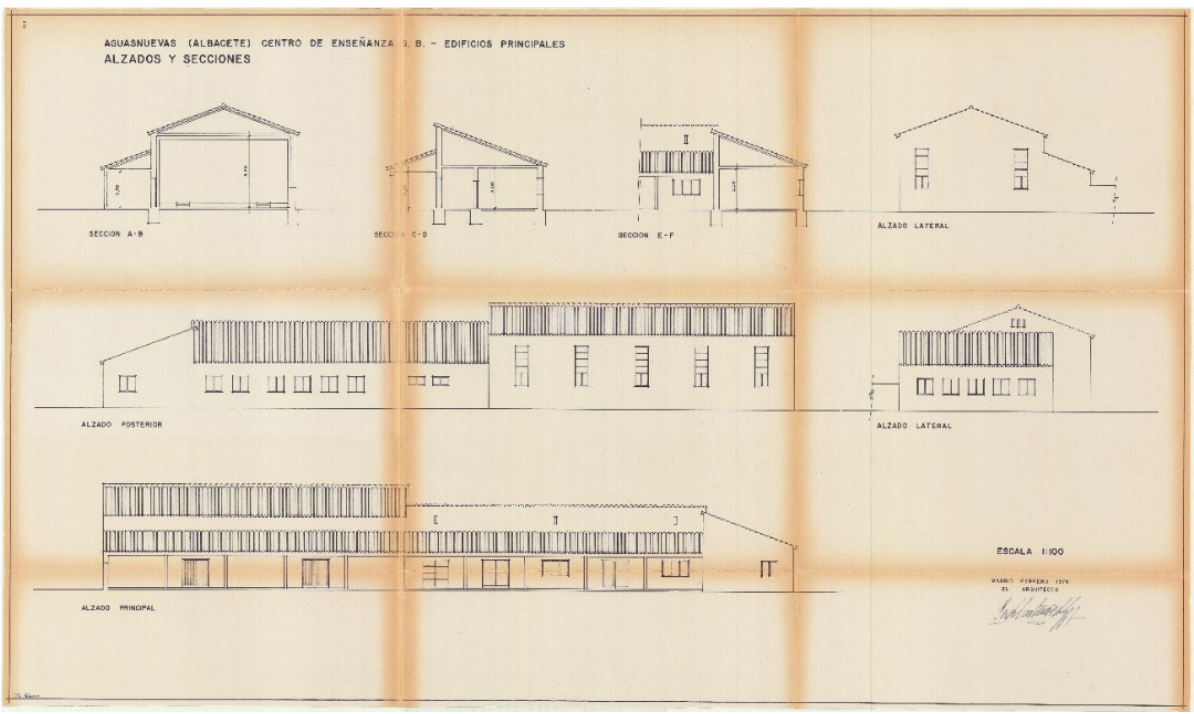

Figura 18. Aguas Nuevas. 1. Alzados y secciones del cuartel de la Guardia Civil. 2. Alzados y secciones de las escuelas. Fuente: Delegación de Agricultura. Archivo Regional de Castilla-La Mancha.
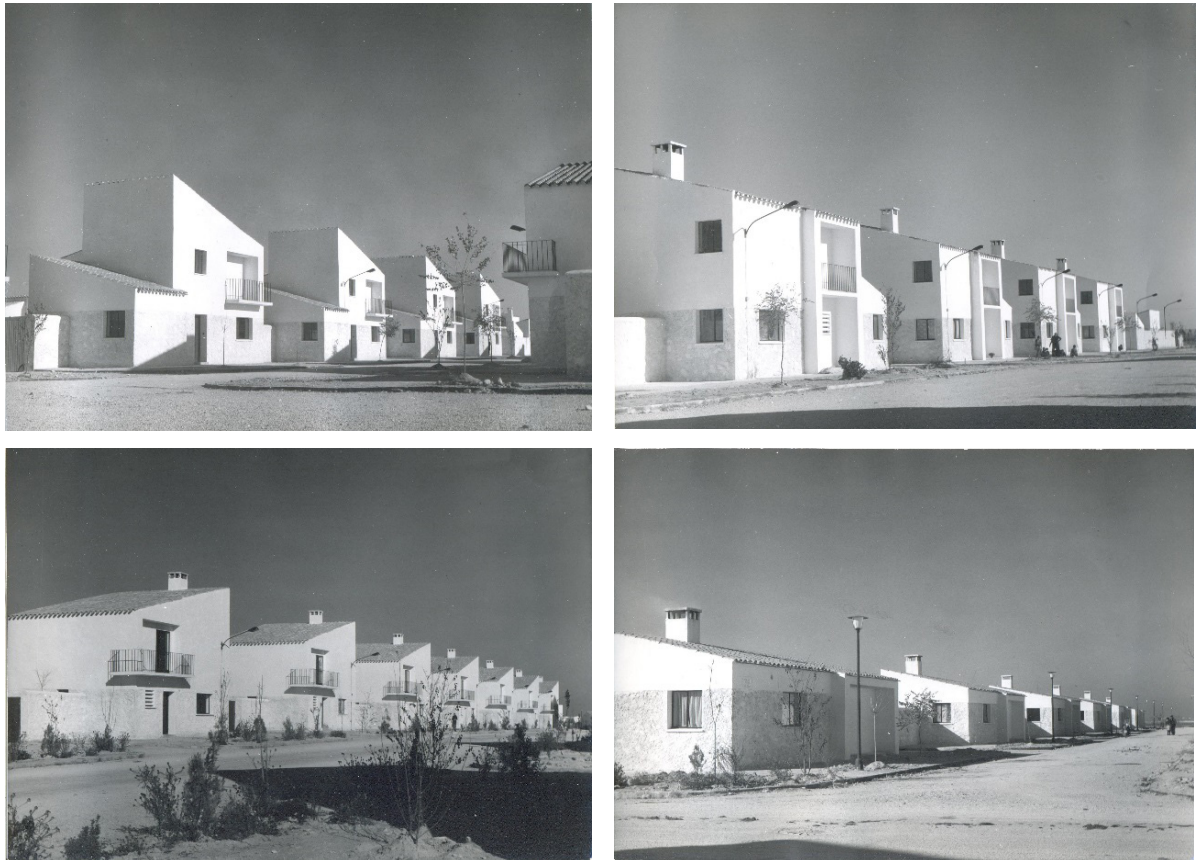

Figura 19. Aguas Nuevas. Viviendas de colonos. Fotografías de Kindel. Fuente: Archivo de Pedro Castañeda Cagigas. 
El total de viviendas de colonos es de 289 y de obreros agrícolas 97, existiendo diferentes tipos de viviendas clasificadas en tipo A, B y C (Fig.19). Gracias a la descripción de ocho casas adjudicadas a nuevos colonos en los años setenta, sabemos la distribución de las viviendas del tipo A y B, elevadas en la 4 a fase de construcción del pueblo. Las viviendas de tipo A son de dos plantas, siendo una de ellas solamente para tres habitaciones. En la planta baja se sitúan la cocina-comedor, un aseo, la despensa y un corral con dependencias agrícolas que aglomera una cuadra, un granero, un henil, el porche, cochiqueras y un gallinero.

La vivienda de tipo B no difiere de la de tipo A en la distribución y funciones dadas a cada espacio habitacional, así como en la superficie total de solar que es de $650 \mathrm{~m}^{2}$ y la del corral de dependencias agrícolas es de $190 \mathrm{~m}^{2}$. Las superficies que ocupan la vivienda (la de tipo A son $77 \mathrm{~m}^{2}$ la de tipo B son $59 \mathrm{~m}^{2}$ ) y el patio son las que marcan la diferencia (la de tipo A es de $383 \mathrm{~m}^{2}$ y la de tipo B es de $\left.401 \mathrm{~m}^{2}\right)^{19}$.

De entre todas las construcciones, la más importante de to-

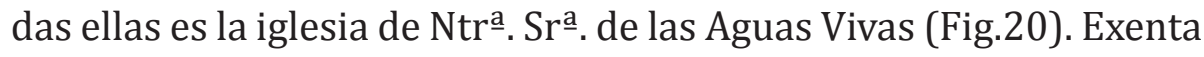
en la plaza principal y peraltada tiene acceso a través de rampas y escaleras. Sobre la explanada el conjunto arquitectónico lo distribuye un claustro abierto que une por un pórtico la iglesia, la torrecampanario y las dependencias de Acción Católica. Frente a la fachada-retablo angulada hay una representación de Ángeles cantores y el árbol de la Vida con aves. Un detalle que ha variado con el paso del tiempo son las facciones de los ángeles como demuestran las fotografías del archivo de Pedro Castañeda Cagigas, anécdota a la que se suma el cambio de ubicación de las imágenes de la Virgen y San Isidro, antes en las capillas laterales y ahora sobre el presbiterio ${ }^{20}$.

${ }^{19}$ Informe sobre el estado de ocupación de las viviendas de Aguas Nuevas, junio de 1976, Archivo Regional de Castilla-La Mancha, Toledo (ARCLM), Fondo de Agricultura, Medio Ambiente y Desarrollo rural, incluidas las direcciones provinciales. Signatura ES.45.021.ACLM/96, Caja 1.

${ }^{20}$ Elementos artísticos de las iglesias de los pueblos del IRYDA. Archivo Central del Ministerio de Agricultura, Madrid (AC-MAPAMA), Inventario general del INC, Carpeta de la provincia de Albacete, $n . \stackrel{0}{ }$ de expediente 7 , Albacete/Aguas Nuevas. 
La visión completa de azulejería blanca y azul de la fachada está dividida por un balcón (Fig.20). La estética cubista de dicho mural, igual a la del pueblo extremeño de Zurbarán (Badajoz, arquitecto Juan Navarro Carrillo, 1957) ${ }^{21}$, datado de 1967, es autoría de Antonio Hernández Carpe.
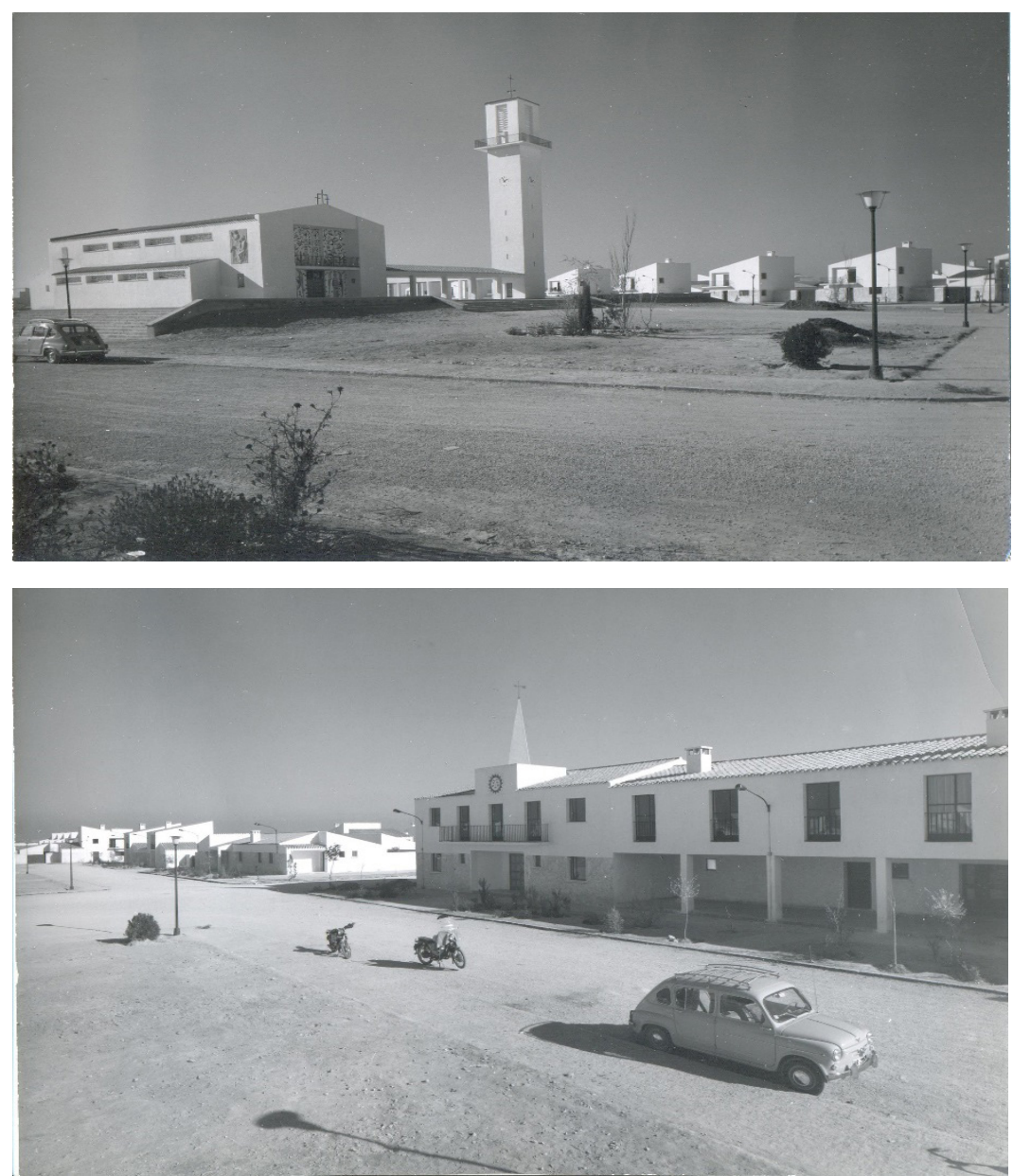

${ }^{21}$ Juan Navarro Carrillo posee la autoría del plano urbano inicial y de la iglesia parroquial de la Sagrada Familia. No obstante, el pueblo tuvo varias ampliaciones urbanas en las que intervinieron los arquitectos Perfecto Gómez Álvarez (1960, 1963, 1964 y 1968), José Luis Fernández del Amo Moreno (1960) y Manuel Mondéjar Horodiski. En el inventario de pueblos de colonización de la Junta de Extremadura y en Proyecto General de Colonización de la Zona Regable por el canal de Orellana, 1955, proyecto n. ${ }^{\mathrm{o}}$ 7616, Archivo Central del Ministerio de Agricultura, San Fernando de Henares, Madrid, (AC-MAPAMA). 

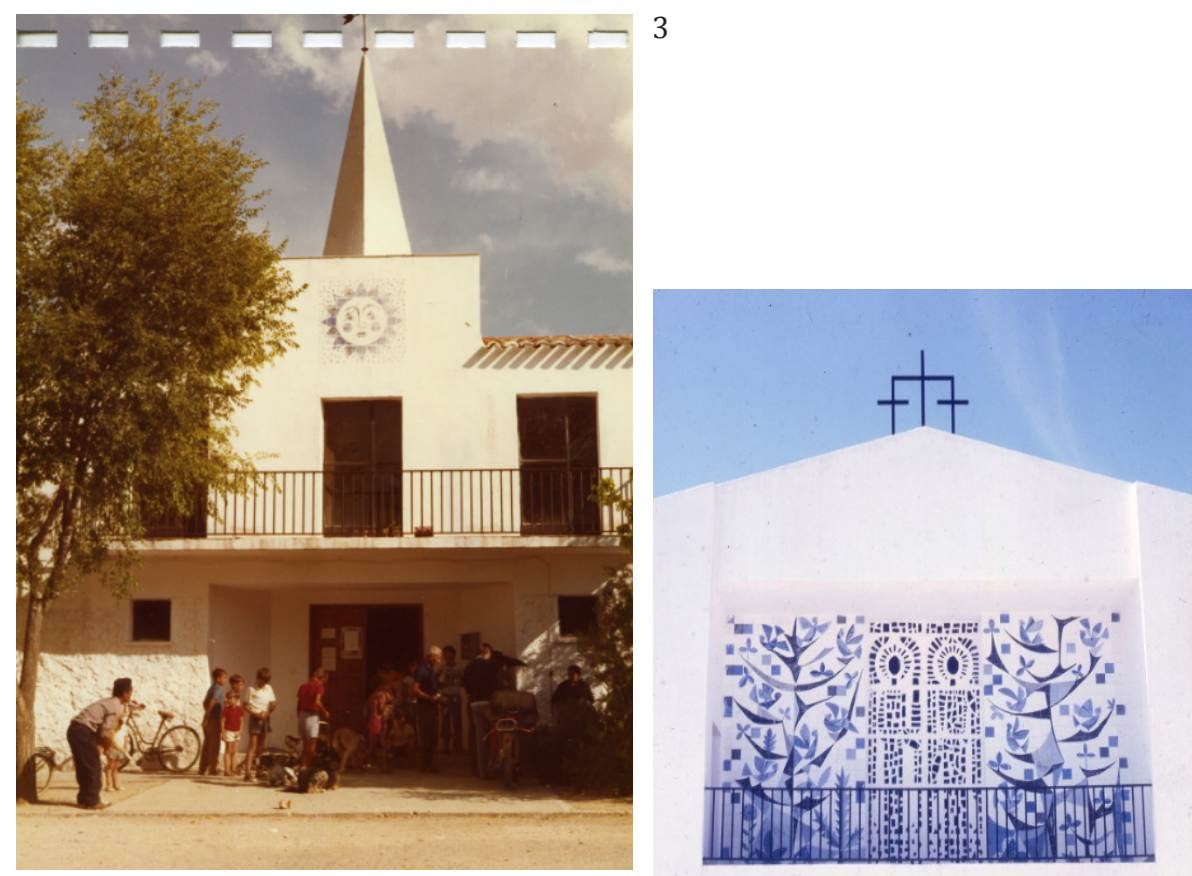

4

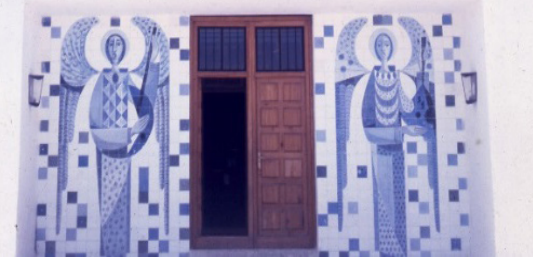

Figura 20. Aguas Nuevas. 1. Vista panorámica de la iglesia 2. Vista panorámica del ayuntamiento 3. Fachada del ayuntamiento 4. Fachada con mural cerámico de Antonio Hernández Carpe. Fuentes: 1, 2 y 4. Archivo de Pedro Castañeda Cagigas (en blanco y negro: Kindel) 3. Mediateca. MAPAMA.

El conocido artista murciano compartió autoría con su mujer Celina Monterde Clavijo en otros pueblos como San Isidro de Albatera (Alicante, arquitecto José Luis Fernández del Amo Moreno, 1953). También se le atribuyen los azulejos con símbolos litúrgicos del rodapié de la entrada a la iglesia. En su técnica empleó el blanco alternado con azul y amarillo y una composición muy recurrente también visible en pueblos extremeños, ya en sus conocidos Vía Crucis, sus murales cerámicos del Bautismo de Cristo en el río Jordán, ya en ángeles cantores sobre el presbiterio. 
1

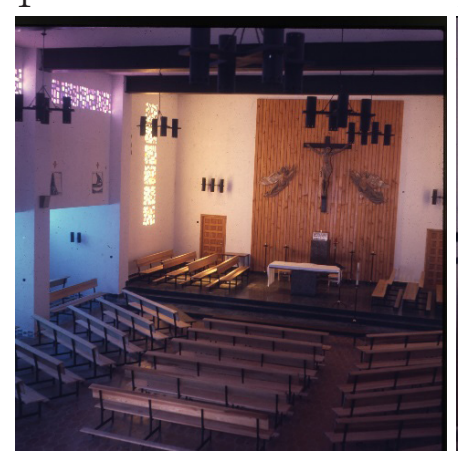

2

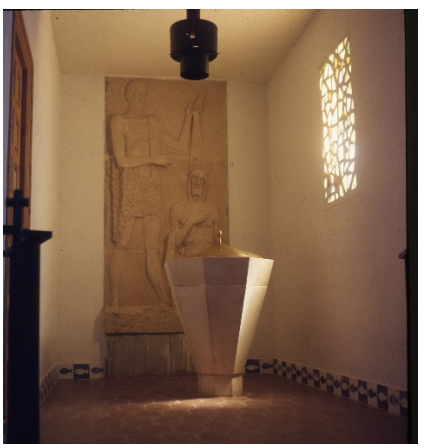

3
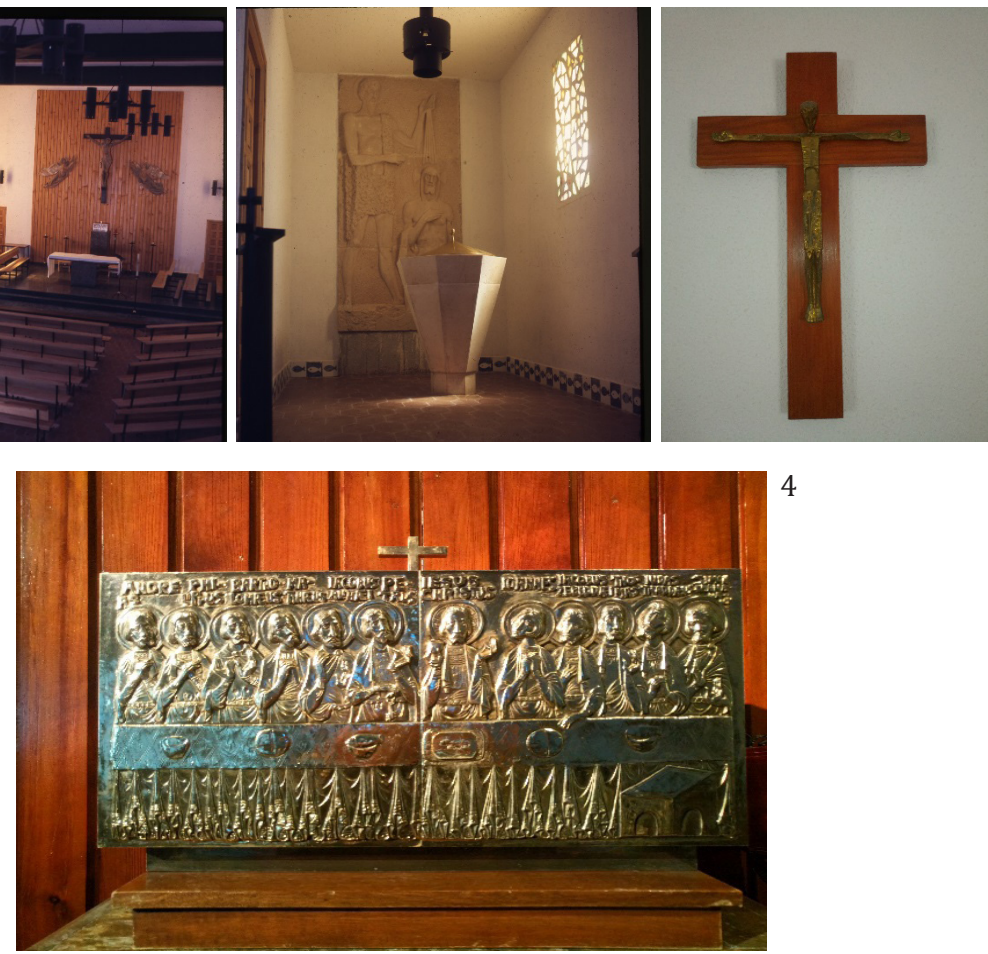

Figura 21. Aguas Nuevas. 1. Interior de la iglesia. Disposición postconciliar en asamblea 2. Baptisterio. Mediorrelieve en piedra del Bautismo de Jesús en el río Jordán de Teresa

Eguíbar Galarza, junto al vitral y zócalo con signos litúrgicos de Antonio Hernández Carpe; pila bautismal, anónimo y apliques de iluminación, Talleres Granda. 3. Crucifijo de bronce en la sacristía, José Luis Sánchez Fernández. 4. Sagrario de los Apóstoles, Talleres Granda. Fuentes: Archivo de Pedro Castañeda Cagigas ((1 y 2) y Fotos de la autora (3 y 4.).

En el interior de la iglesia de una única nave, hay capillas en el lateral izquierdo donde se ubican el confesionario y las advocaciones, reservándose en el nártex el coro y la capilla bautismal donde se encuentra un relieve pétreo del Bautismo de Cristo de Talleres Granda y una pila bautismal poligonal de aristas vivas con cubierta metálica dorada (Fig.21). No obstante, la fachada y los muros presentan vitrales abstractos de hormigón de Antonio Hernández Carpe, autor también del Vía Crucis de 1967.

El altar está presidido por una composición escultórica de 1967 presidido por un Cristo en la cruz de Luis Marco Pérez y dos 
ángeles acompañados por una Virgen con niño de Teresa Eguíbar Galarza (Fig.22). La técnica de cada uno de los escultores es un mar de contrastes en el que la sensualidad y la ternura de Eguíbar choca con la rigidez y el patetismo de Pérez (González, 1988). En la sacristía, se encuentra un Cristo en la cruz en bronce de José Luis Sánchez, otro de mayores dimensiones y luminarias de dos volúmenes circulares y concéntricos con cruces caladas en negro de Talleres Granda, además de porta velas de bronce. En el exterior, la maestría del escultor gallego Antón Faílde Gago sobre el granito deja un San Isidro de trazas neorrománicas y un crucero, próximo a las escuelas (Fig.22).
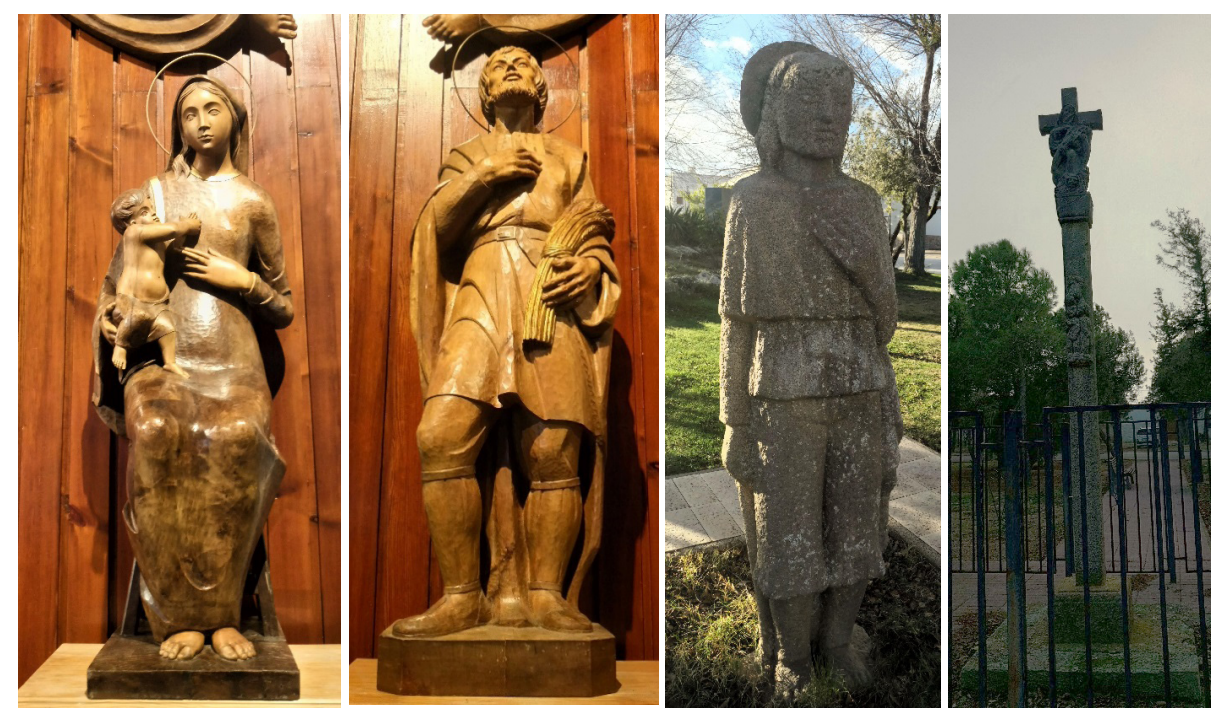

Figura 22. Aguas Nuevas. De izq. a drcha. Talla de bulto redondo de Virgen sedente con niño, Teresa Eguíbar Galarza. Talla en madera de bulto redondo de San Isidro Labrador, Lorenzo Frechilla del Rey. Escultura de San Isidro y crucero en granito, Antón Faílde Gago.

Fuente: Fotos de la autora.

\section{COLONIZACIÓN Y CONCENTRACIÓN PARCELARIA EN LA MANCHUELA}

\subsection{Villatoya y Cilanco}

Ante una población próxima a los cien habitantes se llevó a cabo una inversión de un régimen económico con el fin de mejorar- 
la, que conllevó la construcción de nuevos servicios sociales educativos (tres escuelas y viviendas de maestros), religiosos (una iglesia con hogar parroquial y un híbrido de escuela-capilla), institucionales (ayuntamiento) y obras públicas (plantación de árboles, lavadero público, acequias y muros de contención).

La iglesia de Villatoya (Fig.23), cercana a la carretera principal, de aires minimalistas es fruto de la yuxtaposición del cuerpo vertical de la torre-campanario con el volumen horizontal de la nave y la casa parroquial. El proyecto inicial es de los arquitectos Agustín Marín y Rafael Olalquiaga (original de 1964) y actualizado por el arquitecto valenciano Eugenio Viedma Dutrús entre 1965 y 1967. La planta salón de la iglesia está formada por una única nave y techumbre arquitrabada (Fig.23). En el nártex se ubica un coro y en los laterales de la entrada, se encuentran las capillas del bautismo y la de abluciones. Los muros lisos de la nave no presentaban muchos ornamentos según descripciones de su estado anterior, exceptuándose el Vía Crucis de Julián Gil Martínez de 1970 y una franja de aberturas verticales oblongas que calan el muro derecho en función de lucernario que iluminan también la pila de agua bendita y el coro (Fig.24) ${ }^{22}$.

La división de niveles decidida por los criterios conciliares determinó una elevación limitada a tres escalones del presbiterio. En él se encuentran el ambón de piedra caliza de la misma factura que las pilas bautismales y el ara. Sobre la pared absidial lisa pende un conjunto escultórico de un Crucificado y dos ángeles composición escultórica similar a la de Aguas Nuevas, aunque en este caso, las tallas y el mediorrelieve de madera de la capilla bautismal son de Teresa Eguíbar Galarza, inventariados por el INC y datados en 1970 (Fig.24).

${ }^{22}$ Elementos artísticos de las iglesias de los pueblos del IRYDA. Archivo Central del Ministerio de Agricultura, Madrid (AC-MAPAMA), Inventario general del INC, Carpeta de la provincia de Albacete, n. ${ }^{\circ}$ de expediente 6 , Albacete/Villatoya. 


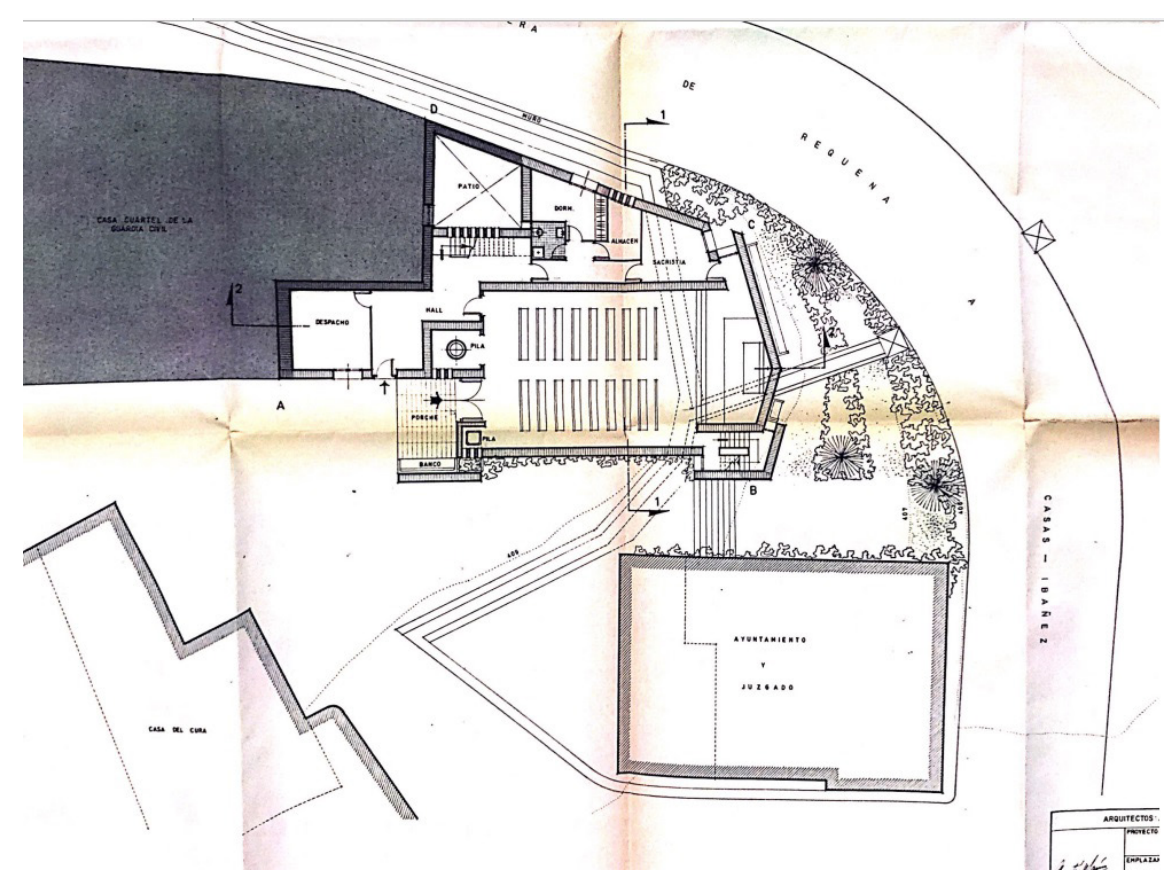

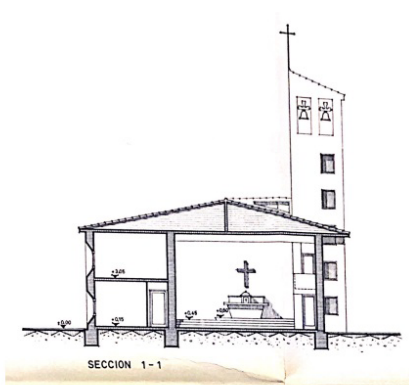

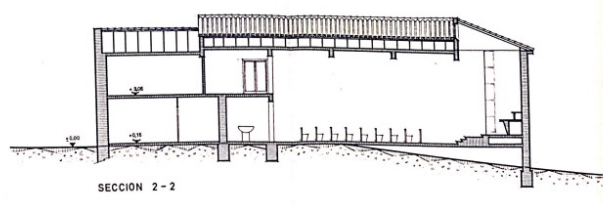

్ֻర

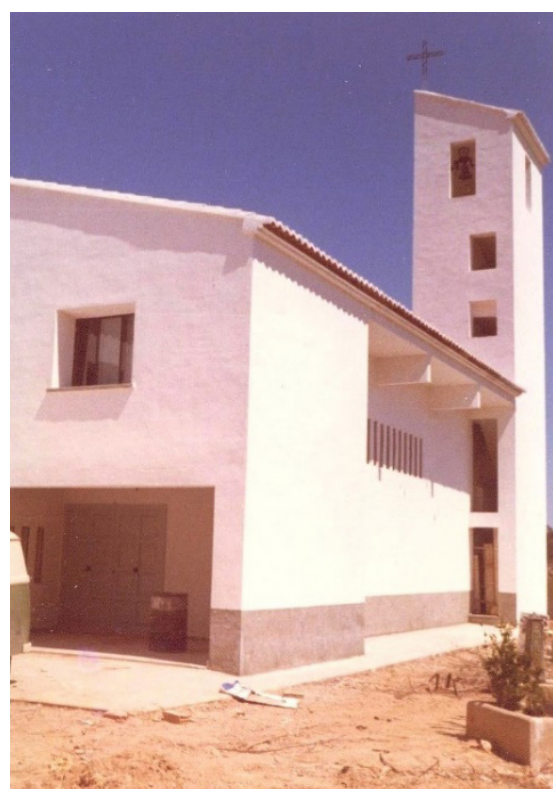

Figura 23. Villatoya. Planta y secciones de la iglesia. Fachada y torre-campanario. Fuentes: Archivo Central del Ministerio de Agricultura y Archivo de Pedro Castañeda Cagigas (fotografía a color). 


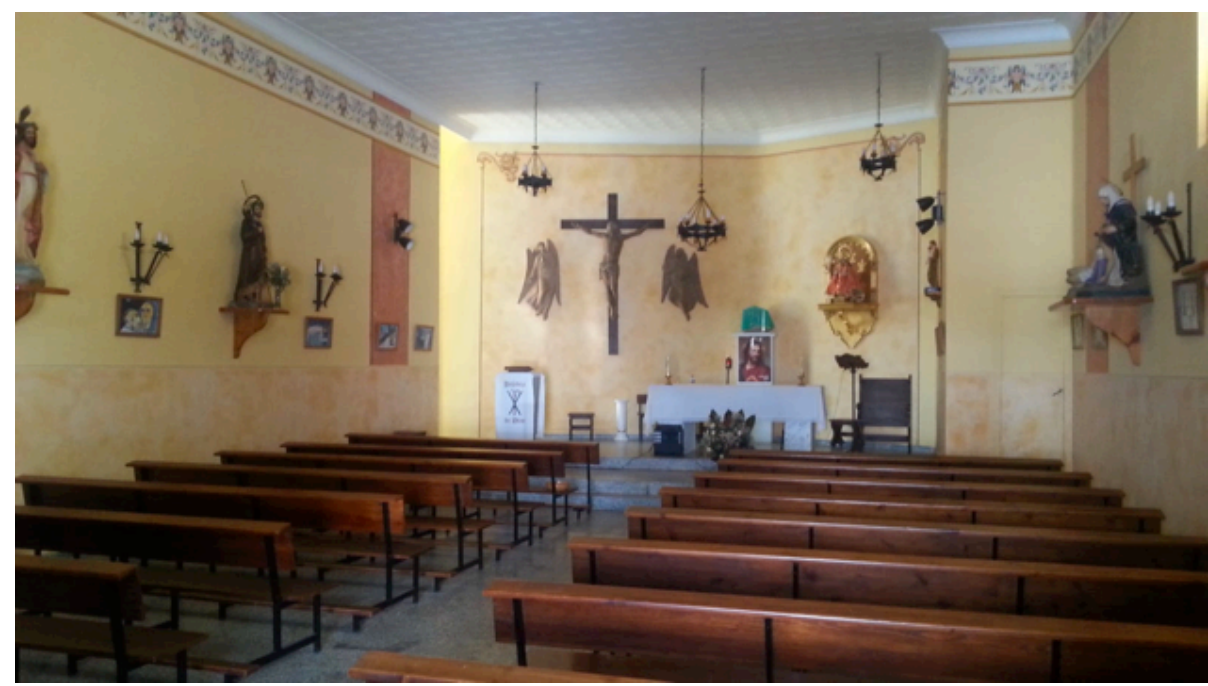

2

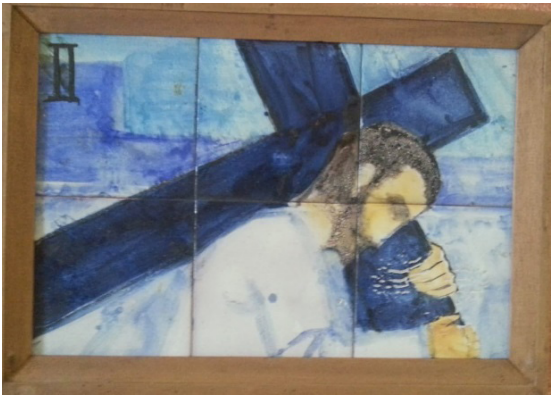

3
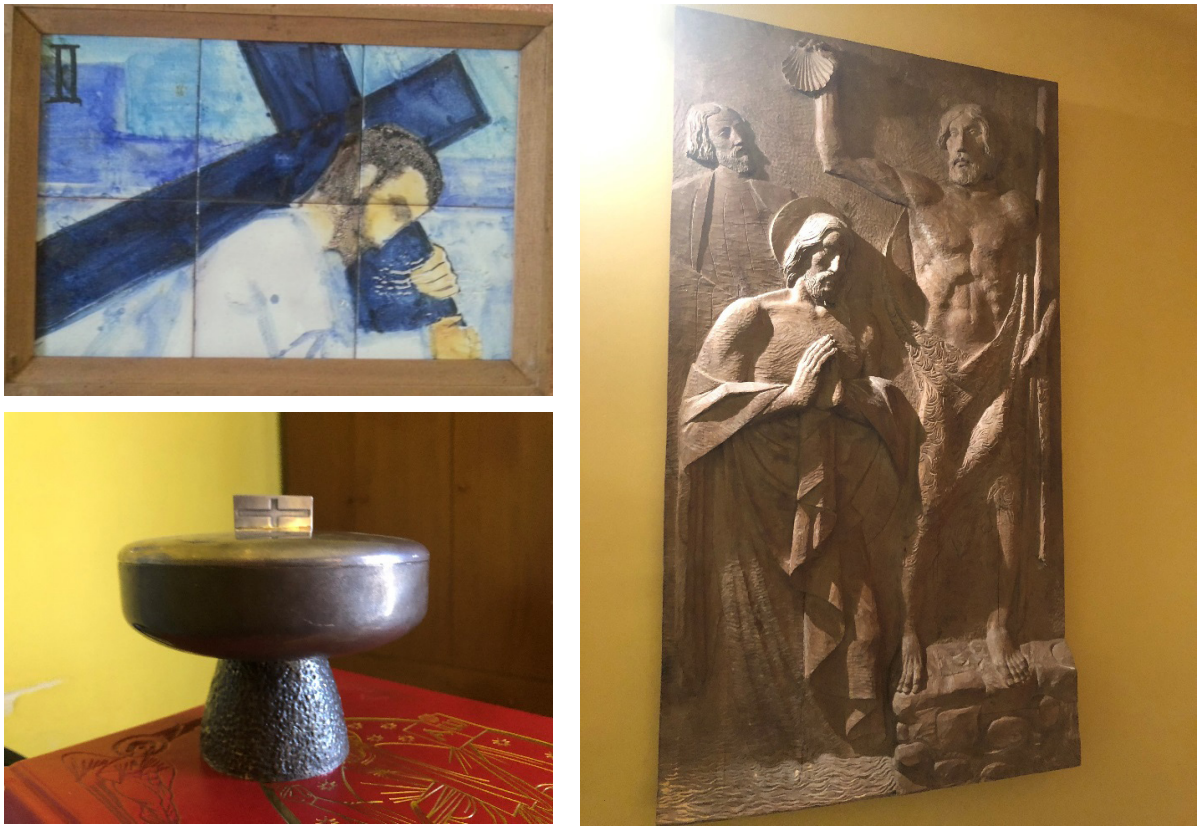

Figura 24. Villatoya. 1. Interior de la iglesia y conjunto escultórico de Cristo asistido por ángeles, Teresa Eguíbar Galarza. 2. Panel de seis azulejos cromáticos, Vía Crucis, Julián Gil. 3. Copón, Talleres Granda. 4. Mediorrelieve en madera del Bautismo de Jesús en el río Jordán, Teresa Eguíbar Galarza. Fuente: Fotos de la autora. 
Junto a ellos, se encuentra el sagrario que guarda la simetría del templo de Talleres Granda. Su única decoración frontal es el repujado de un Pantocrátor. Además, en la sacristía se encuentra el ajuar litúrgico con el copón, la naveta, el hisopo y el incensario, la antigua imagen de la patrona en mal estado de conservación en uno de los armarios, junto a las conocidas luminarias negras con una cruz calada y un Cristo en la cruz de escritorio de Talleres Granda (Fig.24), además de un armario para almacenar las casullas de la firma Caderot.

En cambio, la capilla de Cilanco (Fig.25), ubicada en la plaza de la pedanía, pasa inadvertida por su aspecto cúbico anexado a la escuela y la vivienda del maestro, aunque tiene una espadaña tradicional perpendicular a la fachada. Fue una obra realizada por el arquitecto cántabro Pedro Castañeda Cagigas en 1951 y reformada por el arquitecto valenciano Eugenio Viedma Dutrús en 1958. En el interior de la capilla de Cilanco, que cumplió las funciones de escuela en el pasado como aparece descrito en el informe y en la presencia de una gran puerta de dos hojas, encontramos una planta regular de techumbre arquitrabada.

Detrás del altar se encuentra un cuerpo arquitectónico de menores dimensiones que se corresponde con la sacristía en la que se almacenan un confesionario de diseño, las antiguas casullas Caderot, un hisopo y el Vía Crucis de forja con apliques de iluminación apilados en el suelo. El reducido espacio guarda una pintura mural de aproximadamente 4 metros de alto por 2,50 de ancho sobre el altar a modo de retablo con el tema de La Asunción de la Virgen (Fig.26) ${ }^{23}$. Gracias a las notas autobiográficas de Manuel Rivera, localizadas en el MNCARS, se conoce que fue realizada en 1954 (Rivera, 2007; Bazán, 2016).

El miembro del grupo El Paso colaboró con el INC entre 1952 y 1957 (Bazán, 2016) a través del contacto con José Luis Fernández del Amo Moreno (Rivera, 2007, p. 73), quien lo presentó como co-

${ }^{23}$ Elementos artísticos de las iglesias de los pueblos del IRYDA. Archivo Central del Ministerio de Agricultura, Madrid (AC-MAPAMA), Inventario general del INC,

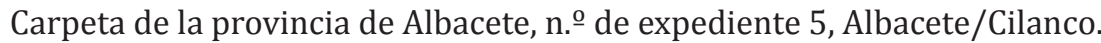


laborador a los demás arquitectos de la plantilla del Servicio de Arquitectura del INC. En su breve participación, dejó un repertorio de 16 encargos entre murales y grandes lienzos, legando a Cilanco un ejemplo en buen estado de conservación. En ella incorporó una variación compositiva, cuando analizamos sus primeros trabajos, donde la mayoría responde a una composición más tradicional, tomando como referencia el orden sinóptico de los retablos, el hieratismo duro de sus primeras obras en Foncastín (Valladolid, 1952-1953), Águeda del Caudillo (Salamanca, 1953-1954) o las tablas al óleo de San Isidro de Benagéber (s/f), que progresivamente modeló conforme progresaba en el estilo figurativo-geométrico más divulgado en Santa Cruz de Mudela (capilla, Ciudad Real, 1955), Doñana-Cártama (Málaga, 1955) y en Extremadura (1953-1957): Ruecas (s/f), San Rafael y San Francisco de Olivenza (1956), Pueblonuevo del Guadiana (1957) (Bazán, 2016).

Su aportación con Cilanco parte de la representación de una única escena, dividida en dos, cuyo centro lo ocupa la Virgen de gran tamaño. El esquema ascendente de pirámide virtual es sencillo, combinando curvas y líneas, sin que por ello se vea afectado el monumentalismo, la expresión contenida contrapuesta a la serenidad de ademanes de la Virgen, y la rigidez anatómica y pesada de los pliegues con que trataba el volumen de sus figuras. En su carácter formal, la perspectiva brilla por su ausencia, representando en un solo plano a todos los personajes y empleando colores suaves: azul, blanco, verdes y tonalidades grisáceas. El ambiente es luminoso desde el margen superior hasta el inferior, donde se superponen lo terrenal, con los apóstoles con isocefalia en el lado izquierdo, y lo celestial, con los dos ángeles que reciben a la Virgen.

La obra de Cilanco convive en estas características pictóricas del fresco de San Antonio de Benagéber (Valencia, arquitecto Pedro Castañeda Cagigas, 1947), datada de 1954-1955, aunque este presenta a modo de serpentinata un cortejo de ángeles y colonos orantes con mayor dinamismo. En esta línea, les siguen los frescos de Majarromaque-José Antonio (Jerez de la Frontera, 1956) y Alberche del Caudillo (Toledo, 1956-1957). 

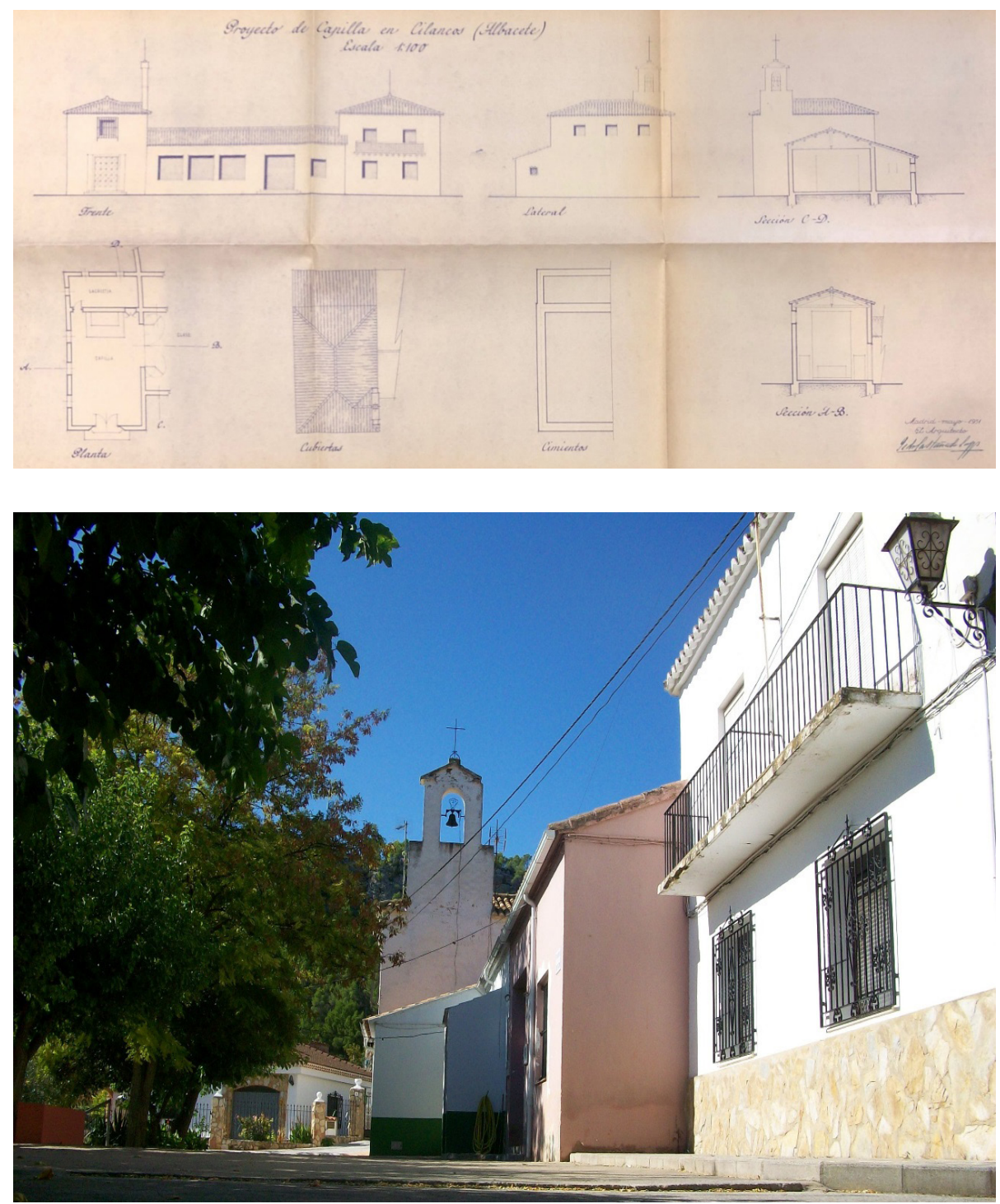

Figura 25. Cilanco. Proyecto con alzado, sección, planta y cubiertas de la escuela-capilla con vivienda del maestro. Fachadas de la escuela-capilla y vivienda del maestro junto a la espadaña de la capilla. Fuentes: Archivo Central del Ministerio de Agricultura (planos) y foto de la autora. 

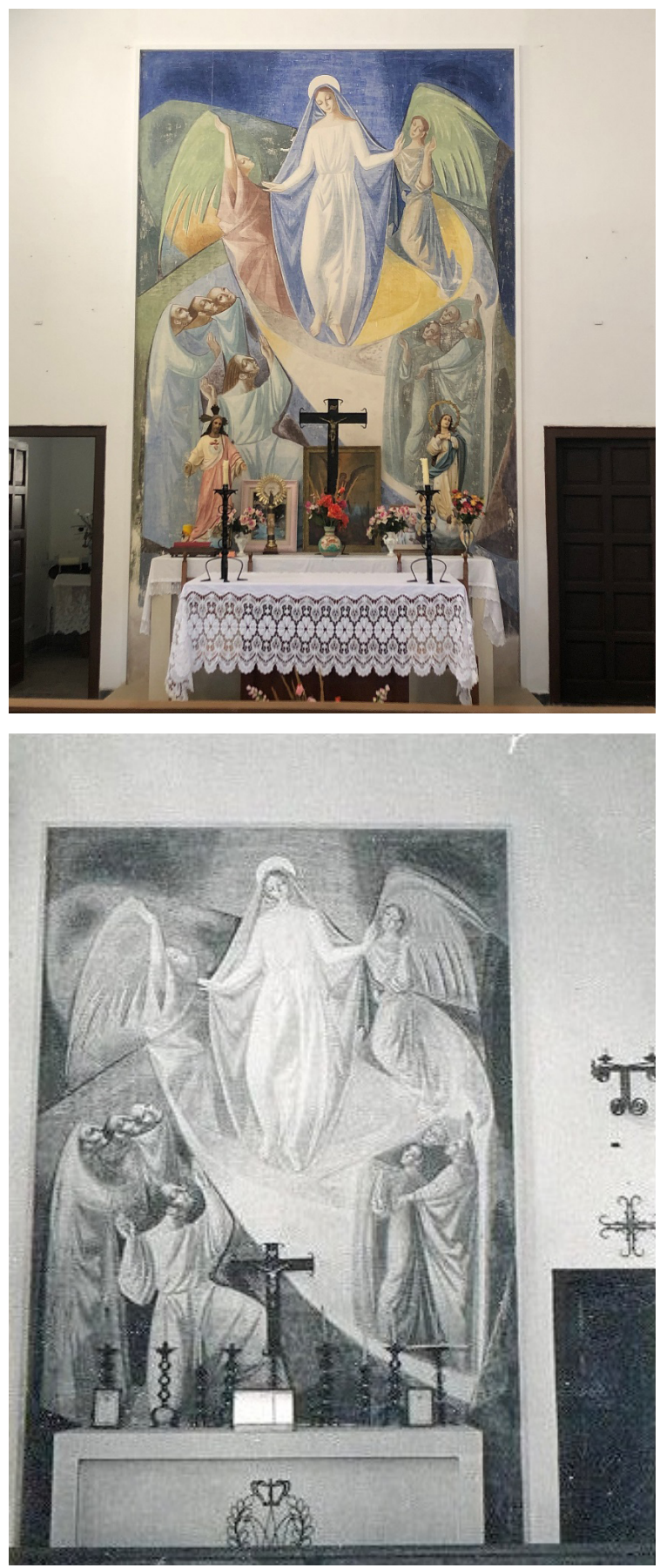

Figura 26. Cilanco. 1 y 2. Fresco sobre el altar de La Asunción, Manuel Rivera Hernández. Fuentes: Archivo de Pedro Castañeda (blanco y negro realizada por el arquitecto) y de la autora (a color). 


\section{CONCLUSIONES}

El desarrollo económico que planteó la continuación de la Reforma Agraria con el Instituto Nacional de Colonización, abarcó un área mayor a la esperada. La asociación de todos los factores que intervinieron, se conjugaron progresivamente en un juego conciliador entre la estética regionalista y la vanguardista. Hasta ahora, sólo se había resaltado la obra de los pueblos de colonización en el aspecto urbano y arquitectónico, eclipsando las aportaciones plásticas de una generación de artistas de variadas tendencias, que progresaron desde un ámbito local hasta uno nacional (José Martínez Zamorano, Luis Marco Pérez, Antonio Hernández Carpe y José Luis Sánchez Fernández) e incluso, internacional (Manuel Rivera Hernández del grupo El Paso, Teresa Eguíbar Galarza y Lorenzo Frechilla del Rey del grupo East-West), entre muchos otros. De este modo, se da a conocer también la participación «anónima» de dichos artistas, en especial, destacando una parte su repertorio artístico que no aparece reflejado en las monografías publicadas sobre ellos. No obstante, persiste la dificultad de identificar la autoría de este variado compendio plástico en los pueblos del INC, aún hoy día complicada cuestión a determinar por los traslados de obras y mobiliario litúrgico a otras parroquias, el almacenaje, la pérdida y la ausencia de un inventario actualizado, que completaría una laguna dentro de la historiografía del arte contemporáneo desarrollado durante el franquismo. Convendría en ello seguir los pasos de la Junta de Extremadura, pionera en esta iniciativa.

Por tanto, el intercambio que hemos visto entre el INC y los artistas sirvió para mantener vivo el espíritu creativo como la supervivencia personal de los artistas, como expresó Arcadio Blasco: «Durante años, los encargos del Instituto de Colonización fueron mi única fuente de ingresos, la que me permitió mantener a mi familia sin tener que renunciar a mi vocación» (Antolín, 1983, p. 101). Todo ello gracias a la labor conjunta de los arquitectos de dicha institución, en palabras del propio José Luis Fernández del Amo: «[...] Ésa 
es la gran obra extendida por buena parte de la Colonización, muy determinada por las actitudes personales de los arquitectos a los que se les encomendaba» (Jiménez, 1995, p. 51).

Definitivamente, la relevancia de los pueblos de colonización reside en su conservación no sólo institucional, sino también social, mostrándose como núcleos que fueron fruto de la transición de la historia etnográfica regional, la conciliación entre lo vernáculo y lo vanguardista que reporta un valor artístico y social vital que todavía continúa siendo denostada, al tiempo que son evidencia permanente hoy día al adaptarse a los nuevos tiempos como estímulo contra la España despoblada. 


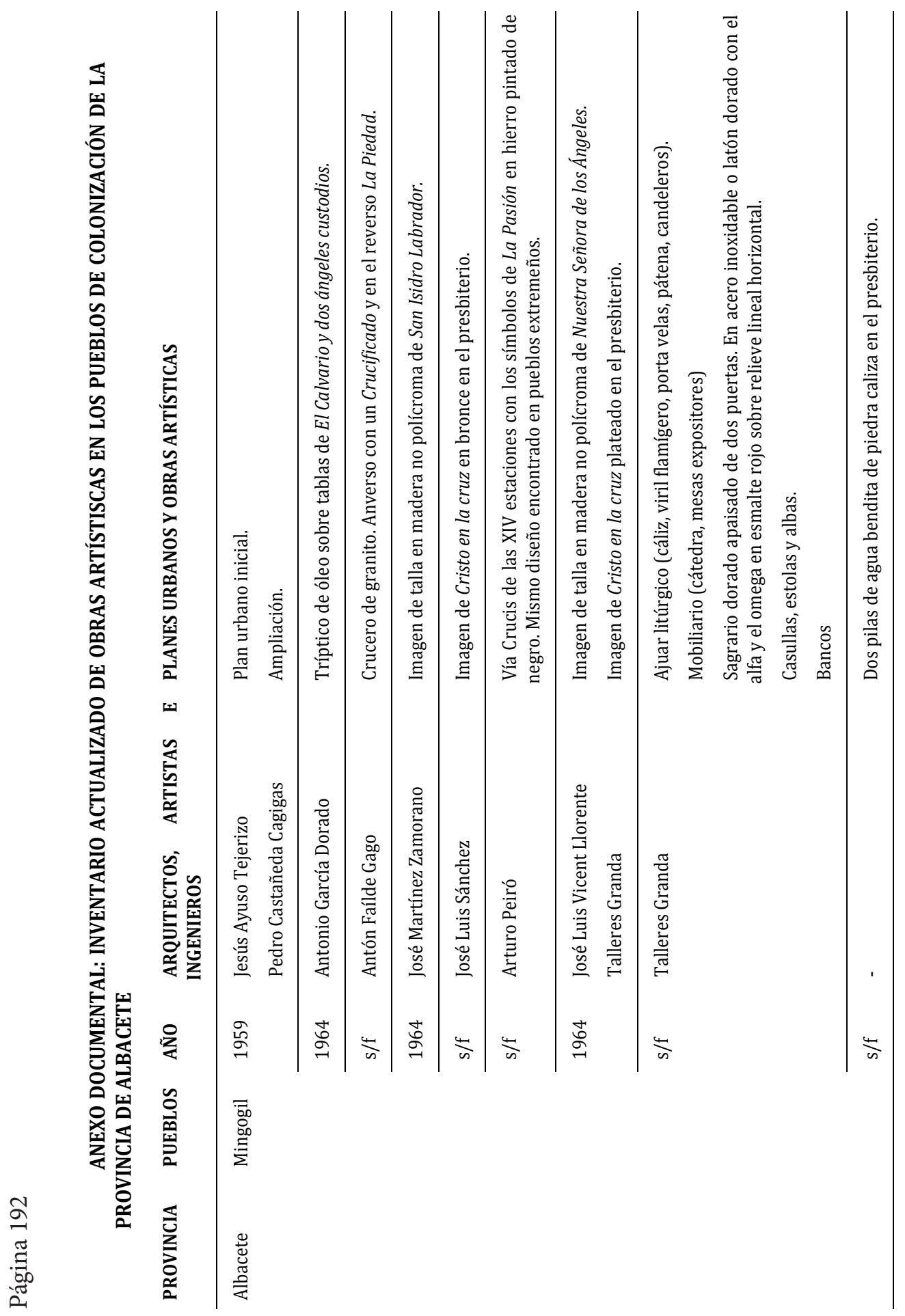




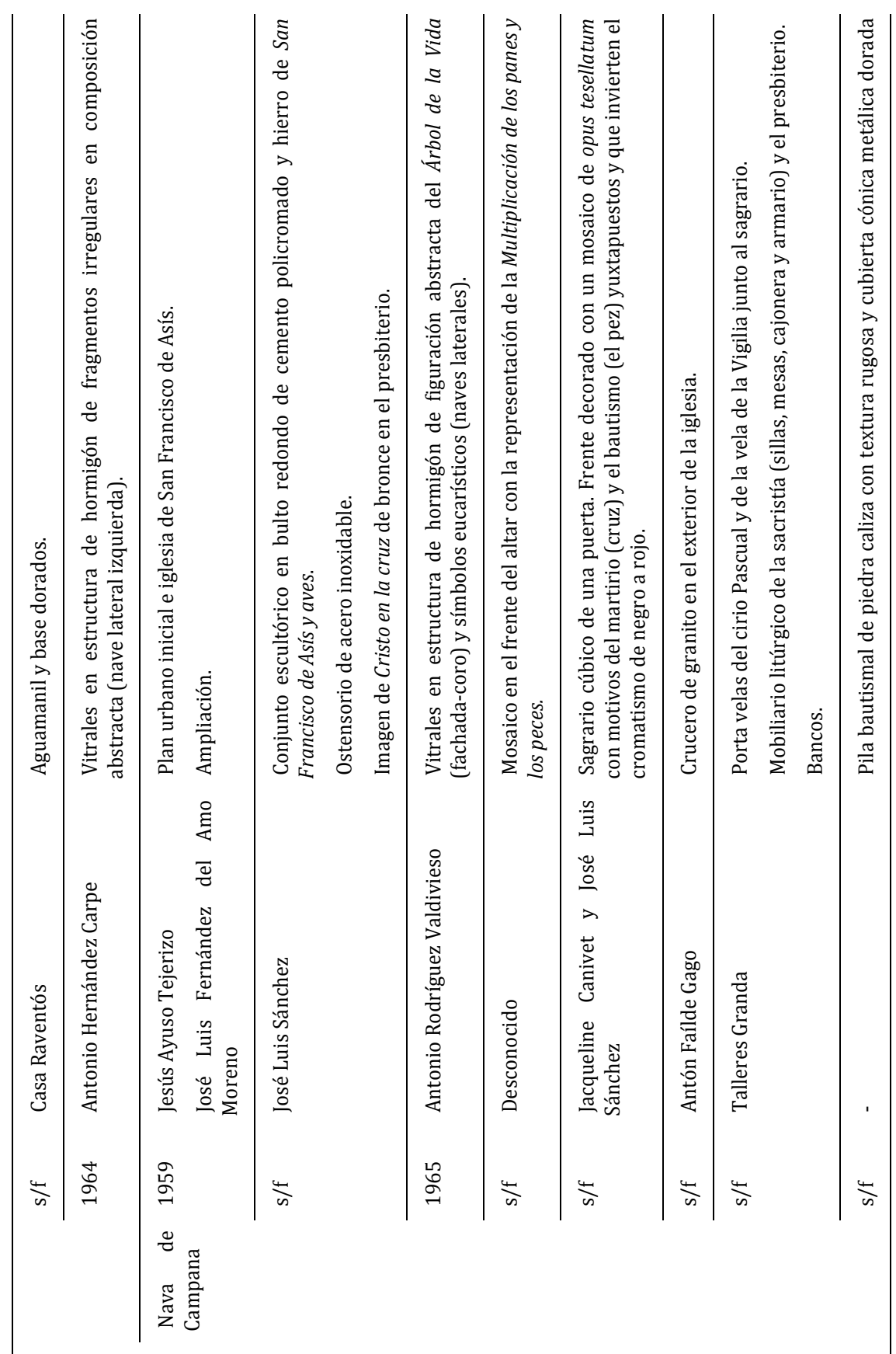

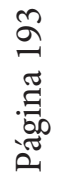




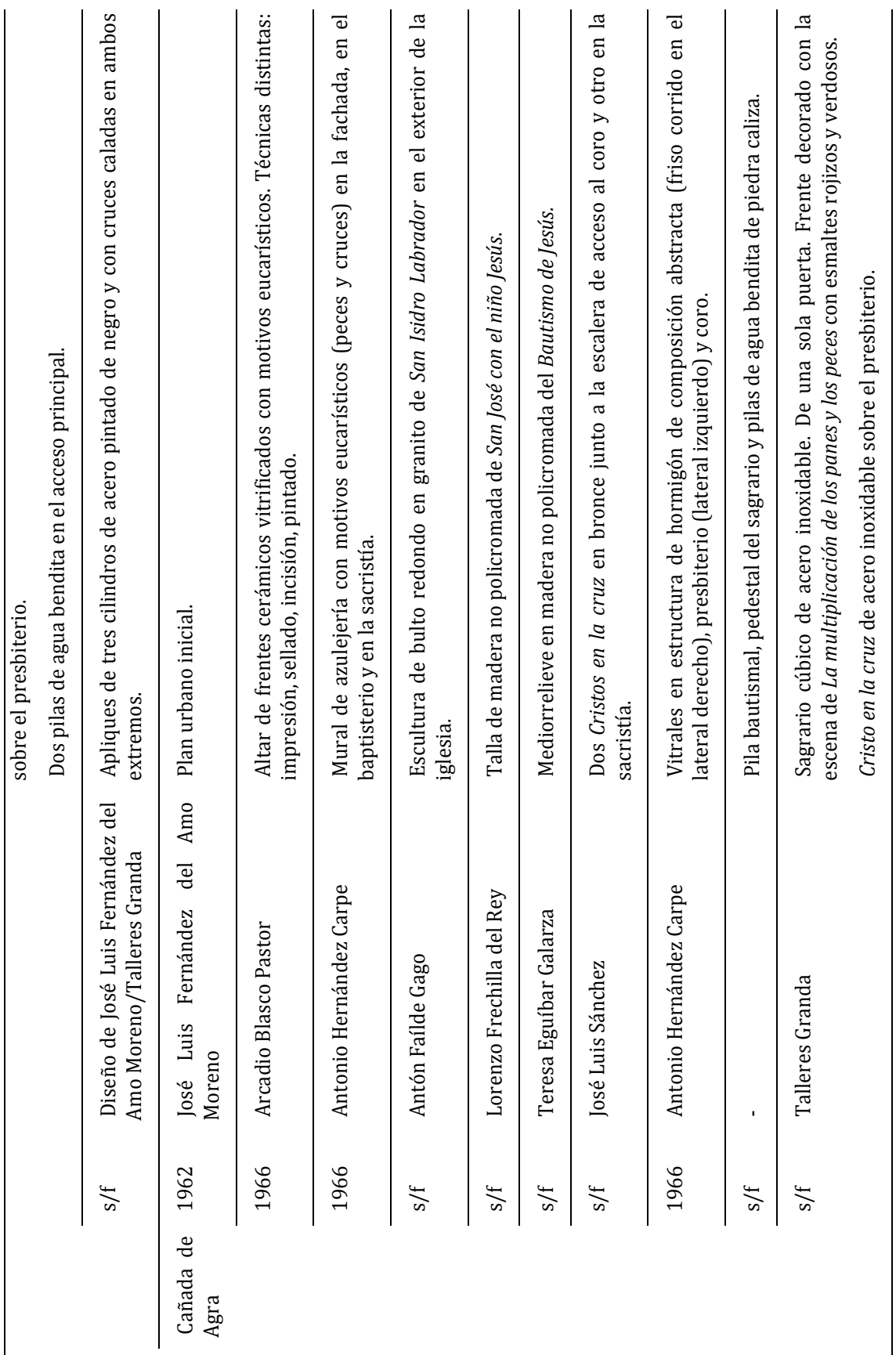




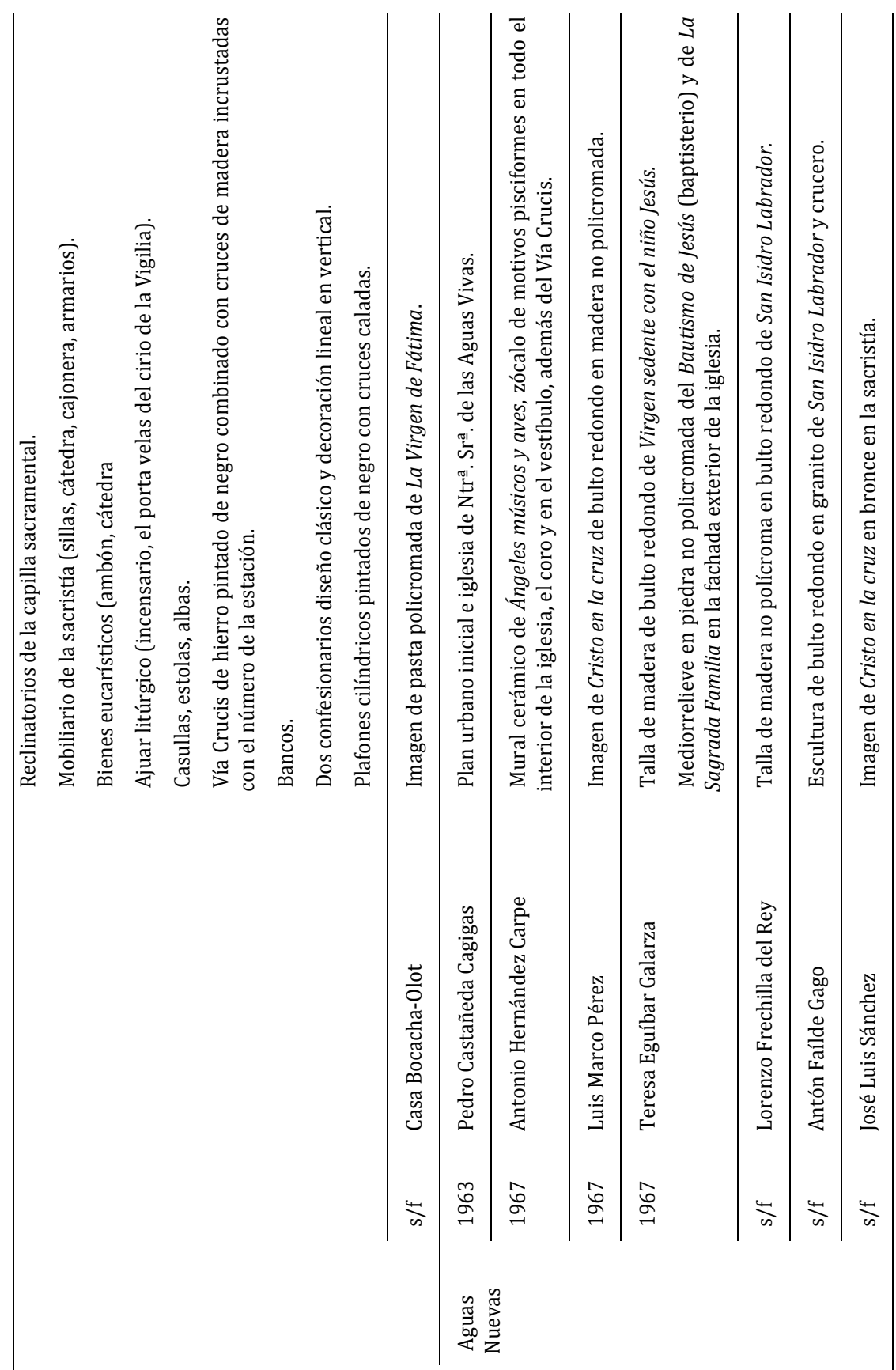




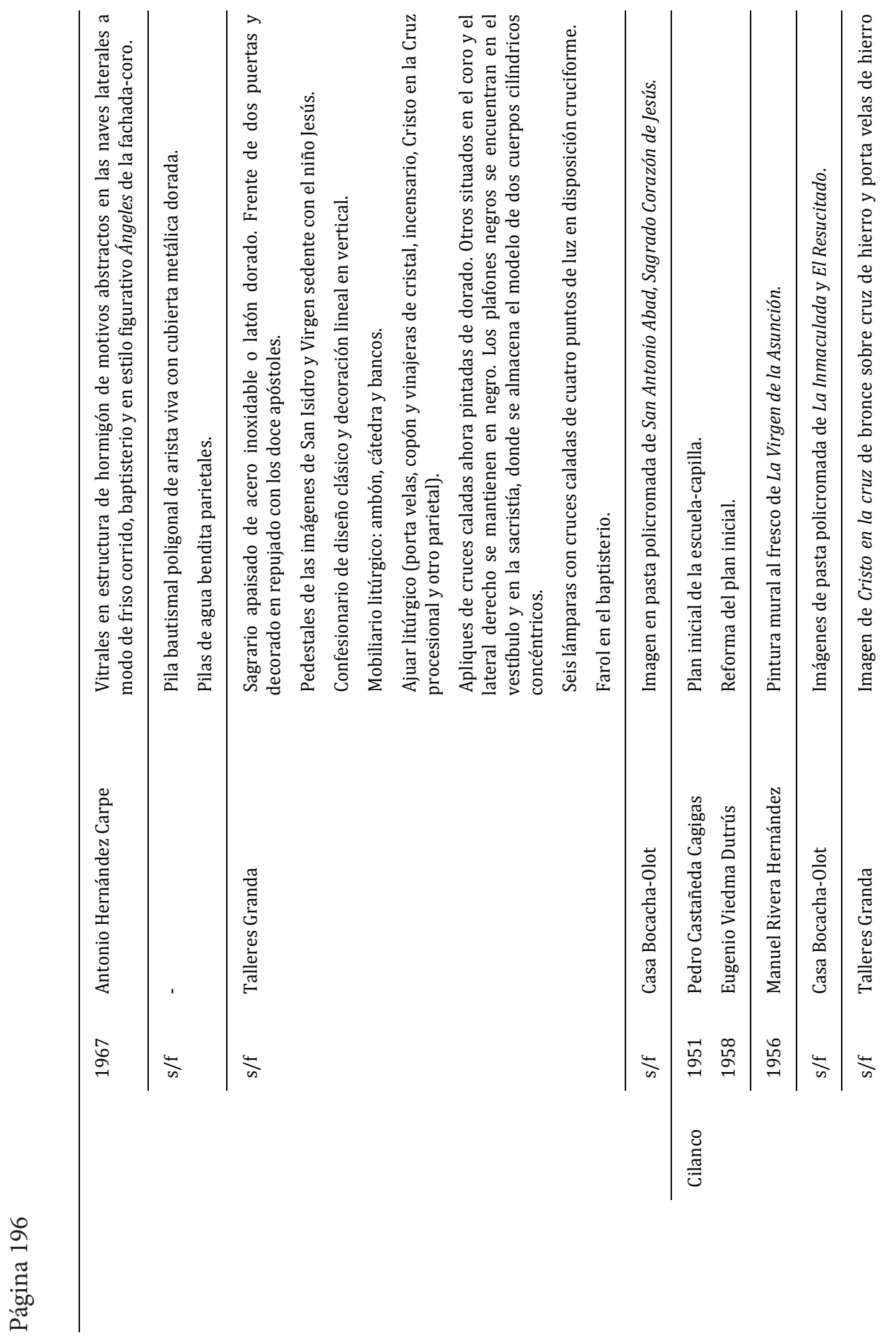




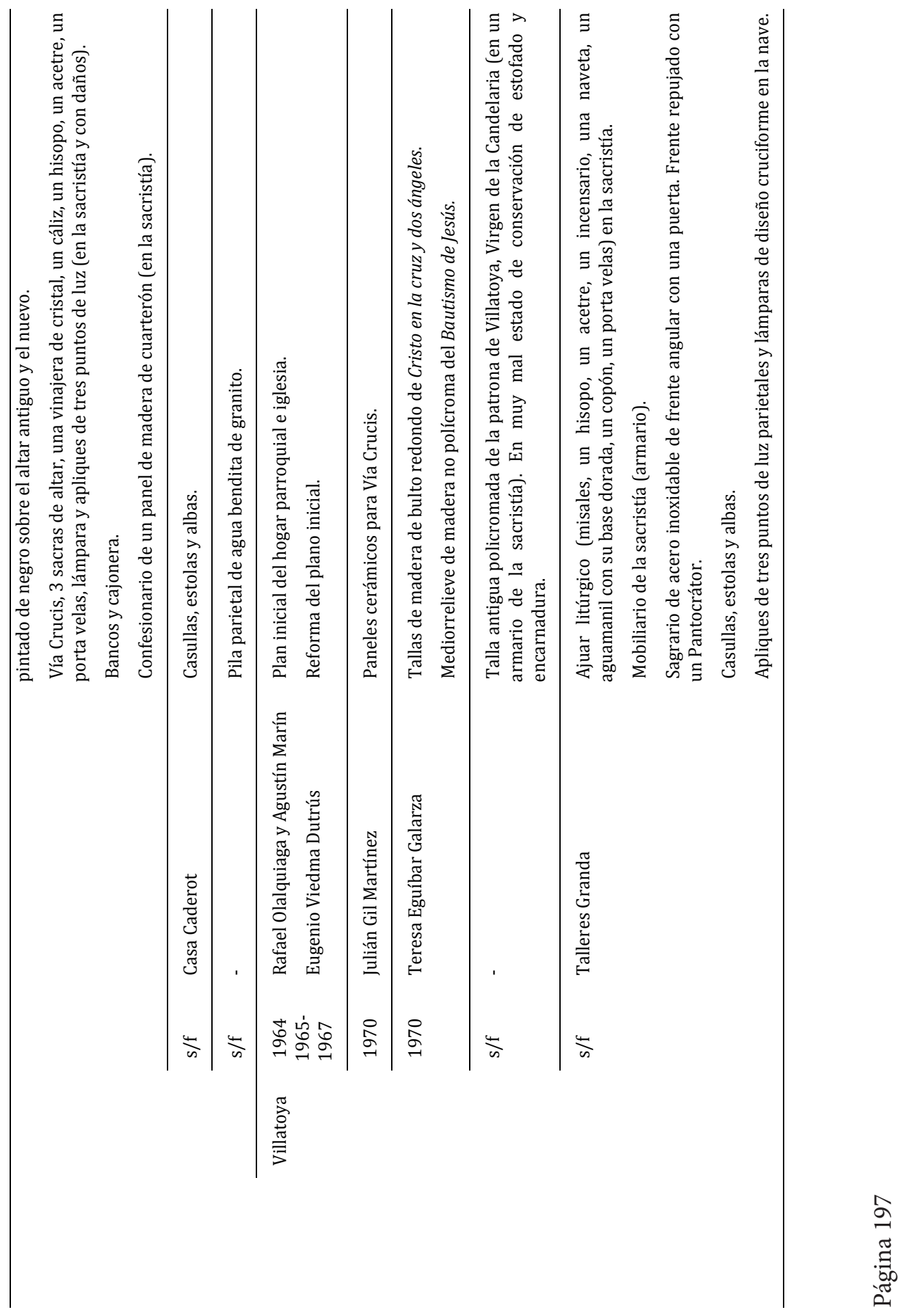




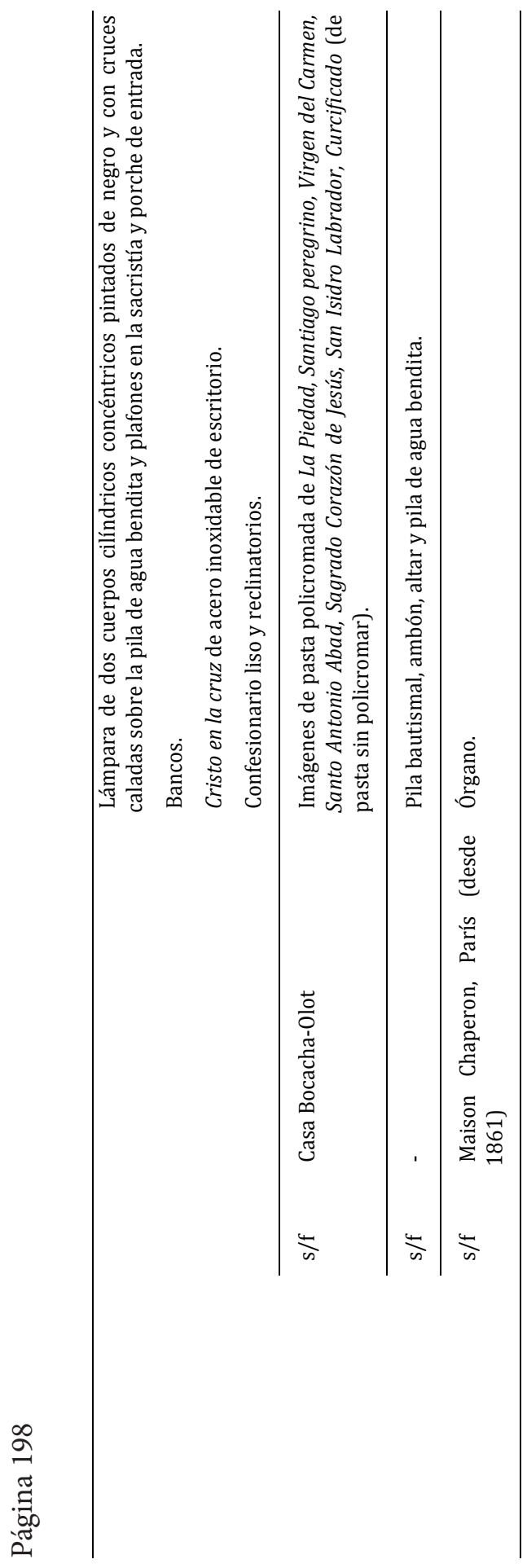




\section{FUENTES PRIMARIAS}

Archivo Central del Ministerio de Agricultura, San Fernando de Henares Madrid (AC-MAPAMA). Proyecto General de Colonización de la Zona Regable por el canal de Orellana, 1955. Proyecto n. 7616.

Archivo Central del Ministerio de Agricultura, San Fernando de Henares Madrid (AC-MAPAMA). Proyecto del pueblo de Cañada de Agra. Zona de Hellín (Albacete), 1962. Proyecto n.ำ 11693.

Archivo Central del Ministerio de Agricultura, Madrid (ACMAPAMA). Proyectos de las cuatro fases del nuevo pueblo de Aguas Nuevas en la zona de los Llanos de Albacete, Proyecto de la primera fase (1963), n.. 12332; de la segunda fase (1964), n. $\stackrel{0}{12797}$; de la tercera fase de edificios generales (1964), n. 13811 y de la cuarta fase (1967), n. $\stackrel{0}{15619 .}$

Archivo Central del Ministerio de Agricultura, Madrid (ACMAPAMA). Elementos artísticos de las iglesias de los pueblos del IRYDA, ¿1973/75?. Inventario general del INC, Carpeta de la provin-

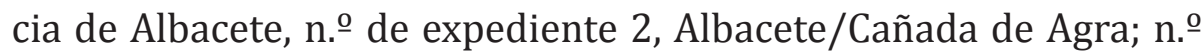
de expediente 3, Albacete/Mingogil; n.을 de expediente 4, Albacete/ Nava de Campana; n.을 de expediente 5 , Albacete/Cilanco; n.으 de expediente 6, Albacete/Villatoya; n. ${ }^{\circ}$ de expediente 7, Albacete/Aguas Nuevas.

Archivo General de la Administración, Madrid (AGA). Extracto Constitución de la Entidad Local Menor de Cañada de Agra, creada por el INC, dependiente del Ayto. de Hellín, 1975. Entidades locales menores INC, Sección 08, Fondo 11018, n. ํ de orden 4340, n.ํ de expediente 01, Albacete/Hellín Cañada de Agra.

Archivo General de la Administración, Madrid (AGA). Expediente de constitución de la Entidad Local Menor de Mingogil, creada por el Instituto Nacional de Colonización en el término municipal de Hellín, 1975. Entidades locales menores INC, Sección 08, Fondo 11018, n. $\stackrel{\circ}{\text { de }}$ orden 4340, n.o de expediente 02, Albacete/Hellín Mingogil. 
Archivo General de la Administración, Madrid (AGA). Extracto Constitución de la Entidad Local Menor de Nava de Campana, creada por el INC en el término de Hellín, 1975. Entidades locales menores INC, Sección 08, Fondo 11018, n.ํㅜ de orden 4341/1, n.ํ de expediente 01, Albacete/Hellín Nava de Campana.

Archivo Regional de Castilla-La Mancha, Toledo (ARCLM). Proyecto del cuartel de la Guardia Civil redactado por el arquitecto Pedro Castañeda Cagigas en enero de 1972 y aprobado en abril del mismo año, con la asistencia del aparejador Ernesto García Domingo, Fondo de Agricultura, Medio Ambiente y Desarrollo rural, incluidas las direcciones provinciales. Signatura ES.45.021.ACLM/97, Caja 2, nº. 4640 .

Archivo Regional de Castilla-La Mancha, Toledo (ARCLM). Proyecto de las escuelas y edificios principales del centro de enseñanza general básica (EGB) de Aguas Nuevas, Fondo de Agricultura, Medio Ambiente y Desarrollo rural, incluidas las direcciones provinciales. Signatura ES.45.021.ACLM/96, Caja 1.

Archivo Regional de Castilla-La Mancha, Toledo (ARCLM). Informe sobre el estado de ocupación de las viviendas de Aguas Nuevas, junio de 1976, Fondo de Agricultura, Medio Ambiente y Desarrollo rural, incluidas las direcciones provinciales. Signatura ES.45.021. ACLM/96, Caja 1.

Ateneo de Madrid. Antonio García Dorado, Cuadernos de Arte Sala del Prado del Ateneo de Madrid, n.o 119, 1968. En la Biblioteca Museo Nacional Centro de Arte Reina Sofía (B-MNCARS), Fondo Biblioteca Fernández del Amo, Depósito Normal, Folletos, caja 41-27, 218173, CDB. 218173.

Biblioteca Museo Nacional Centro de Arte Reina Sofía (B-MNCARS), Depósito Normal, Folletos, caja 140-23, 88213, CDB. 88213. 


\section{REFERENCIAS BIBLIOGRÁFICAS}

ALMARCHA NÚÑEZ-HERRADOR, Mạ. E. (1996). Urbanismo y arquitectura rural de nueva planta en Castilla-La Mancha (19391959), Añil: Cuadernos de Castilla-La Mancha, (10), 195-209. ALMARCHA NÚÑEZ-HERRADOR, Mà. E. (1997). Arquitectura y urbanismo rural durante el período de la autarquía en Castilla-La Mancha. Dirección General de Regiones Devastadas y Reparaciones e Instituto Nacional de Colonización. Ed. Universidad de Castilla-La Mancha.

ALMARCHA NÚÑEZ-HERRADOR, Mạ. E. (2003). El arte en CastillaLa Mancha durante el Franquismo. En Castilla-La Mancha en el Franquismo (pp. 255-272). Biblioteca Añil, Ed. Almud.

ALMARCHA NÚÑEZ-HERRADOR, Mạ. E. (2004). La actividad edilicia del Instituto Nacional de Colonización: Cañada de Agra (Albacete). En J. A. Mancebo Roca (Coord.), El territorio de la memoria: homenaje a la profesora Rocío Rodríguez (pp. 1732). Universidad de Castilla-La Mancha.

ALMARCHA NÚÑEZ-HERRADOR, Mạ. E. (2008). Los poblados de colonización en zonas de secano en Castilla-La Mancha. En Pueblos de colonización durante el Franquismo. La arquitectura en la modernización del territorio rural (pp. 236-252). Consejería de Cultura de Andalucía: Instituto Andaluz del Patrimonio Histórico. https://www.researchgate.net/profile/Esther-Almarcha/publication/322901134_Poblados_ de_colonizacion_en_zonas_secano_en_Castilla-La_Mancha/ links/5a74ca0c0f7e9b41dbce3090/Poblados-de-colonizacion-en-zonas-secano-en-Castilla-La-Mancha.pdf

ANTOLÍN, E. (1983). Artistas infiltrados. Rojos, ateos y abstractos en los pueblos de Franco, Revista Cambio 16, (592), 98-103. https://www.fernandezdelamo.com/portfolio-item/3413/

AZPILICUETA ASTARLOA, E. (2004). La construcción de la Arquitectura de Postguerra en España (1939-1962) (Tesis doctoral inédita. Universidad Politécnica, Madrid). http://oa.upm. es/23197/ 
BAZÁN DE HUERTA, M. (2016). Rivera antes de Rivera. Los trabajos pictóricos de Manuel Rivera para el Instituto Nacional de Colonización. Arte y Ciudad - Revista de Investigación, (9), 6190. https://doi.org/10.22530/ayc.2016.N9.354

BAZÁN DE HUERTA, M. (2017). Las artes plásticas en las iglesias de colonización de las Vegas Altas del Guadiana. En VV.AA., Paisajes culturales del agua, Universidad de Extremadura, 221243.

BAZÁN DE HUERTA, M. y CENTELLLAS SOLER, M. (2018). Arte religioso en las Vegas Bajas del Guadiana. Propuestas renovadoras y presencia femenina en las iglesias de colonización. En VV.AA., Paisajes culturales entre el Tajo y el Guadiana, Universidad de Extremadura, 37-63.

BEZARES FERNÁNDEZ, D. (2018). El papel de Fernández del Amo en el arte sacro de los pueblos de colonización (Tesis doctoral inédita). Universidad de Navarra, Pamplona. https://hdl.handle.net/10171/56813

BIRRIEL SALCEDO, M. (1998). Las instituciones de la repoblación del reino de Granada (1570-1592). Anuario de Historia del Derecho Español, (58), 173-203. http://hdl.handle. net/10481/50212

BUSTOS JUEZ, C. (2016). Patrimonio arquitectónico luso-español en los años 40. Dos congresos a través de la participación de Muguruza. En J. M. Pozo Municio (Coord.), X Congreso de Arquitectura importada y exportada en España y Portugal (1925-1975). Pamplona (171-178). ETSA.

https://www.unav.edu/documents/29070/13966351/X+C ongreso_2016+Arquitectura+importada+y+exportada+en+ Espan\%CC\%83a+y+Portugal.pdf

CANALES MARTÍNEZ, G. \& JEREZ CORDERO, D. (1993). La actuación del Instituto Nacional de Colonización en el municipio de Hellín (Albacete). Investigaciones Geográficas, (11), 71-91. http://hdl.handle.net/10045/510 
CARMONA ZUBIRI, D. (2012). Colonización, Promisión e Igualdad en las tres joyas de Hellín. Revista de Estudios Albacetenses Al-Basit. Instituto de Estudios Albacetenses «Don Juan Manuel», (57), 161-200.

http://iealbacetenses.dipualba.es/viewer.vm?id=00000503 03 \&page $=1 \&$ search=\&lang=es\&view=main

CENTELLAS SOLER, M. (2010). Los pueblos de colonización de Fernández del Amo. Arte, arquitectura y Urbanismo. Fundación Arquia.

CENTELLAS SOLER, M. y BAZÁN DE HUERTA, M. (2017). La obra de Arcadio Blasco en las iglesias del Instituto Nacional de Colonización (1954-1965). En Arcadi Blasco. Art, Arquitectura i Memòria (1954-1974). Universitat d'Alacant y Museu Universitat d'Alacant, 34-69 y 131-183. http://www.mua.ua.es/ archivos/2017_ArcadiBlasco.pdf

Cordero Ampuero, Á. (2014). Fernández del Amo. Aportaciones al arte y la arquitectura contemporánea (Tesis doctoral inédita). Universidad Politécnica de Madrid. http://oa.upm. es/30980/

CORDERO AMPUERO, Á. \& GUTIÉRREZ MOZO, E. (2020). Cañada de Agra, composing with topography and landscape. VLC Arquitectura 7, (1), 123-143. https://doi.org/10.4995/ vlc.2020.10991

CRUZ VILLEGAS, I. (2010). El Instituto Nacional de Colonización en Castilla-La Mancha (Tesis doctoral inédita). Universidad de Castilla-La Mancha.

CRUZ VILLEGAS, I. (2015). Las políticas agrarias y de colonización en la provincia de Ciudad Real: los nuevos pueblos de colonización y otras actuaciones. En M. S. Campos Díez, Á. R. del Calle Calzado, F. Alía Miranda (Coord.). I Congreso Nacional Ciudad Real y su provincia, (Vol. I, Tomo I). (pp. 475-488), https://ceclmdigital2.uclm.es/viewer.vm?id=0001806098 \&page $=2 \&$ search $=$ Congreso $\% 20$ Nacional $\% 20$ Ciudad $\% 20$ Real\%20y\%20su\%20provincia\&lang=es\&view=libros 
DE NITO, L. (2003). L'architettura dei nuevos pueblos di José Luis Fernández del Amo. Fondazioni agrarie in Spagna: 1953-1964 (Tesis doctoral inédita. Università degli Studi di Palermo). DOMÍNGUEZ ORTIZ, A. (1992). La sociedad española en el siglo XVII. Biblioteca de Historia, Consejo Superior de Investigaciones Científicas, Universidad de Granada, (Vol. I).

FERNÁNDEZ DEL AMO, J. L. (1974). Del hacer de unos pueblos de colonización. Revista de Arquitectura, (192), 33-40. https://www.coam.org/media/Default\%20Files/fundacion/biblioteca/revista-arquitectura-100/1973-1975/ docs/revista-articulos/revista-arquitectura-1974-n192pag33-40.pdf

FERNÁNDEZ DEL AMO, J. L. (1991). Encuentro con la Creación. Madrid: Real Academia de Bellas Artes de San Fernando de Madrid.

FERNÁNDEZ DEL AMO, J. L. (1995). Palabra y Obra. Escritos reunidos. Madrid: Textos Dispersos, Colegio Oficial de Arquitectos de Madrid.

FERNÁNDEZ DEL AMO, R., \& CENTELLAS SOLER, M. (2015). Cañada de agra, pueblo de colonización de José Luis Fernández del Amo. En Couceiro Núñez, T. (Coord.) II Congreso pioneros de la arquitectura moderna española: Aprender de una obra (pp. 275-283). Fundación Alejandro de la Sota.

GÓMEZ AYAU, E. (1978). De la Reforma Agraria a la Política de Colonización. Agricultura y sociedad, (7), 87-121.

GÓMEZ BENITO, C. (2004). Una revisión y una reflexión sobre la política de colonización agraria en la España de Franco. Historia del presente, (3), 65-86.

GONZÁLEZ VICARIO, Ma․ T. (1988). Aproximación a la escultura religiosa contemporánea en Madrid. Universidad Nacional de Educación a Distancia, Colección Aula Abierta (31).

JIMÉNEZ-BLANCO, Maㅡ. Dolores (1995). Treinta preguntas a José Luis Fernández del Amo. En Zugaza, M.; Ruiz-Giménez, J.; Jiménez-Blanco, Ma. D. (eds.). José Luis Fernández del Amo. Un proyecto de Museo de Arte Contemporáneo (pp. 51-55). Museo Nacional Centro de Arte Reina Sofía. 
MANCHÓN RUIZ, E. (2006). Un camino de modernidad en la arquitectura de los poblados de colonización de José Luis Fernández del Amo (Tesis doctoral inédita. Universitat Politècnica de València).

MARTÍNEZ MEDINA, A. \& OLIVA MEYER, J. (2008). Los poblados de colonización en la «zona de Levante» 1950-1970. En Pueblos de colonización durante el franquismo. La arquitectura en la modernización del territorio rural (pp. 287-311). Consejería de Cultura de Andalucía: Instituto Andaluz del Patrimonio Histórico.

https://rua.ua.es/dspace/bitstream/10045/34996/3/02c_ PobladosyViviendas_TXT.pdf

MOLINA BALLESTEROS, P. (2020). Arquitectura social española. Los pueblos de colonización (1940-1970). José Luis Fernández del Amo en la provincia de Albacete. Albacete: Publicación propia.

RÍO VÁZQUEZ, A. S. (2012). Antonio Alés Reinlein y la modernización del territorio rural gallego. En Alonso Pereira, J. R. (Coord.) Modernidad y contemporaneidad en la arquitectura de Galicia (pp. 63-83). Coruña: Universidade da Coruña. http://hdl. handle.net/2183/16123

RIVERA HERNÁNDEZ, M. (2007). Memorias 1928-1971. Diputación de Granada: Los libros de la Estrella (30).

RODRÍGUEZ GARCÍA, J. L. (2015). Dinámicas sociales del paisaje en el campo de Albacete (Tesis doctoral inédita. Universidad Nacional de Educación a Distancia). http://e-spacio.uned.es/ fez/view/tesisuned:GeoHis-Jlrodriguez

RUIZ TRILLEROS, M. (2016). José Luis Sánchez. Trayectoria de un escultor. Consejería de Cultura, Turismo y Artesanía de Castilla-La Mancha.

SÁNCHEZ ORTEGA, D. (1996). Campo y sociedad en la Mancha oriental. Tierra, historia y cultura en el paisaje de Los Llanos. Diputación Provincial de Albacete. 
TAMÉS ALARCÓN, J. (1988). Actuaciones del Instituto Nacional de Colonización 1939-1970. Urbanismo Colegio Oficial de Arquitectos de Madrid, (3), 4-12. https://www.coam.org/media/Default\%20Files/fundacion/biblioteca/revista-urbanismo/docs/revista-urbanismo-n3-pag4-12.pdf

ZAS GÓMEZ, E. (2008). Los pueblos de colonización en Galicia durante el franquismo: una propuesta de ordenación del disperso. En Pueblos de colonización durante el Franquismo. La arquitectura en la modernización del territorio rural (pp. 252-268). Consejería de Cultura de Andalucía: Instituto Andaluz del Patrimonio Histórico. 